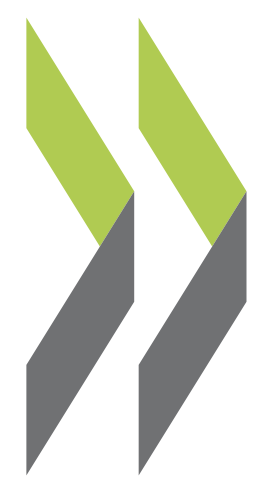

OECD Health Working Papers No. 48

\title{
Improving Lifestyles, Tackling Obesity: The Health and Economic Impact of Prevention Strategies
}

Franco Sassi, Michele Cecchini, Jeremy Lauer, Dan Chisholm 
Organisation de Coopération et de Développement Économiques

Organisation for Economic Co-operation and Development

20-Nov-2009

DIRECTORATE FOR EMPLOYMENT, LABOUR AND SOCIAL AFFAIRS

English text only

HEALTH COMMITTEE

\section{Health Working Papers}

OECD HEALTH WORKING PAPERS No. 48

IMPROVING LIFESTYLES, TACKLING OBESITY:

THE HEALTH AND ECONOMIC IMPACT OF PREVENTION STRATEGIES

Franco Sassi, Michele Cecchini, Jeremy Lauer* and Dan Chisholm*

*World Health Organisation, Department of Health Systems Financing

JEL Classification(s): D61, D63, H51, I12, I18

All Health Working Papers are now available through OECD's Internet website at http://www.oecd.org/els 


\title{
DIRECTORATE FOR EMPLOYMENT, LABOUR AND SOCIAL AFFAIRS
}

\author{
www.oecd.org/els
}

\section{OECD HEALTH WORKING PAPERS}

\section{http://www.oecd.org/els/health/workingpapers}

This series is designed to make available to a wider readership health studies prepared for use within the OECD. Authorship is usually collective, but principal writers are named. The papers are generally available only in their original language - English or French - with a summary in the other.

Comment on the series is welcome, and should be sent to the Directorate for Employment, Labour and Social Affairs, 2, rue André-Pascal, 75775 PARIS CEDEX 16, France.

The opinions expressed and arguments employed here are the responsibility of the author(s) and do not necessarily reflect those of the OECD.

\section{Applications for permission to reproduce or translate all or part of this material should be made to:}

\author{
Head of Publications Service \\ OECD \\ 2, rue André-Pascal \\ 75775 Paris, CEDEX 16 \\ France
}

\section{Copyright OECD 2009}




\section{ACKNOWLEDGEMENTS}

The authors would like to thank Marion Devaux, Ji Hee Youn and Fareen Hassan for assistance on aspects of the analysis presented in this paper; Francesco Branca, Julia Critchley, Evi Hatziadreu, Taavi Lai, Klim McPherson, Marc Suhrcke, Godfrey Xuereb for comments at various stages of the work; and representatives of the food and beverage industry and of the sports and exercise industry who provided comments through the Business and Industry Advisory Committee to the OECD (BIAC). The authors would also like to thank all the experts who participated in the Expert Group meeting held in Paris in April 2009 on behalf of OECD member countries. Finally, they are grateful to David Evans, Mark Pearson, Peter Scherer, Elizabeth Docteur, John Martin and Martine Durand for comments provided on various drafts, and to Judy Zinnemann and Aidan Curran for editorial assistance. The authors remain responsible for any errors and omissions.

The Economics of Prevention project is partly funded through regular contributions from OECD member countries. Additional voluntary contributions to the project were made by the following member countries: Australia, Denmark, Mexico, Netherlands, Sweden and Switzerland.

The project is also partly supported by a grant from the Directorate General for Public Health and Consumer Affairs of the European Commission. The contents of this paper do not necessarily reflect the views of the Commission.

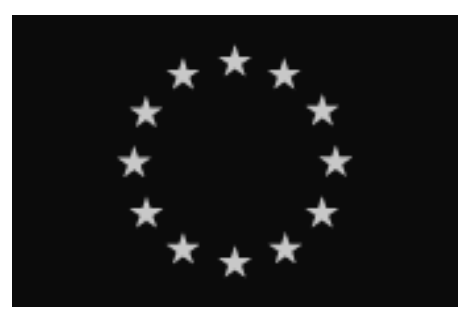




\section{FOREWORD}

The analysis presented in this paper is the result of work jointly undertaken by the OECD and the World Health Organisation (WHO) following a mandate received from the OECD Health Committee. The OECD had a leading role in designing the study, identifying relevant input data and conducting the analyses, while the WHO had a leading role in developing the model and the costing methods upon which the analysis is based. Both organisations contributed to the interpretation of the results.

The findings presented in this paper are the result of the assumptions, analytical methods and input data discussed in the text, which have evolved during the course of the work and will continue to be updated after the publication of this working paper as new evidence becomes available.
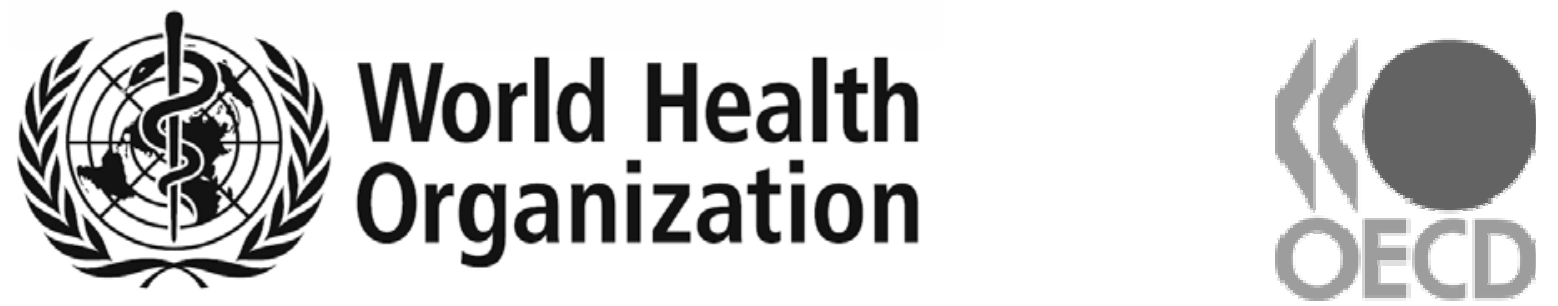


\begin{abstract}
In an attempt to contain rising trends in obesity and associated chronic diseases, many governments have implemented a range of policies to promote healthy lifestyles. These efforts have been hindered by the limited availability of evidence about the effectiveness of interventions in changing lifestyles and reducing obesity. Evaluations of the cost-effectiveness and distributional impacts of such interventions are even fewer and narrower in terms of numbers of options considered. An economic analysis was developed jointly by the OECD and the WHO with the aim of strengthening the existing evidence-base on the efficiency of interventions to tackle unhealthy diets and sedentary lifestyles. The analysis was broadly based on the WHO-CHOICE (CHOosing Interventions that are Cost-Effective) approach, and it aimed at assessing the efficiency of a range of policy options to tackle unhealthy lifestyles and related chronic diseases. Additionally, compared to the traditional CHOICE framework, the analysis assessed the distributional impacts of preventive strategies on costs and health outcomes. Most of the preventive interventions evaluated as part of the project have favourable cost-effectiveness ratios, relative to a scenario in which no systematic prevention is undertaken and chronic diseases are treated once they emerge. However, since the determinants of obesity are multi-factorial and affect all age groups and social strata, interventions tackling individual determinants or narrowly targeted to one groups of individuals will have a limited impact at the population level, and will not reduce significantly the scale of the obesity problem. Although the most efficient interventions are found to be outside the health sector, health care systems can have the largest impact on obesity and related chronic conditions by focusing on individuals at high risk. Interventions targeting younger age groups are unlikely to have significant health effects at the population level for many years. The cost-effectiveness profiles of such interventions may be favourable in the long-term, but remain unfavourable for several decades at the start of the interventions. Preventive interventions do not always generate reductions in health expenditure, when the costs of treating a set of diseases that are directly affected by diet, physical activity and obesity are considered.
\end{abstract}

Key words: Obesity, chronic disease prevention, cost-effectiveness analysis, health expenditure, health inequalities. 


\section{EXECUTIVE SUMMARY}

1. Overweight and obesity rates have been increasing relentlessly over recent decades in all industrialised countries, as well as in many lower income countries. OECD analyses of trends over time support the grim picture drawn in the international literature and so do projections of overweight and obesity rates over the next ten years. The circumstances in which people have been leading their lives over the past 20-30 years, including physical, social and economic environments, have exerted powerful influences on their overall calorie intake, on the composition of their diets and on the frequency and intensity of physical activity at work, at home and during leisure time. Many countries have been concerned not only about the pace of the increase in overweight and obesity, but also about inequalities in their distribution across social groups, particularly by socio-economic status and by ethnic background.

2. Governments have implemented a wide range of interventions at the national and local levels, particularly during the past 5 years. They have been taking action in accordance with calls by international organisations and pressure by the media and the public health community, but without a strong body of evidence on the effectiveness of interventions, and virtually no evidence of their efficiency and distributional impact.

3. The OECD, in collaboration with the WHO, carried out a model-based assessment of a range of interventions to prevent chronic diseases by improving diet and by increasing physical activity. The assessment was broadly based on the WHO-CHOICE (CHOosing Interventions that are Cost-Effective) approach. The aim of the analysis was to assess the efficiency of a range of policy options to tackle unhealthy lifestyles and related chronic diseases. Additionally, compared to the traditional CHOICE framework, the analysis assessed the distributional impacts of preventive strategies on costs and health outcomes.

4. Most of the preventive interventions evaluated as part of the project have favourable costeffectiveness ratios, relative to a scenario in which no systematic prevention is undertaken and chronic diseases are treated once they emerge. However, since the determinants of obesity are multi-factorial and affect all age groups and social strata, interventions tackling individual determinants or narrowly targeted to one groups of individuals will have a limited impact at the population level, and will not reduce significantly the scale of the obesity problem. Although the most efficient interventions appear to be outside the health sector, health care systems can have the largest impact on obesity and related chronic conditions by focusing on individuals at high risk. Interventions targeting younger age groups are unlikely to have any significant health effects at the population level for many years. The cost-effectiveness profiles of such interventions may be favourable in the long-term, but may remain unfavourable for several decades at the start of the interventions.

5. Preventive interventions do not always generate reductions in health expenditure, when the costs of treating a set of diseases that are directly affected by diet, physical activity and obesity are considered. Individuals may live longer with chronic diseases, as a result of prevention, and may survive long enough to experience unrelated diseases which they would not have experienced otherwise. All of the interventions assessed in the economic analysis generate a requirement for additional resources to be made available within the public sector, in other areas of government intervention, or within the private sector. Most interventions constitute efficient uses of such resources; however, a large part of those resources would need to be made available upfront, while health returns are often delayed. Governments should determine 
what level of resources (budgets) they are willing and able to convey to prevention, and they may use the findings of the OECD economic analysis to assess what portfolio of interventions would make the best use of such budgets.

6. The cost-effectiveness ratios resulting from the economic analysis are subject to a certain degree of uncertainty because of the heterogeneity and relatively wide confidence intervals of the estimates of effectiveness used as inputs in the modelling work. Although a range of sensitivity analyses confirmed that model estimates are relatively robust, the range of variation in potential inputs suggests that interventions need to be very carefully designed in order to achieve at least the same levels of effectiveness recorded in the studies referred to in the economic analysis, at no greater cost.

7. The distributional impact of preventive interventions appears generally favourable, with reductions both in overall inequalities in age at death and in inequalities in life expectancy and disabilityadjusted life expectancy between socio-economic groups. However, inequalities in age at death are reduced only to a small extent. The extent to which inequalities between socio-economic groups may be reduced depends crucially on possible differences in the effectiveness of interventions between the relevant groups and there is little reliable evidence about whether this is the case.

8. Tackling major risk factors for health, or chronic diseases linked to behaviours that are highly prevalent in a population, requires more than a single preventive intervention, however effective and broadly based it may be. Turning the tide of diseases that have assumed epidemic proportions during the course of the $20^{\text {th }}$ century requires fundamental changes in the social norms that regulate individual and collective behaviours. Such changes will only be triggered by wide ranging prevention strategies addressing multiple determinants of health. A prevention strategy can be devised by selecting an appropriate mix of interventions, which must balance available resources, timing of expenditures and health effects, distribution of costs and health effects across population groups, and interference with individual choice.

9. The adoption of a "multi-stakeholder" approach is increasingly invoked by many as the most sensible way forward to prevent chronic diseases linked to unhealthy diets and sedentary lifestyles. No party is in a position to meaningfully reduce the size of the obesity problem and associated chronic diseases without the co-operation of other stakeholders. 


\section{RESUME}

10. Les taux de surpoids et d'obésité ne cessent d'augmenter depuis plusieurs décennies dans tous les pays industrialisés, ainsi que dans beaucoup de pays ayant un revenu plus faible. Les analyses consacrées par l'OCDE aux tendances structurelles confirment le sombre tableau qui a été brossé dans les publications internationales, tout comme le font les prévisions établies sur les taux de surpoids et d'obésité pour les dix prochaines années. Les conditions dans lesquelles vivent les individus depuis vingt ou trente ans, notamment sur le plan matériel, social et économique, ont très fortement influé sur leur ration calorique globale, la composition de leur alimentation, ainsi que la fréquence et l'intensité de leur activité physique au travail, à la maison et pendant les loisirs. Beaucoup de pays sont préoccupés non seulement par le rythme auquel progressent le surpoids et l'obésité, mais aussi par le caractère inégal de leur répartition entre les catégories sociales, en particulier selon la situation socioéconomique et l'origine ethnique.

11. Afin d'y remédier, les pouvoirs publics ont mis en oeuvre tout un éventail de mesures aux niveaux national et local, en particulier au cours des cinq dernières années. Ils l'ont fait conformément aux appels des organisations internationales et à la pression exercée par les médias et les milieux concernés par la santé publique, mais sans disposer d'un corpus de données solide sur l'efficacité de ces actions, ni quasiment aucune preuve de leur efficience et de leur impact sur la répartition des facteurs de risque dans la population.

12. En collaboration avec l'OMS, l'OCDE a procédé, à partir d'un modèle, à l'évaluation de plusieurs actions destinées à prévenir les maladies chroniques par l'amélioration de l'alimentation et l'augmentation de l'activité physique. Cet exercice s'est appuyé dans l'ensemble sur la méthode WHOCHOICE (CHOosing Interventions that are Cost-Effective). Son but était d'apprécier l'efficience de diverses mesures envisageables pour lutter contre les mauvaises habitudes de vie et les affections chroniques ayant un rapport avec elles. De plus, par comparaison avec le système CHOICE classique, cette analyse avait pour objet d'apprécier l'impact des stratégies de prévention sur la répartition des coûts et des résultats en matière de santé.

13. La majeure partie des actions de prévention qui ont été évaluées dans le cadre de ce projet offrent un rapport coût-efficacité favorable, relativement à un scénario où il y a absence de prévention systématique et où les affections chroniques sont traitées après qu'elles ont fait leur apparition. Cependant, aucune des actions examinées ne peut permettre de réduire sensiblement l'ampleur du problème de l'obésité si elle est menée de façon isolée. Bien que les interventions les plus efficientes semblent se situer à l'extérieur du secteur de la santé, c'est le système de santé qui peut influer le plus fortement sur l'obésité et les affections chroniques qui en résultent en privilégiant les personnes très menacées. Il est peu probable que les mesures visant les groupes d'âge relativement jeunes produisent des effets tant soit peu importants sur la santé au niveau de la population avant de nombreuses années. Le rapport coût-efficacité de ces mesures sera sans doute positif à long terme, mais il peut rester négatif pendant plusieurs décennies après leur mise en œuvre.

14. Les actions de prévention n'entraînent pas toujours une baisse des dépenses de santé, et ce constat vaut même lorsque l'analyse est limitée à un ensemble de maladies qui sont liées de façon relativement directe à l'alimentation, à l'activité physique et à l'obésité. Il est possible de vivre plus longtemps avec une affection chronique du fait de la prévention, et l'on peut survivre suffisamment longtemps pour contracter des maladies sans rapport avec celle-ci, que l'on n'aurait pas eues autrement. La 
totalité des mesures sur lesquelles a porté l'analyse économique rendent nécessaire la mise en œuvre de ressources supplémentaires à l'intérieur du secteur public, dans d'autres domaines d'action des pouvoirs publics ou au sein du secteur privé. La plupart d'entre elles représentent une utilisation rationnelle de ces ressources ; il faudrait cependant que ces dernières puissent être en grande partie mobilisées en amont, alors que les effets positifs sur la santé mettent souvent un certain temps à se manifester. Les pouvoirs publics devraient définir le volume de ressources (le budget) qu'ils sont désireux et capables d'affecter à la prévention, et ils peuvent utiliser les résultats de l'analyse économique de l'OCDE pour déterminer quel éventail de mesures appliquer pour faire une utilisation optimale de ces ressources.

15. Les rapports coût-efficacité dégagés de l'analyse économique sont dans une certaine mesure entachés d'incertitude en raison de l'hétérogénéité et de l'intervalle de confiance relativement large des estimations de l'efficacité utilisées pour l'exercice de modélisation. $\mathrm{Si}$ un ensemble d'analyses de sensibilité ont confirmé que les estimations dégagées du modèle étaient relativement solides, la variabilité des données d'entrée potentielles tend à montrer que les actions doivent être très soigneusement conçues pour permettre d'obtenir au moins les mêmes niveaux d'efficacité que ceux dont font état les études évoquées dans l'analyse économique, et ce sans augmentation du coût.

16. L'impact des actions de prévention sur la répartition semble dans l'ensemble positif, avec une réduction aussi bien des inégalités générales concernant l'âge au moment du décès que des inégalités en matière d'espérance de vie et d'espérance de vie en bonne santé entre les différentes catégories socioéconomiques. Néanmoins, les inégalités d'âge au décès ne diminuent que dans une faible mesure. Le degré de réduction possible des inégalités entre les catégories socioéconomiques dépend de façon déterminante des différences possibles d'efficacité des actions selon les catégories et il y a peu de preuves fiables qui montrent si c'est le cas.

17. La lutte contre les importants facteurs de risque auxquels peut être exposée la santé, ou contre les maladies chroniques liées à des comportements très fréquents dans une population, exige davantage qu'une simple action de prévention, quelles que soient son efficacité et sa portée. Pour faire reculer les maladies qui ont pris l'ampleur d'une épidémie au cours du 20ème siècle, il est nécessaire de modifier profondément les normes sociales qui régissent les comportements individuels et collectifs. Ce changement ne sera suscité que par des stratégies de prévention de grande envergure qui prennent en compte les multiples déterminants de la santé. Il est possible de définir une stratégie de prévention en choisissant un assortiment adapté de mesures qui doivent mettre en équilibre les ressources disponibles, le calendrier des dépenses et le moment où s'exerceront les effets sur la santé, la répartition des coûts et des effets sur la santé entre les différentes catégories de la population, et l'intervention dans les choix individuels, autant de dimensions entre lesquelles il faudra envisager de procéder à des arbitrages.

18. L'adoption d'une approche «multipartite » est de plus en plus souvent citée comme le moyen le plus judicieux de progresser pour prévenir des affections chroniques liées à de mauvaises habitudes alimentaires et à un mode de vie sédentaire. Aucune partie n'est en mesure de réduire sensiblement l'ampleur du problème de l'obésité et des maladies chroniques qui lui sont associées sans coopérer avec les autres. 


\section{TABLE OF CONTENTS}

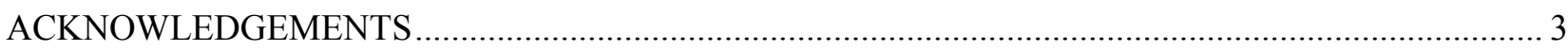

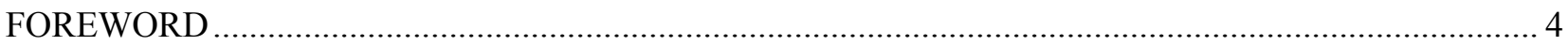

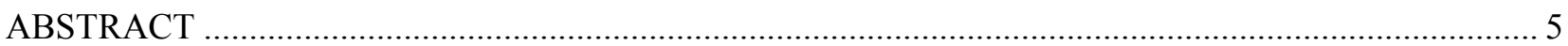

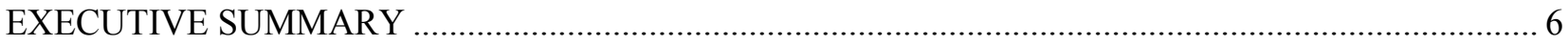

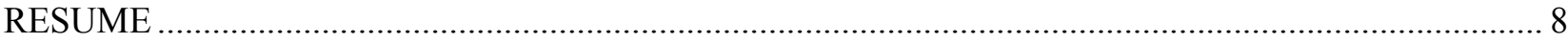

SECTION I. TACKLING OBESITY: WHAT DO WE KNOW? ............................................................ 12

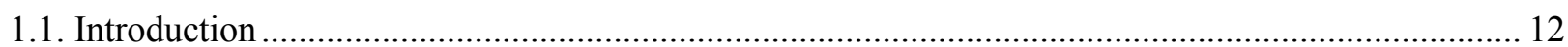

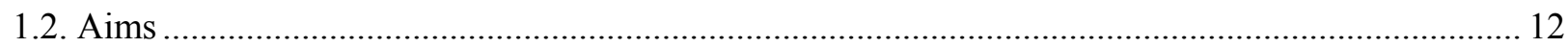

1.3. Existing evidence about the efficiency and distributional impact of prevention ............................. 13

1.4. Cost-effectiveness analysis: a generalized approach............................................................... 17

SECTION II. MODELLING THE IMPACT OF INTERVENTIONS.................................................... 19

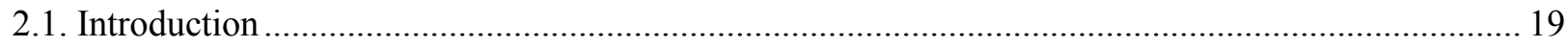

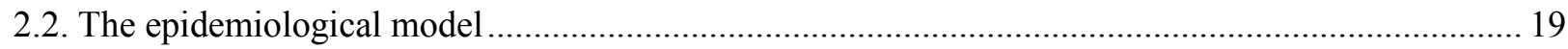

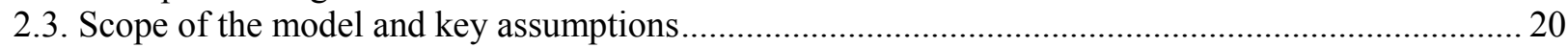

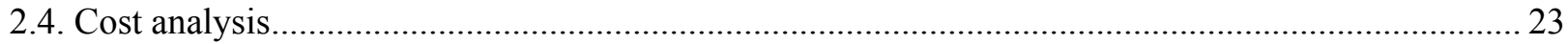

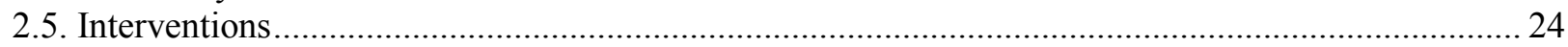

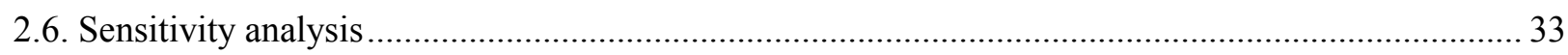

SECTION III. THE IMPACTS OF PREVENTIVE INTERVENTIONS …............................................. 35

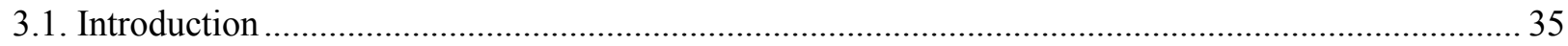

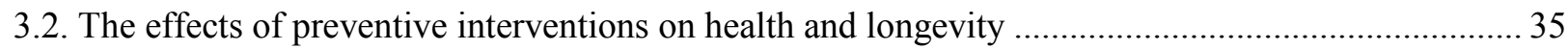

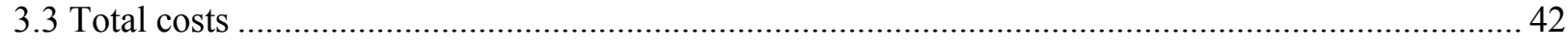

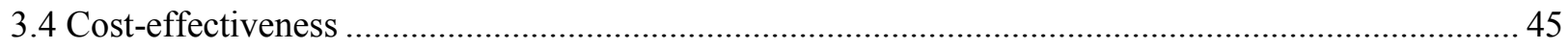

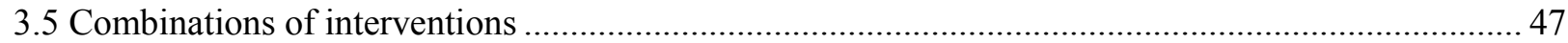

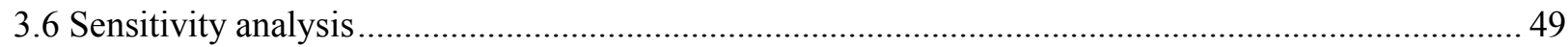

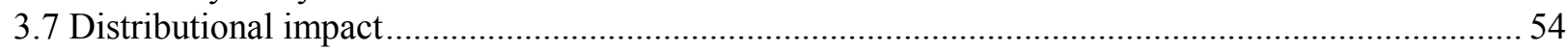

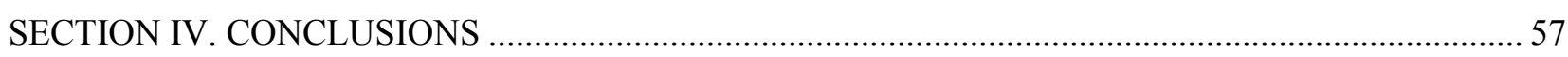

ANNEX 1. EVIDENCE OF THE COST-EFFECTIVENESS OF INTERVENTIONS 59

ANNEX 2. LIST OF ARTICLES AND PUBLICATIONS ON THE COST-EFFECTIVENESS AND COST-BENEFIT OF INTERVENTIONS TO TACKLE OVERWEIGHT AND OBESITY THROUGH

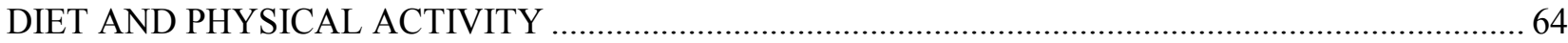

ANNEX 3. LIST OF ARTICLES AND PUBLICATIONS ON PARAMETERS OF THE

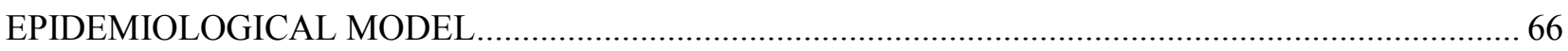

ANNEX 4. STRUCTURE OF MICRO-SIMULATION MODEL FOR ECONOMIC ANALYSIS ........... 70

ANNEX 5. EVIDENCE OF THE EFFECTIVENESS OF INTERVENTIONS ......................................... 76

ANNEX 6. LIST OF ARTICLES AND PUBLICATIONS ON THE EFFECTIVENESS OF INTERVENTIONS TO TACKLE OVERWEIGHT AND OBESITY THROUGH DIET AND PHYSICAL ACTIVITY

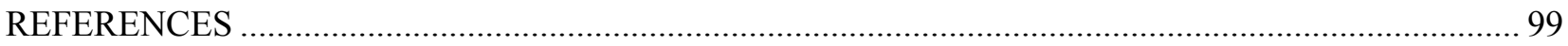




\section{Tables}

Table 1. Parameters used to feed the model and their reference.......................................................... 22

Table 2. Summary of coverage and main effects of selected preventive interventions .......................... 27

Table 3. Disability-adjusted life years gained at steady state.................................................................. 41

\section{Figures}

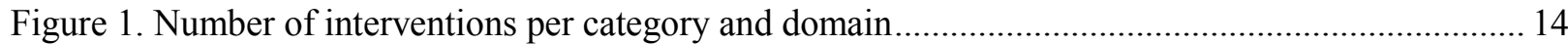

Figure 2. Time to reach steady state (school-based intervention) ….................................................. 25

Figure 3. Decrease in obesity rates for 25 and 65 year olds and whole population ............................... 36

Figure 4. Decrease in disease incidence at the population level ............................................................. 37

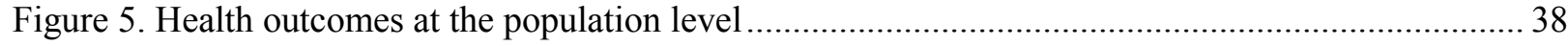

Figure 6. Health outcomes at the population level by age group .................................................... 39

Figure 7. Cumulative disability-adjusted life years gained (millions) over time ................................... 42

Figure 8. Economic assessment of interventions at the population level ............................................. 43

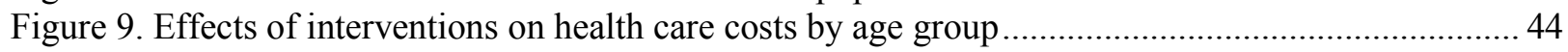

Figure 10. Cost-effectiveness of interventions over time (\$/DALY) ..................................................... 46

Figure 11. Incremental cost-effectiveness of interventions at steady state .......................................... 47

Figure 12. Health outcomes and impact on health expenditure for combinations of

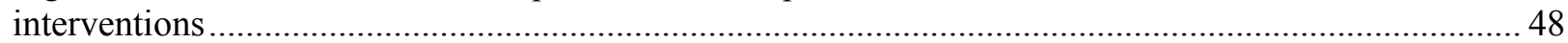

Figure 13. Cost-effectiveness of combinations of interventions over time (\$/DALY) ........................... 49

Figure 14. Sensitivity analysis of health outcomes and impact on health expenditure for selected

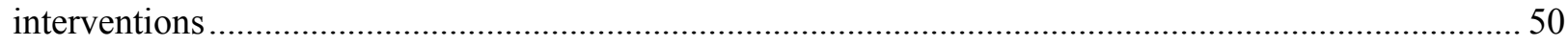

Figure 15. Sensitivity analysis: cost-effectiveness of interventions over time

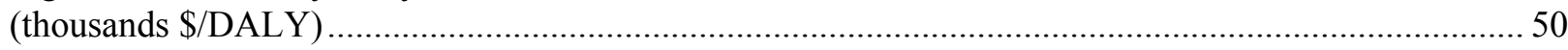

Figure 16. Sensitivity analysis: alternative assumptions about the long-term effects of interventions

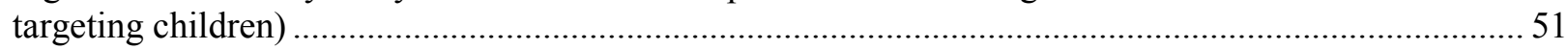

Figure 17. Probabilistic sensitivity analysis of the cost-effectiveness of interventions at 10 and

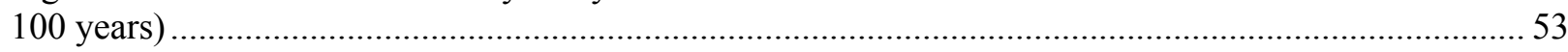

Figure 18. Life-year gain for different socio-economic groups ...................................................... 54

Figure 19. Sensitivity analysis: life-year gain for different socio-economic groups (fiscal measures) .... 56

Figure 20. Decrease in the Gini coefficient for life years and disability-adjusted life years

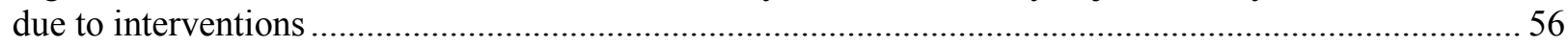

Figure A4.1: The static causal web for risk factor prevalences implemented in the CDP model ............ 73

Figure A4.2: The dynamic causal web for risk factor transitions implemented in the CDP model......... 74

Figure A4.3: The dynamic causal web for disease events implemented in the CDP model .................... 75

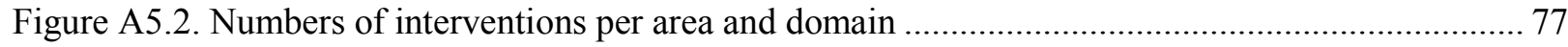

\section{Boxes}

Box 1. The CDP (Chronic Disease Prevention) model. 


\section{SECTION I. TACKLING OBESITY: WHAT DO WE KNOW?}

\subsection{Introduction}

19. There is widespread concern in OECD countries about increasingly unhealthy dietary habits and sedentary lifestyles. This concern has been prompted by rising rates of overweight and obesity and by an increasing burden associated with chronic diseases such as diabetes. In an attempt to alter these trends, governments have implemented a range of policies, among which interventions to promote lifestyle changes play a major role. A strategy based on improving health-related behaviours is strongly supported, for instance, by the WHO, which considers diet and physical activity as "public health priorities". In 2004, the WHO published a "Global Strategy on Diet, Physical Activity and Health" (WHO, 2004). Action on diet and physical activity may both contribute to the prevention of further increases in overweight, obesity and chronic diseases, and help to reduce the magnitude of the existing problem.

20. However, such efforts are severely limited by the lack of a sound evidence base on the effectiveness of interventions aimed at improving health habits. Many evaluations have been based on qualitative research, or have measured intermediate outcomes that do not provide a clear idea of the extent to which interventions may reduce the incidence of chronic diseases or improve mortality in the long run. For example, studies such as the PorGrow project (Millstone and Lobstein, 2007) and Foresight's "Tackling Obesities" (Butland et al., 2007) were mainly based on stakeholder or expert ratings of a number of possible policy options, in terms of their acceptability and potential impact. At the same time, intergovernmental organisations have produced reviews of policy developments (e.g. WHO Europe, 2006; EC, 2007; OECD, forthcoming) showing how countries are increasingly taking action to promote a healthier nutrition and physical activity. Despite this, only a limited number studies undertaken at national level have gathered empirical evidence on the effectiveness of interventions to improve diet and increase physical activity.

21. Evaluations of the cost-effectiveness of policies on diet and physical activity are even fewer, and narrower in terms of numbers of options considered, and no comprehensive assessment of large-scale interventions has ever been carried out. Although there is evidence that interventions promoting healthy diets and physical activity would be effective in the short term, there is no certainty that these results are sustainable in the long run and of an impact of behaviour changes on risk factors such as overweight, or blood glucose and lipid levels.

\subsection{Aims}

22. The OECD has undertaken a project on the economics of chronic disease prevention starting in 2007 (Sassi and Hurst, 2008; Sassi et al., 2009a; Sassi et al., 2009b); The primary aim of the costeffectiveness modelling component of the above project is to develop an economic model of the impact of interventions to tackle overweight/obesity and associated risk factors (particularly unhealthy diets and lack of physical activity) at the population level. The economic analysis model, as well as the underlying epidemiological model, is designed to be broadly applicable to the largest possible number of countries. The model was used to appraise a range of interventions in terms of their efficiency and their distributional impact across different life-stages and socio-economic conditions. The focus of the modelling work was on 
identifying efficient and equitable means of pursuing population health improvements through appropriate combinations of prevention and treatment of chronic diseases.

\subsection{Existing evidence about the efficiency and distributional impact of prevention}

23. A review was undertaken to identify existing cost-benefit and cost-effectiveness analyses of interventions to improve diet and physical activity. This follows a previous preliminary review of the "Cost-effectiveness of interventions to prevent or treat obesity and type 2 diabetes" undertaken by the OECD Secretariat in the year 2004 (unpublished mimeo).

24. The interventions and the studies reviewed are listed, respectively, in Annex 1 and Annex 2. The inclusion criteria for the present review were set along three dimensions: target population, intervention domain, and study design. In particular, we chose to limit our review to interventions targeting healthy individuals, regardless of their BMI, therefore including interventions on the general population as well as those targeting overweight/obese individuals in good health. As a consequence, we excluded studies of interventions targeting sub-groups such as individuals with diabetes or cardiovascular disease. However, given the higher risk for obese individuals to develop chronic diseases, some interventions do include in their samples small proportions of individuals with diabetes or hypertension. In terms of intervention domain, we exclusively reviewed studies aimed at improving lifestyles by increasing physical activity and/or promoting healthy diets. Thus, other interventions such as surgery or pharmacological interventions were excluded. Finally, in terms of study design, only cost-benefit and cost-effectiveness analyses were selected for inclusion in the review.

25. Electronic searches were conducted using the medical literature database Medline and the Cochrane Library. In both cases we used the embedded hierarchy of MeSH (Medical Subject Heading) terms. This system is designed to retrieve publications that were previously indexed by multiple descriptors and qualifiers. In the case of Medline we used as plausible descriptors a number of combinations of the following terms: overweight/obesity, diet, food technology, nutrition technology, motor activity, costbenefit analysis and primary prevention. In our search of the Cochrane Library we used obesity as main term and diet therapy, economics, prevention \& control as qualifiers. Every time a potentially relevant paper was identified, we manually browsed through the studies identified by the relevant search engines as "related articles". Electronic literature searches were complemented by web-based searches of grey literature, mainly official documents produced by national governments and inter-governmental organisations.

26. Twenty-four studies covering forty-two interventions met our inclusion criteria. Eleven interventions exclusively involved changes in dietary habits, nineteen aimed at improving physical activity while twelve entailed a modification of both diet and physical activity. With few exceptions, papers were generally published in the period 1998-2006. Countries analyzed are mainly Australia and the US with a smaller set of studies coming from the UK and from Nordic countries.

27. Generally, economic evaluations were carried out alongside randomised controlled trials (ten studies). In a further three studies, economic evaluations were undertaken on the basis of previous trials. Two studies were cost analyses, four reported results based on models, and three were reviews of studies undertaken previously. Finally one paper reported cost ratios per service user.

28. The outcomes used in different studies were very heterogeneous. Seven studies assessed interventions in terms of before-after differences in variables such as body mass index, weight or other biological indicators (e.g. blood pressure or level of blood lipids), six studies reports results in terms of QALYs gained or DALYs of disease burden averted, five studies assess the differences in self-reported 
modifications of behaviours (i.e. physical activity and/or diet), and, finally, five studies reported benefit/cost ratios.

29. Evaluations focused on a wide range of interventions, which we grouped into the following four areas: counselling in the community, counselling in general practice, school-based interventions, and environmental modifications. Six additional isolated interventions did not easily fit into any of the above groups; therefore they were labelled as "others". Figure 1 shows, for each group, the numbers of interventions in each of the three domains: diet, physical activity and both.

Figure 1. Number of interventions per category and domain

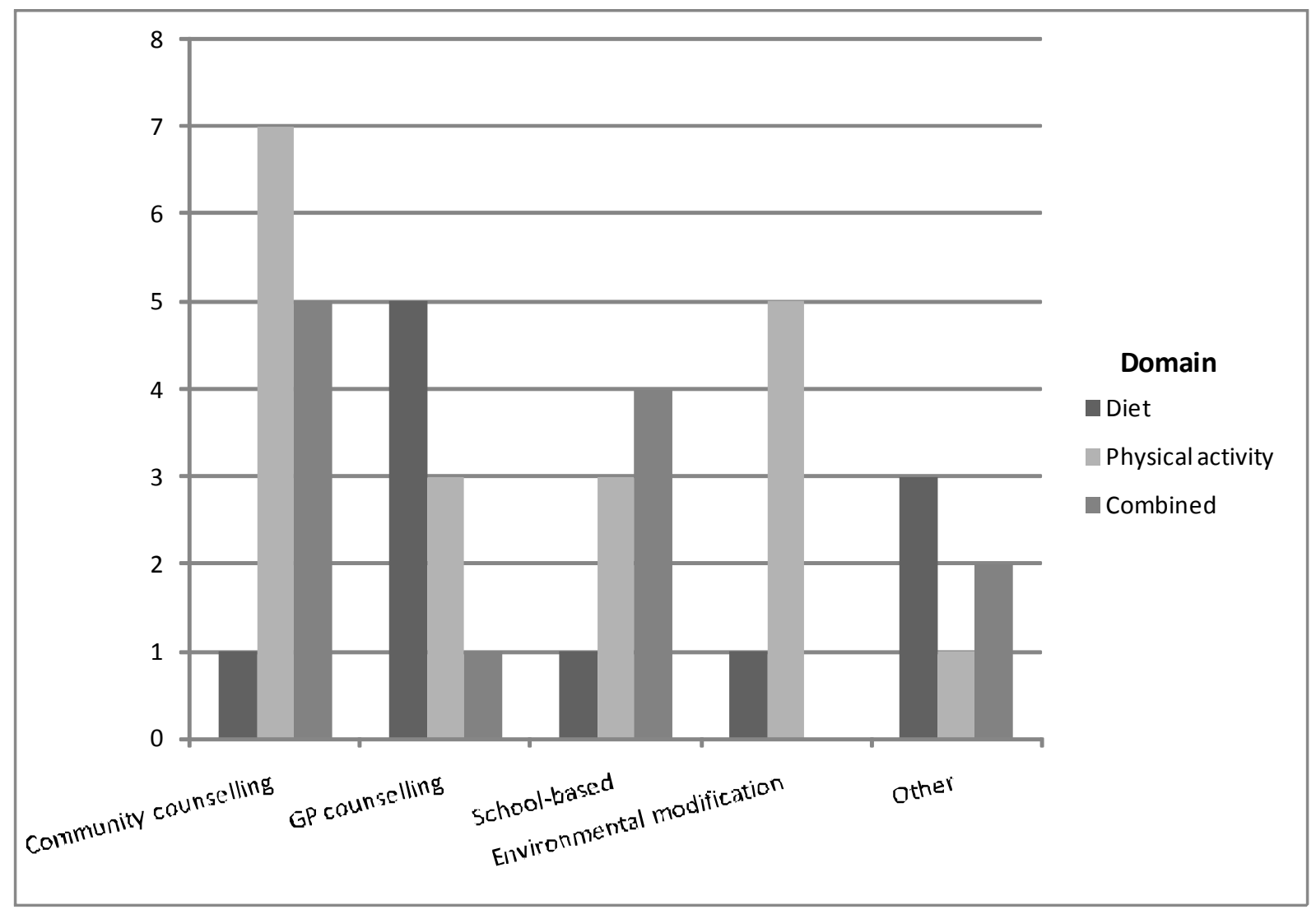

30. A brief description of the main characteristics and outcomes of each intervention is reported in the table in Annex 1. To facilitate comparisons, all cost values were transformed in 2005 US dollars using OECD purchasing power parity conversion rates. In the reminder of this section, we shall present a discussion of the main findings of the review in each of the 5 groups of interventions. In particular, the discussion will focus on methodological aspects, analytical approaches and key results from each evaluation.

31. The group of interventions defined as counselling in the community is the largest in terms of numbers of studies available. This group includes outreach actions delivered in community settings, generally by professionals such as physiologists, nutritionists, nurses, or even medical doctors. Programmes tended to focus on adult individuals who were overweight or obese, or those who presented one or more risk factors for obesity. This included, for instance, individuals with a self-assessed tendency to be physically inactive. Some interventions targeted families whose children were identified as being overweight. 
32. Individuals were often recruited through general practices or schools and were offered a series of information sessions organized either on an individual basis or in small groups. In some cases, complementary written information was provided. Some studies attempted to compare traditional delivery methods with innovative approaches such as computer-based systems or videotaped messages. In two cases, interventions not only provided information on the benefits of physical activity but required participants to undertake certain physical activities. This was done by providing free subscriptions to gyms, or by organizing after-school activities for pupils.

33. Results are not always directly comparable, because a variety of outcome measures were used to assess interventions in this group. Two studies measuring outcomes in terms of DALYs show how costs per DALY averted over the life course can vary from almost $\$ 2,750$ to $\$ 61,990$. In a similar way, the cost per QALY gained varies between $\$ 15,259$ and $\$ 73,227$. The cost for an additional serving of fruit or vegetables varies between $\$ 390$ and $\$ 1,460$.

34. The group of interventions under the name of counselling in general practice includes all those services involving the delivery of lifestyle advice in a general practice setting. Such advice was generally provided by health professionals, in most cases general practitioners themselves, but sometimes by dieticians or nurses. Individuals were often targeted opportunistically, when they visited a practice for a normal consultation. The individuals selected for receiving lifestyle advice may be those who had a BMI or waist circumference above a certain threshold, or those who belonged to specific population groups. In these cases, advice was delivered at the beginning or at the end of the consultation. Alternatively, some interventions involved a mailing of invitations to individuals deemed to be at risk for obesity or chronic diseases, for instance through a school-based screening based on the measurement of children's height and weight.

35. Advice was provided orally on an individual basis. In some cases oral information was complemented by supporting written materials. In one case, a telephone follow-up was organised after advice sessions. None of the interventions reviewed involved an explicit requirement for individuals to undertake specific physical activities.

36. Three studies measured outcomes in terms of QALYs: two of these reported average cost per QALY ratios and one reported an incremental cost-effectiveness ratio relative to usual care (which may involve the delivery of lifestyle advice, but not on a systematic basis). One paper measured outcomes in DALYs averted compared to usual care. Other results focused on the cost of persuading an individual to eat at least 5 portions of fruits or vegetables a day or on the cost of losing one kilogram of body weight. Results would suggest that, for example, decreasing the weight of a person of $1 \mathrm{~kg}$ would cost about $\$ 8$ while gains both in terms of QALYs or DALYs would cost between $\$ 22,000$ and $\$ 26,000$.

37. Compared to other categories, school-based interventions are relatively homogeneous. This group includes interventions delivered during the school year, in most cases as part of the standard school curriculum. Most interventions entailed the delivery of educational sessions held either by health professionals or by school teachers appropriately trained or supported by health professionals. One programme additionally involved the participation of responsible older students who acted as peer counsellors, while others involved children's families. Two interventions did not entail an educational component. Of these, one encouraged children to walk to school and another was aimed at promoting exercise through specific public events.

38. All interventions targeted children in primary school (i.e. about 7 to 11 years old), with the exception of one aimed at pupils in middle school. Programmes were directed to whole classes and only in one case they focused on children that were believed to be at risk for obesity. Intervention usually involved the delivery of interactive teaching sessions on the benefits of a healthy diet and of physical activity. Four 
interventions required children to do additional exercise by introducing extra hours of physical activity into the curriculum and organizing community events such as "leave the car at home week".

39. Most evaluations assessed outcomes in terms of DALYs and used current practice as the comparator. In summary, interventions involving extra physical activity had cost-effectiveness ratios ranging from $\$ 4,820$ to $\$ 0.53$ million per DALY gained over the life course. Intervention without physical activity had cost-effectiveness ratios from $\$ 2,070$ to $\$ 9,640$.

40. Six interventions labelled as environmental modifications targeted the environments in which people live in trying to make healthier choices simpler. Since these interventions directly modify environments they target whole communities. Five interventions increased the availability of facilities for physical exercise, primarily by building or improving walking and cycling track networks. In one case, a hypothetical intervention involved a ban on television advertising of food products with high fat and/or sugar density during times when at least $15 \%$ of the audience is composed by youngsters of up to 14 years of age.

41. In this group, results were often expressed as benefit to cost ratios. For example, estimates were produced of the costs of building and maintaining trails, compared with the sum of the social costs avoided (e.g. environmental and health burden) and the individual benefits arising (e.g. reduced congestion). Benefit/cost ratios for implementing trails would range from 1.4:1 to $14: 1$ according to the different parameters considered and the features of the track. The hypothetical advertising ban intervention seems one of the most cost-effective approaches, as it would avert one DALY of disease burden for only $\$ 2.5$, relative to unregulated advertising.

42. The last group (other interventions) is a collection of interventions that cannot be classified in any of the five clusters above. A multimedia campaign was analysed in one study. It consisted of a television advertising campaign to promote a healthy diet and, particularly, an increase in the consumption of fruits and vegetables. The campaign was divided into different phases, each focused on a specific target group, such as individuals in poor socio-economic circumstances, or mothers with children. The results suggest a cost of \$36 per QALY gained compared with doing nothing, over a 20 -year period.

43. Two interventions were aimed at improving nutrition through hospital prescribed diets, compared either with doing nothing or with a low carbohydrate diet. One modelling study assessed the benefits of the regular practice of physical exercise. A similar study was performed on a hypothetical cohort of overweight and obese women to assess the effect of an intervention comprising diet, exercise and behavioural modification. One last study reported the effects of a behavioural programme administered by correspondence. The populations targeted by these interventions varied from the general population to overweight and obese individuals. In one case the group was restricted to females. Outcomes were usually measured in terms of QALYs and cost-effectiveness ratios ranged from $\$ 13,800$ to $\$ 19,280$ per QALY gained.

44. Independently from the environments in which interventions were implemented (i.e. community, general practice, school), they usually implied some form of individual education. This may be achieved through school-based classes or through counselling sessions aimed at either individuals or groups. The objective is to make individuals more informed and therefore, at least in principle, more oriented towards making healthy choices. Only a limited number of studies investigated the effects of modifying the environments in which individuals live, rather than individual attitudes. This is partially because modifying the environment generally takes a longer time and possibly because assessing the effects of environmental interventions may be more complicated as it may require the study of a larger number of individuals. 
45. A further issue arises in relation to the time horizon of the studies reviewed. Many interventions produce discernible effects, for example on weight, only after a substantial time lag. Besides, once positive results are generated, it is important to assess how long these will last and whether they could be sustained in the long term. In our analysis, the effectiveness of interventions is typically evaluated only in a short term perspective, while cost-effectiveness calculations are generally made on the assumption that the improvements obtained at the end of the follow-up period will persist throughout the rest of the lives of the individuals concerned. Thus, the credibility of the results may be, at least in part, weakened. One last issue arises in relation to the difficulties associated with making comparisons across studies, even within the same groups, mainly due to differences in the outcome measures used in assessing the effectiveness of interventions.

\subsection{Cost-effectiveness analysis: a generalized approach}

46. Cost-effectiveness analysis (CEA) is concerned with how to make the best use of scarce health resources. The large and growing literature on the topic is dominated by the comparison of interventions aimed at a particular disease, risk factor or health problem, which provides relevant information to programme managers or practitioners with this specific disease mandate. In practice, however, different types of policy makers and practitioners have different demands. Managers of hospital drug formularies must decide which of a vast array of pharmaceuticals they should stock, taking into account the available budget. Countries where health is funded predominantly from the public purse make decisions on what type of pharmaceuticals or technologies can be publicly funded or subsidized, while all types of health insurance - social, community or private - must select a package of services that will be provided. These types of decisions require a broader set of information, involving comparison of different types of interventions across the entire health sector - whether they are aimed at treating diabetes, reducing the risk of stroke, or providing kidney transplants. This type of analysis can be referred to as "sectoral costeffectiveness analysis".

47. Although the number of published cost-effectiveness studies is now huge, there are a series of practical problems in using them for sectoral decision making (Hutubessy et al., 2003). The first is that most published studies take an incremental approach, addressing questions such as how best should small changes (almost always increases) in resources be allocated, or whether a new technology is more costeffective than the existing one it would replace. Traditional analysis has not been used to address whether existing health resources are allocated efficiently, despite evidence that in many settings current resources do not in fact achieve as much as they could (Tengs et al., 1995). A second problem is that most studies are very context specific. The efficiency of additional investment in an intervention aimed at a given disease depends partially on the level and quality of the existing health infrastructure (including human resources). This varies substantially across settings and is related to a third problem - individual interventions are almost always evaluated in isolation despite the fact that the effectiveness and costs of most will vary according to whether other related interventions are currently undertaken or are likely to be introduced in the future.

48. In response to these concerns, a more generalized approach to CEA has been developed by WHO in order to allow policy makers to evaluate the efficiency of the mix of health interventions currently available and to maximize the generalizability of results across settings. Generalized cost-effectiveness analysis (GCEA) and its implementation via the CHOICE project allows for an assessment of the efficiency of the current mix of interventions by analysing all interventions and combinations incremental on doing nothing (Murray et al., 2000; Tan Torres et al., 2003; www.who.int/choice). Operationally, the counterfactual that has been adopted in applied studies is defined in terms of what would happen to population health if all interventions being provided now were stopped. 
49. Many interventions interact in terms of either costs or effects at the population level and interacting interventions are undertaken in different combinations in different settings. Neither the health impact of undertaking two interventions together nor the costs of their joint production are necessarily additive. To understand whether they are efficient uses of resources independently or in combination requires assessing their costs and health effects independently and in combination. Only then is it possible to account for non-linearities in costs and effects.

50. GCEA seeks to maximize generalizability across settings. Most cost-effectiveness studies have been undertaken in developed countries, but not even the richest have been able to evaluate the full set of interventions required to undertake a sectoral analysis specific to their own country. All countries need to borrow results of cost or effectiveness studies from other settings, but the fact that most published studies are very specific to a particular setting makes this difficult. WHO-CHOICE reports results for 14 subregions of the world, but has developed tools enabling county-level analysis too.

51. GCEA has now been applied to a wide range of specific diseases (including malaria, tuberculosis, cancers and mental disorders) as well as risk factors (for example, child under-nutrition, unsafe sex, unsafe water, hygiene and sanitation, hypertension and smoking) (see, for example, Chisholm et al., 2004a; Chisholm et al., 2004b; Groot et al., 2006; Murray et al., 2003; Shibuya et al., 2003; WHO, 2002). Like all CEA, GCEA focuses on only one outcome, population health. There are many other possible outcomes people care about - inequalities in health, responsiveness, fairness of financing, for example (Murray and Evans, 2003). Accordingly, the results of GCEA cannot be used to set priorities by themselves but should be introduced into the policy debate to be considered along with the impact of different policy and intervention mixes on other outcomes. 
DELSA/HEA/WD/HWP(2009)6

\section{SECTION II. MODELLING THE IMPACT OF INTERVENTIONS}

\subsection{Introduction}

52. This section illustrates the methods and the input data used in the assessment of the efficiency and distributional impact of interventions to prevent chronic diseases linked to unhealthy diets and sedentary lifestyles. The analysis was undertaken by developing a micro-simulation model of the health outcomes arising from lifestyle risk factors typically associated with obesity. The model is described in section 2.2. and the key assumptions upon which it rests are discussed in section 2.3. Further details about the structure and characteristics of the epidemiological model are available in Annex 4. Input parameters and the costing approach are described in sections 2.4. and 2.5., while the remainder of the section is devoted to illustrating the characteristics of the preventive interventions assessed in the analysis, as well as the data sources and assumptions used in modelling the effectiveness of those interventions.

\subsection{The epidemiological model}

53. The epidemiological model (called "CDP") used in the economic analysis implements a "causal web" of lifestyle-oriented risk factors for selected adult chronic diseases. The concept of a causal web includes the idea that risk factors range in the immediacy of their effect on disease events from more distant exposures ("distal risk factors"), which are several steps away from disease events in the chain of causation, to more proximate exposures ("proximal risk factors"), which are more immediately connected to disease events. The causal web concept also typically includes the possibility, as also implemented here, that risk factors can influence other risk factors. Thus, in a causal web, disease events are influenced by risk factors both directly and indirectly. The definition of the risk factors, as well as the thresholds used to identify individuals at risk, is largely based on data provided by the WHO publication "Comparative Quantification of Health Risks" (Ezzati et al., 2004).

54. The CDP model explicitly accounts for three groups of chronic diseases: stroke, ischemic heart diseases and cancer (including lung, colorectal and breast cancer). In the model, proximal risk factors, such as high blood pressure, high cholesterol and high blood glucose, have a direct influence on the probability of developing such chronic diseases. This accounts for the effect of known pathophysiological mechanisms. Conversely, distal risk factors such as low intake of fruit and vegetables, high fat intake and insufficient physical activity have an indirect influence on chronic diseases. The indirect effect is mediated by BMI, which acts on proximal risk factors as well as directly on disease events. The model accounts for mortality from all causes of death. The model assumes that mortality associated with diseases that are not explicitly modelled remains stable at the rates currently observed in the relevant populations.

55. The CDP model is a stochastic microsimulation model. The term "microsimulation" refers to the fact that the model separately represents the lifetimes of many different individuals; emergent properties about the population are then obtained by "adding up" across individual histories. The term "stochastic" refers to the fact that the model employs random variation, for example, individuals are randomly assigned risk factor status and are randomly assigned waiting times for disease and mortality events; the program ensures that the number of individuals with, for example, a given risk factor status approaches the observed risk factor prevalence in the population being represented as the number of individuals modelled becomes large; in the same sense, the program ensures that the annual disease rates of populations simulated in the model matches, on average, the disease rates in the population being modelled. 
56. The model is dynamic in the sense that effects are measured with reference to individual life histories with unique beginning and end points in model time. Effects are manifested through hazards (risks) to develop disease conditions or risk factor states; the structure of the model is thus inherently designed to manifest time-dependent effects. At simulation start, the initial population in the model reproduces, in cross section, the demographic features of the population being modelled at an arbitrary point in time. Normally the model starting position is set up so as to correspond to "current time" for the population of interest, although other scenarios are possible. The model embodies a full age, period and cohort representation of the simulated population. Typical lifetable variables, such as residence time in various states, can be collected and reported for the purpose of measuring health effects or reporting on other epidemiological features of interest.

\section{Box 1. The CDP (Chronic Disease Prevention) model}

The epidemiological model, named CDP, is a stochastic microsimulation model able to simulate population dynamics. It was written in a C++ pre-compiler called ModGen (www.statcan.gc.ca/spsd/Modgen.htm), which is a generic "Model Generator" language created by Statistics Canada for developing and working with microsimulation models. The CDP model is based on an earlier child health model originally created by Statistics Canada based on a design provided by the World Health Organization. As the ChildHealth model also implemented a version of a causal web, it provided a useful starting point for the development of the CDP model.

CDP was jointly developed by the OECD and the WHO as a component of the Economics of Prevention project. Interested researchers may apply for access to the model by contacting either Michele Cecchini (michele.cecchini@oecd.org) or Jeremy Lauer (laueri@who.int).

\subsection{Scope of the model and key assumptions}

57. The present version of CDP is able to simulate the dynamics of the European population (Austria, Belgium, Czech Republic, Denmark, Finland, France, Germany, Greece, Iceland, Ireland, Israel, Italy, Luxembourg, Malta, Netherlands, Norway, Portugal, United Kingdom, Slovenia, Spain, Sweden and Switzerland) and assumes as starting point the year 2000. The population is simulated accounting for its distribution by three dimensions: gender, age (0 to 100) and social class (upper and lower). With some appropriate changes in the distribution of these dimensions and in the epidemiology of risk factors as well as of considered diseases, CDP can be adapted to simulate any specific country or, with some caveats, even other sets of conditions. Analyses presented in the reminder of this paper were calculated by assuming the following:

- A time perspective of 100 years to allow all interventions to reach a "steady state" and show their full potential effectiveness.

- Interventions are assumed to influence individual behaviours in line with existing evidence while they are being delivered, but to have no effects after they are completed, with the exception of interventions aimed at children and designed to influence their long-term preferences (schoolbased interventions, food advertising regulation and self-regulation), which are assumed to retain $50 \%$ of their original effectiveness once completed.

- In line with most current practice in cost-effectiveness analysis, we discounted both future costs and effects at a $3 \%$ rate.

- The impact on disability and premature death for the considered diseases is expressed in disability-adjusted life years (DALYs). Age weighting is not used. 
The impact of interventions on health expenditure only accounts for the diseases and the risk factors explicitly included in the model, that is: hypertension, hypercholesterolemia, diabetes (including major complications such as chronic renal failure, retinopathy and neuropathy), cancer, ischemic heart diseases and stroke.2.3. Parameters of the epidemiological model

58. The model requires a series of epidemiological data by gender (males and females), by class of age (age 0 to age 100) and, in some cases, by socioeconomic status (upper and lower). A first group of parameters allows the software to model the general population changes over time. This includes global mortality, fertility and prevalence of individuals by gender and age.

59. The second group refers to the three levels of risk factors (i.e. distal, intermediate and proximal). In this component we need four types of epidemiological parameters: prevalence, incidence of new cases, remission rates, and relative risks (RRs). The first three reflect the epidemiology of the population as a whole. For example, the incidence of pre-obesity indentifies the fraction of the overall population becoming pre-obese in a given period of time. RRs, instead, reflect either the probability of an individual to fall in one category or the likelihood of someone with a risk factor of moving in the next step of the web, compared to someone of the same gender and with the same age but without that specific risk factor.

60. The last group details the parameters used to model diseases. As before, we will consider prevalence, incidence rates, remission rates and relative risks. Additionally, now, there is a further parameter called case-fatality hazard. This corresponds to the hazard of dying due to a disease for individuals who have that disease. Relative risks can be divided into three categories: RRs of fatality, RRs of incidence of new cases and RRs of remission from the diseases. In the latter case, the value is in the range $0-1$ as the presence of a risk factor negatively influences the likelihood of recovering from a disease and, therefore, people for instance with diabetes are less likely than people without diabetes to recover from stroke. Finally one should specify the values to be assigned to each year of life spent in full health, with a disease or with combinations of diseases. Assigning weighted values to years spent in less than full health in burden of disease calculations allows to estimate how diseases affect life in qualitative, as well as in quantitative, terms.

61. We used the best available sources of information on the epidemiology of risk factors and chronic diseases to populate the micro-simulation model. A full reference list, by parameter, can be found in annex 3. In general most of the data we use to feed the model comes from WHO datasets, while RRs were obtained from peer reviewed publications. When it has not been possible to find inputs in this way, they were calculated through the WHO software DisMod II (Barendregt et al., 2003) or directly by using national health surveys. We selected data following two main criteria: i) maximize the representativeness of the population and ii) use data evaluated in a homogeneous period.

62. DisMod II is a software able to evaluate age- and gender-specific epidemiologic features of a population. It works using seven disease-specific variables (incidence, prevalence, remission, case fatality, duration, mortality, RR mortality) and two population variables (population structure and mortality). By inputting at least three of the disease specific variables DisMod II can calculate the other four. 
Table 1. Parameters used to feed the model and their reference

\begin{tabular}{|c|c|c|c|}
\hline \multicolumn{3}{|c|}{ Parameters } & References \\
\hline \multirow{3}{*}{$\begin{array}{l}\mathscr{D} \\
\infty \\
\mathbb{1} \\
\mathbb{1} \\
\mathscr{\infty} \\
0\end{array}$} & 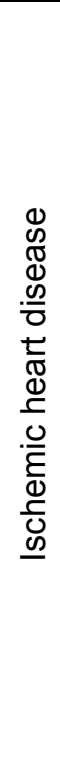 & $\begin{array}{c}\text { Prevalence } \\
\text { Incidence hazard } \\
\text { RR of incidence relative to high } \\
\text { blood pressure } \\
\text { RR of incidence relative to high } \\
\text { cholesterol } \\
\text { RR of incidence relative to diabetes } \\
\text { RR of incidence relative to obesity } \\
\text { RR of incidence relative to SES } \\
\text { RR of fatality relative to high blood } \\
\text { pressure } \\
\text { RR of fatality relative to high } \\
\text { cholesterol } \\
\text { RR of fatality relative to diabetes } \\
\text { RR of fatality relative to obesity } \\
\text { RR of mortality relative to SES }\end{array}$ & $\begin{array}{c}\text { Lopez et al., } 2006 \\
\text { Lopez et al., } 2006 \\
\text { Lim et al., } 2007 \\
\text { Lim et al., } 2007 \\
\text { van Baal et al., } 2008 \\
\text { van Baal et al., } 2008 \\
\text { Forssas et al., 2008; Salomaa et al., } 2000 \\
\text { Hu et al., 2005b; Stevens et al., 2004; Hart } \\
\text { et al., 1999 } \\
\text { Hart et al., 1999; Boshuizen et al., } 2007 \\
\text { Hu et al., 2005a; Hu et al., } 2006 ; \text { Hu et al., } \\
\text { 2005b; Hart et al., } 1999 \\
\text { Batty et al., 2006; Pardo Silva et al., 2006 } \\
\text { Haan et al., 1987; Logue et al., 1990; } \\
\text { Kaplan et al., 1993 }\end{array}$ \\
\hline & 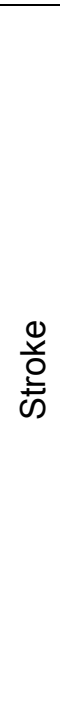 & $\begin{array}{c}\text { Prevalence } \\
\text { Incidence hazard } \\
\text { RR of incidence relative to high } \\
\text { blood pressure } \\
\text { RR of incidence relative to high } \\
\text { cholesterol } \\
\text { RR of incidence relative to diabetes } \\
\text { RR of incidence relative to obesity } \\
\text { RR of incidence relative to SES } \\
\text { RR of fatality relative to high blood } \\
\text { pressure } \\
\text { RR of fatality relative to high } \\
\text { cholesterol } \\
\text { RR of fatality relative to diabetes } \\
\text { RR of fatality relative to obesity } \\
\text { RR of mortality relative to SES }\end{array}$ & $\begin{array}{c}\text { Lopez et al., } 2006 \\
\text { Lopez et al., } 2006 \\
\text { Lim et al., } 2007 \\
\text { Lim et al., } 2007 \\
\text { Lim et al., } 2007 \\
\text { van Baal et al., } 2008 \\
\text { Hart et al., 2000; Kuper et al., } 2007 \\
\text { Stevens et al., 2004; Boshuizen et al., } \\
\text { 2007; Menotti et al., } 2003 \\
\text { Boshuizen et al., 2007; Menotti et al., } 2003 \\
\text { Hu et al., 2005a; Wannamethee et al., } \\
\text { 2004 } \\
\text { Batty et al., 2006; Pardo Silva et al., } 2006 \\
\text { Arrich et al., 2005; Jakovljević et al., } 2001\end{array}$ \\
\hline & 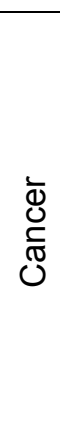 & $\begin{array}{l}\text { Incidence hazard } \\
\text { Mortality } \\
\text { RR of incidence relative to fibre } \\
\text { consumption } \\
\text { RR of incidence relative to obesity } \\
\text { RR of incidence relative to SES } \\
\text { RR of fatality relative to fibre } \\
\text { consumption } \\
\text { RR of fatality relative to obesity } \\
\text { RR of mortality relative to SES }\end{array}$ & $\begin{array}{c}\text { Parkin et al., } 2005 \\
\text { IARC/WHO, } 2008 \\
\text { Lock K et al., } 2005 \\
\\
\text { van Baal et al., } 2008 \\
\text { van Loon et al., } 1995 \\
\text { Skuladottir et al., 2006; Pierce et al., 2007; } \\
\text { Jansen et al., } 1999 \\
\text { Calle et al., } 2003 \\
\text { van Loon et al., } 1995\end{array}$ \\
\hline
\end{tabular}


DELSA/HEA/WD/HWP(2009)6

\begin{tabular}{|c|c|c|c|}
\hline \multicolumn{3}{|c|}{ Parameters } & References \\
\hline \multirow{3}{*}{ 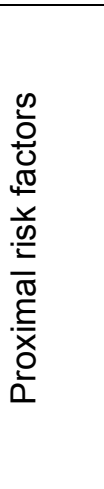 } & 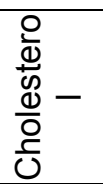 & $\begin{array}{c}\text { Prevalence } \\
\text { Mortality } \\
\text { RR of high cholesterol relative to } \\
\text { obesity }\end{array}$ & $\begin{array}{c}\text { Lawes et al., 2004b } \\
\text { Stamler et al., } 2000 \\
\text { based on Health Survey for England }\end{array}$ \\
\hline & 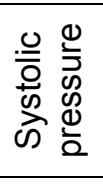 & $\begin{array}{c}\text { Prevalence } \\
\text { Mortality } \\
\text { RR of high systolic blood pressure } \\
\text { relative to obesity }\end{array}$ & $\begin{array}{c}\text { Lawes et al., 2004a } \\
\text { Lawes et al., 2004a } \\
\text { based on Health Survey for England }\end{array}$ \\
\hline & $\begin{array}{l}\frac{0}{0} \\
\frac{0}{\pi} \\
\frac{0}{0}\end{array}$ & $\begin{array}{c}\text { Prevalence } \\
\text { Mortality } \\
\text { RR of diabetes relative to obesity }\end{array}$ & $\begin{array}{c}\text { Wild et al., } 2004 \\
\text { Lopez et al., } 2006 \\
\text { van Baal et al., } 2008\end{array}$ \\
\hline 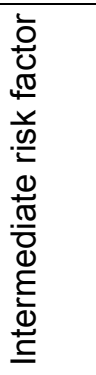 & 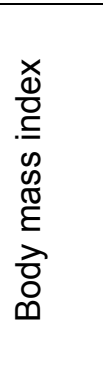 & $\begin{array}{c}\text { Prevalence } \\
\text { Mortality } \\
\text { RR of obesity relative to fat diet } \\
\text { RR of obesity relative to physical } \\
\text { activity } \\
\text { RR of obesity relative to fibre } \\
\text { consumption }\end{array}$ & $\begin{array}{c}\text { James et al., } 2004 \\
\text { Flegal et al., 2005; Ringback, Weitoft et } \\
\text { al., } 2008 \\
\text { based on the National Health And Nutrition } \\
\text { Examination Survey } \\
\text { based on the National Health And Nutrition } \\
\text { Examination Survey } \\
\text { based on the National Health And Nutrition } \\
\text { Examination Survey }\end{array}$ \\
\hline \multirow{6}{*}{ 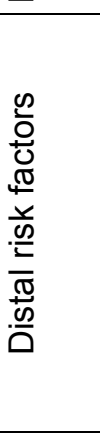 } & \multirow{2}{*}{ 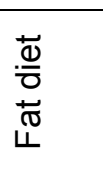 } & Prevalence & $\begin{array}{c}\text { FAOSTAT, } 2008 \text { and National Health And } \\
\text { Nutrition Examination Survey }\end{array}$ \\
\hline & & RR of fat diet relative to social class & $\begin{array}{c}\text { based on the National Health And Nutrition } \\
\text { Examination Survey }\end{array}$ \\
\hline & \multirow{2}{*}{ 浐 } & Prevalence & Lock et al., 2004 \\
\hline & & $\begin{array}{l}\text { RR of fibre consumption relative to } \\
\text { social class }\end{array}$ & $\begin{array}{c}\text { based on the National Health And Nutrition } \\
\text { Examination Survey }\end{array}$ \\
\hline & \multirow[b]{2}{*}{ 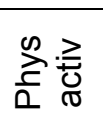 } & Prevalence & Special Eurobarometer 183-6/Wave 58.2 \\
\hline & & $\begin{array}{c}\text { RR of physical activity relative to } \\
\text { social class }\end{array}$ & $\begin{array}{c}\text { based on the National Health And Nutrition } \\
\text { Examination Survey }\end{array}$ \\
\hline 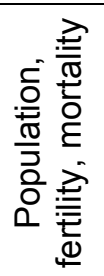 & \multicolumn{2}{|r|}{$\begin{array}{l}\text { Starting population distribution } \\
\text { Distribution by SES } \\
\text { Proportion of newborn males } \\
\quad \text { Total mortality } \\
\text { RR of mortality relative to SES } \\
\text { tors for disability-adjusted life years }\end{array}$} & $\begin{array}{c}\text { WHO-CHOICE, } 2008 \\
\text { National health survey datasets } \\
\text { WHO-CHOICE, } 2008 \\
\text { WHO-CHOICE } 2008 \\
\text { Mackenbach et al., } 1997 \\
\text { Lopez et al., } 2006\end{array}$ \\
\hline
\end{tabular}

\subsection{Cost analysis}

63. At a conceptual level, the benefit of an intervention is the gain in welfare associated with the health improvement, while the cost is the loss of welfare associated with foregone non-health consumption (due to resources being used to provide the intervention). Accordingly, costs should be measured from the perspective of society as a whole, to understand how best to use resources regardless of who pays for them, or indeed, whether they are paid for at all. In practical terms, however, there are a number of cost consequences that are difficult to quantify due to lack of good-quality or consistent data, for example the costs incurred by people to access services (e.g. travel costs) or provide informal care-giving. The impact of interventions on the time and potential earnings of patients and unpaid carers - i.e. work time lost - is a vexing question in cost-effectiveness analysis but are often excluded on ethical grounds (inclusion would give priority to extending the life of people who earn more). Domestic taxes are also typically excluded from consideration, since they simply transfer financial resources from one person to another and do not use up a physical resource such as capital or labour. The conceptual foundations and practical 
implementation of costing within a Generalized cost-effectiveness (GCEA) framework are discussed in greater detail elsewhere (Tan Torres et al., 2003; Evans et al., 2005).

64. In the implementation of GCEA via the WHO-CHOICE project, costs are divided into those incurred at the patient or programme level. Patient-level costs involve face-to-face delivery by a health provider (broadly defined) to a recipient - e.g. medicines, outpatient visits, in-patient stays, individual health education messages. Programme-level costs include all resources required to establish and maintain an intervention - administration, publicity, training, delivery of supplies. Interventions like radio delivery of health education messages largely involve the former, while treatment at health centres largely involves the latter. A standardized ingredients approach is used, requiring information on the quantities of physical inputs needed and their unit cost (i.e. total costs are quantities of inputs multiplied by their unit costs). For programme-level costs, the physical inputs - human resources, office space, vehicles, electricity, other services, and a variety of consumables - required to introduce and run a programme are based on estimates by costing experts commissioned for this purpose, using a standard template (Johns et al., 2003, 2006). This was supplemented by information from programme managers in other countries known by WHO staff. These resource estimates represent a key building block for estimation of the costs of populationbased intervention strategies, such as tobacco control or salt reduction programmes.

65. For patient-level costs, quantities are taken from a variety of sources. Where effectiveness estimates were available from published studies, the resources necessary to ensure the observed level of effectiveness are identified. In other cases, the resources implied by the activities outlined in WHO treatment practice guidelines were estimated. Since it is not always possible to identify the exact quantities of primary inputs (human resources, consumables) necessary for patient-level costs, certain quantities and prices are estimated at an intermediate level for several inputs - inpatient days at different hospital levels, outpatient visits and health centre visits (Tan Torres et al., 2003).

66. Unit costs for each input were derived from an extensive search of published and unpublished literature and databases along with consultation with costing experts. For goods that are traded internationally, the most competitive price available internationally was used. For example, estimates of drug prices were based on the median supply price published in the International Drug Price Indicator Guide, subsequently marked-up to account for transportation and distribution costs. For goods available only locally (e.g. human resources, inpatient bed days) unit costs have been shown to vary substantially across countries, although international comparisons found similar cost-of-illness patterns in several OECD countries (Heijink et al., 2004). As a result, cross country regressions, mainly accounting for country GDP and local characteristics of the supply of health care, have been run using the collected data to estimate the average cost (with adjustments for capacity utilization) for each setting (Adam et al., 2003, 2006).

67. Costs are reported in international dollars, or dollar purchasing power parities (\$PPPs) rather than US dollars, with 2005 as the base year. An international dollar has the same purchasing power as the US dollar has in the United States, and therefore provides a more appropriate basis for comparison of cost results across countries or world regions. Future costs are discounted using a 3\% discount rate.

\subsection{Interventions}

68. We evaluated a full range of interventions from different government departments: mass media campaigns, school-based interventions, worksite interventions, fiscal measures, regulation of food advertising to children and compulsory food labelling. The choice, the design as well as the gathering of the quantitative data that were used to feed the model were based on a review of studies about the effectiveness of interventions to improve diet and physical activity. 
69. From the body of evidence we collected, we selected those studies which appeared particularly strong because of the size of the sample, the duration of the study and the robustness of the experimental design. For some interventions (e.g. school-based, worksite) we were able to retrieve multiple studies. In this case we identified studies which adopted homogeneous interventions and combined results. In other cases (e.g. regulation of food advertising) we selected one single study.

70. The effectiveness of interventions is modelled on three dimensions: efficacy in changing behaviours and risk factors, coverage (i.e. share of the population covered by the intervention) and time to steady state. Data for the first two dimensions were retrieved from the literature following the approach illustrated in the previous paragraphs and discussed in further detail in Annex 5. For instance, in the case of school-based interventions, we found evidence of an increased consumption of fruit and vegetables and of a decrease of fat intake and BMI. These changes were applied to all children covered by the intervention (children aged 8 or 9). The third dimension, time to steady state, is a direct reflection of the age groups covered by the intervention. During the first year of a school-based intervention (period 1) only children aged 8 and 9 are exposed to the intervention (see Figure 2). The following year (period 2) the intervention will cover children aged 8 and 9 (who were 7 and 8 , respectively, in period 1) while children aged 10 (who were 9 in period 1) will retain half of the effectiveness of the intervention. The steady state is reached when the intervention affects the largest possible share of the population. For school-based intervention this happens when school children who were 9 years old in period 1 become 100 years old, thus 91 years after the first implementation of the intervention.

Figure 2. Time to reach steady state (school-based intervention)

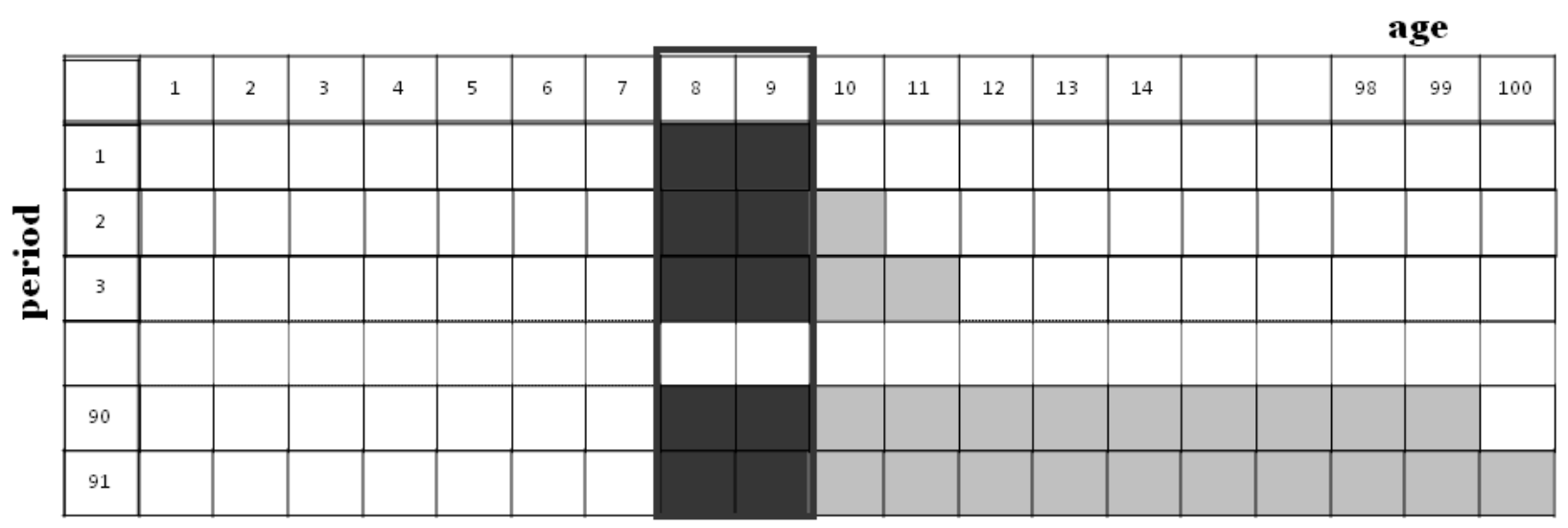

71. Costs of interventions were evaluated using the standard WHO-CHOICE "ingredient" approach. The total cost of an intervention is calculated as the sum of three components: cost at the target level (e.g. working hours of health personnel, equipments), program costs (e.g. planning and enforcing at the central level) and training costs (i.e. education of personnel involved in the intervention). Consumption of resources was directly retrieved by the source papers, while the cost of each component was provided by the WHO. Although these costs might have a certain degree of inaccuracy, they offer the advantage of allowing cross-country comparison. Costs are expressed in 2005 international dollars.

\subsubsection{Review of the evidence on the effectiveness of interventions}

72. A broad review of the existing evidence concerning the effectiveness of interventions to prevent chronic diseases linked to unhealthy diets and sedentary lifestyles was undertaken. This provided a sound basis for determining the characteristics and the likely effects of a range of preventive interventions which were assessed in the analysis. The review revealed that a significant number of studies are available in one area, namely school-based interventions, while substantially smaller bodies of evidence may be gathered on the effectiveness of a range of interventions in other areas, such as worksite interventions, interventions 
in the health care sector, interventions on the physical environment and transport system, interventions on the broader social and economic environment, etc. The detailed results of the review of existing evidence of the effectiveness of interventions are reported in Annex 5.

\subsubsection{Modelled interventions}

73. The main characteristics of the interventions evaluated in the analysis are summarised below. The most important effects (share of the population affected, impacts on risk factors and costs) of such interventions are reported in Table 2.

\subsubsection{Counselling of at-risk individuals in primary care.}

74. In many OECD countries most citizens have a primary care physician who acts as their first point of contact with the health service and as a usual source of primary health care. Primary care physicians are also an important source of information and advice on lifestyles and the prevention of chronic diseases. However, such advice is not offered systematically, and is generally provided in response to specific individual demands. 
DELSA/HEA/WD/HWP(2009)6

Table 2. Summary of coverage and main effects of selected preventive interventions

Note: see text for a description of the interventions

\begin{tabular}{|c|c|c|c|c|c|c|c|c|c|}
\hline & $\begin{array}{l}\text { School-based } \\
\text { Intervention }\end{array}$ & $\begin{array}{l}\text { Worksite } \\
\text { intervention }\end{array}$ & $\begin{array}{l}\text { Mass media } \\
\text { Campaign }\end{array}$ & $\begin{array}{l}\text { Fiscal } \\
\text { measures }\end{array}$ & $\begin{array}{l}\text { Physician } \\
\text { counselling }\end{array}$ & $\begin{array}{l}\text { Physician/ } \\
\text { dietician } \\
\text { counselling }\end{array}$ & $\begin{array}{l}\text { Food } \\
\text { advertising } \\
\text { regulation }\end{array}$ & $\begin{array}{c}\text { Food } \\
\text { advertising } \\
\text { self-reg. }\end{array}$ & $\begin{array}{c}\text { Food } \\
\text { labelling }\end{array}$ \\
\hline \multicolumn{10}{|l|}{ Target } \\
\hline Age range & $8-9$ & $18-65$ & $18+$ & $0+$ & \multicolumn{2}{|c|}{$22-65$} & \multicolumn{2}{|c|}{$2-18$} & $0+$ \\
\hline Restrictions & $\begin{array}{l}\text { only school- } \\
\text { children }\end{array}$ & large employers & none & none & \multicolumn{2}{|c|}{$\begin{array}{l}\mathrm{BMI} \geq 25 \text { or high chol/blood } \\
\text { pressure or diabetes }\end{array}$} & \multicolumn{2}{|c|}{ none } & $\begin{array}{l}\text { only label } \\
\text { users }\end{array}$ \\
\hline Target as $\%$ of the population & $2.3 \%$ & $5.8 \%$ & $79.4 \%$ & $100 \%$ & \multicolumn{2}{|c|}{$7.22 \%$} & \multicolumn{2}{|c|}{$19.7 \%$} & $67.9 \%$ \\
\hline$\%$ Pop. affected at steady-state & $91.3 \%$ & $7.2 \%$ & $79.4 \%$ & $100 \%$ & \multicolumn{2}{|c|}{$9.71 \%$} & \multicolumn{2}{|c|}{$97.9 \%$} & $67.9 \%$ \\
\hline \multicolumn{10}{|l|}{ Effectiveness } \\
\hline Fruit/vegetables (g/day) & +37.6 & +45.6 & +18.4 & +8.6 & - & - & - & - & +9.87 \\
\hline Fat ( $\%$ of total energy from fat) & -1.64 & -2.2 & - & -0.77 & -1.6 & -9.8 & 0.39 & 0.2 & -0.36 \\
\hline Physical activity (\% of active) & - & +11.9 & +2.4 & - & - & - & - & - & - \\
\hline $\mathrm{BMI}\left(\mathrm{kg} / \mathrm{m}^{2}\right)$ & -0.2 & -0.5 & - & - & -0.83 & -2.32 & $\begin{array}{l}-0.12 \text { to }- \\
0.18\end{array}$ & -0.06 to -0.9 & -0.02 \\
\hline Cholesterol $(\mathrm{mmol} / \mathrm{l})$ & - & - & - & - & -0.12 & -0.55 & - & - & - \\
\hline Systolic blood press. $(\mathrm{mmHg})$ & - & - & - & - & -2.3 & -12 & - & - & - \\
\hline \multicolumn{10}{|l|}{ Costs (\$PPPs) } \\
\hline Per target individual & $\$ 112.95$ & $\$ 77.13$ & $\$ 2.27$ & $\$ 0.28$ & $\$ 99.13$ & $\$ 210.82$ & $\$ 7.11$ & $\$ 0.51$ & $\$ 3.18$ \\
\hline Per capita (whole population) & $\$ 2.59$ & $\$ 4.51$ & $\$ 1.80$ & $\$ 0.28$ & $\$ 7.16$ & $\$ 15.23$ & $\$ 1.40$ & $\$ 0.10$ & $\$ 2.16$ \\
\hline
\end{tabular}


75. Characteristics of the modelled intervention. The intervention targets individuals between the ages of 25 and 65 who present at least one of the following risk factors: a BMI of $25 \mathrm{~kg} / \mathrm{m} 2$ or above, high cholesterol $\left(75^{\text {th }}\right.$ percentile or above), high systolic blood pressure $(>140 \mathrm{mmHg})$, and type II diabetes. Based on a selection of three studies which provide detailed accounts of controlled experiments of similar counselling interventions in primary case (Ockene et al., 1996; Herbert et al., 1999; Pritchard et al., 1999), it was assumed that $80 \%$ of primary care physicians join the programme and that $90 \%$ of eligible individuals choose to participate in the programme. Of the latter, $75 \%$ successfully complete the program.

76. Candidates are either recruited opportunistically, by screening patients waiting for a consultation (Pritchard et al., 1999), or identified using the information contained in practice records and invited for a consultation through a telephone call (Ockene et al., 1996; Herbert et al., 1999). Individuals are asked to complete a health and lifestyle questionnaire while they wait for their consultation, which will be used to tailor physician advice. Physicians spend roughly 8-10 minutes providing information and advice on lifestyle, and particularly on diet. The same information is repeated in following consultations.

77. A second, more intensive, version of the intervention involves additional counselling provided by a dietician upon referral. This consists of a first 45 minute individual session, followed by 5 group sessions of 15 minutes and by a final 45 minute individual session.

78. Effects of the intervention. The intervention will modify risk factors at all the three levels modelled in the analysis. It will decrease fat consumption, body mass index, systolic blood pressure and total cholesterol. Effects are assumed to disappear once individuals cease to be exposed to the intervention.

79. The estimated cost of the intervention is about $\$ 100$ per target individual ( $\$ 210$ in the more intensive version). A large share of this (about $70 \%$ in the standard version and $75 \%$ in the intensive form) covers the cost of extra working hours of physicians and other health professionals, including dieticians and office support staff. In particular, we assume that target individuals spend on average 25 minutes over 2.6 sessions with their physician for a total cost of about $\$ 70$ while, in the intensive counselling option we include the involvement of a dietician costing an additional $\$ 92$. Laboratory costs account for between $\$ 14$ and $\$ 25$, while costs for the training of health professionals and basic organization costs account for less than $\$ 10$.

\subsubsection{Mass media campaigns.}

80. The mass media can reach vast audiences rapidly and directly. Health promotion campaigns broadcast by radio and television may raise awareness of health issues and increase health information and knowledge in a large part of the population.

81. Characteristics of the modelled intervention. The campaign is assumed to be broadcast on television and radio channels at the national and local levels, and to follow a two year pattern alternating 6 months of intensive broadcasting with 3 months of less intensive broadcasting. During the more intensive phases television and radio channels broadcast 30 second advertisements 6 times a day, 7 days a week. In the less intensive phases they broadcast 15 second advertisements 3 times a day, 7 days a week. Advertisements contain messages both on diet and physical activity. Broadcast messages are associated with the distribution of printed material, which is assumed to reach $10 \%$ of households.

82. Effects of the intervention. Based on the evidence provided in three studies selected from a broader literature review (Dixon et al., 1998; Foerster et al., 1995; Craig et al., 2006), the intervention will increase consumption of fruit and vegetables as well as the proportion of the population undertaking adequate levels of physical activity. 
83. The estimated cost of the intervention is $\$ 2.27$ per target individual, almost two thirds of which is spent in broadcasting advertisements on national and local radio and television channels and on producing and distributing flyers and leaflets. The remaining resources are mainly devoted to hiring personnel to design, run and supervise the programme. We assume that public health specialists are involved in designing the prevention programme. Planning and administration costs are spread over a large target population.

\subsubsection{School-based interventions.}

84. School enrolment is nearly universal in the OECD area at younger ages; therefore, schools provide the means for reaching a large audience of children from all backgrounds. Additionally, food preferences are formed during childhood and helping children to develop a taste for healthier foods may have an effect on their diets persisting into their adult life.

85. Characteristics of the modelled intervention. The intervention targets all children attending school in the age group 8-9, but it is assumed that just above $60 \%$ of children will fully participate in the activities which form part of the intervention.

86. The intervention entails the integration of health education into the existing school curriculum with support from indirect education and minor environmental changes such as healthier food choices in cafeterias. The main component is represented by an additional 30 hours per school year (about 1 hour per week) of health education focused on the benefits of a healthy diet and an active lifestyle. This is associated with an opening lecture held by a guest speaker, and further activities during ordinary teaching hours (e.g. science) with the support of school nurses. Indirect education consists of the distribution of brochures or posters, while environmental changes are pursued by re-negotiating food service contracts and re-training of staff.

87. Effects of the intervention. A range of studies (Gortmaker et al., 1999; Luepker et al., 1998; Perry et al., 1998; Reynolds et al., 2000) indicate that school-based interventions of the kind described above modify distal risk factors, particularly by increasing the intake of fruit and vegetables and decreasing energy from fat. The analysis was based on the assumption that children will enjoy the benefits of the intervention throughout the course of their lives, although dietary changes will be reduced after exposure to the programme ceases.

88. The estimated cost per target individual is $\$ 113$, divided in the following way: $48 \%$ is spent in programme organization costs and $12 \%$ in training of teachers and food service staff. Of the remaining part (about \$45), \$30 are spent for extra teaching and for additional curricular activities, e.g. guest speakers, while the remainder is spent on brochures, books, posters and equipment in general. The single most expensive item is extra teaching hours. We calculate that the cost for any additional hour of curricular activities cost about $\$ 31.5$. Costs do not include change in food service contract, vouchers/coupons from sponsors and school nurse time.

\subsubsection{Worksite interventions.}

89. Working adults spend a large part of their time at the workplace, where they are exposed to a number of factors that may influence their lifestyles and health habits. Existing evidence suggests that health education, peer pressure, and changes in the work environment contribute to changing lifestyles and preventing certain chronic diseases.

90. Characteristics of the modelled intervention. The intervention targets individuals between the ages of 18 and 65 working for companies with at least 50 employees. It is assumed that $50 \%$ of employers, and $45 \%$ of their employees, will participate in the programme. 
91. The intervention involves an introductory lecture by a guest speaker and a series of 20 minute group sessions with a nutritionist every two weeks for twenty months. Messages are reinforced by the distribution of information materials and posters in common areas and cafeterias. Other activities are coordinated by volunteers who also act as peer educators and organize "walk-clubs" or similar initiatives. As part of the intervention, catering staff are re-trained to prepare healthy dishes and food service contracts are re-negotiated.

92. Effects of the intervention. Based on evidence provided in a range of studies (Sorensen et al., 1996; 1998; 1999; Emmons et al., 1999; Buller et al., 1999), the intervention increases the consumption of fruit and vegetables and physical activity, and decreases fat intake. After retirement, those exposed to the intervention retain some of the benefits accrued.

93. The estimated cost per target individual is $\$ 77$. Organization and training of peer-educators and food service staff account for less than $9 \%$, while the largest component of the cost of the intervention (about $80 \%$ ) is represented by seminar organisation and nutritionist fees. Other costs include information materials and a guest speaker. The costs involved in re-negotiating food service contracts or accessory measures (e.g. installation of bicycle racks) were not included in the analysis.

\subsubsection{Fiscal measures to promote consumption of fruit and vegetables and reduce consumption of fats.}

94. Fiscal incentives can directly affect consumption behaviours, and therefore influence lifestyle choices. Taxes, tax exemptions and subsidies are widely used in agriculture and food markets in the OECD area. Differential taxation of food products is relatively common. Sales taxes, or value added taxes, are often applied at different rates to different types of food. In many countries most foods are exempt, or subject to a reduced rate taxation, but certain foods are often subject to higher rates, particularly manufactured foods, or foods containing larger amounts of certain ingredients, such as sugar. Food taxes are often viewed as not particularly effective in changing patterns of food consumption, but several studies suggest that they can have an impact on both consumption of unhealthy foods and people's weight. Fiscal measures may be complex to design and enforce, and their impacts may be somewhat unpredictable as the price elasticity of lifestyle commodities varies across individuals and population groups, and substitution effects are not always obvious. However, the demand for foods which might be subjected to taxation in the pursuit of health objectives is generally inelastic. As discussed in Sassi and Hurst (2008), this is associated with more limited substitution. Rather, individuals end up consuming less of the taxed commodity while at the same time spending more of their income on that same commodity, which may also displace other forms of consumption to a certain degree. The combined use of taxes and subsidies on different types of foods whose demand is similarly inelastic may neutralise such displacement effect, although experimental evidence of the effects of similar combined measures is lacking at present. Fiscal measures also have potentially large re-distributive effects, which are mostly dependent upon existing differences in price elasticities between socioeconomic groups, overall consumption of the foods targeted by fiscal measures, and cross-elasticities between the demand for these and for other foods. Income distribution effects are not explicitly addressed in the analyses reported in this paper.

95. Characteristics of the modelled intervention. Taxes and subsidies typically affect all consumers. The intervention assessed in the analysis involves fiscal measures that will both increase the price of foods with a high fat content (e.g. many dairy products) by $10 \%$ and will decrease the price of fruit and vegetables in the same proportion. No assumptions are made as to what specific measures should be taken to achieve those price changes.

96. Effects of the intervention. Existing evidence suggests that changes in food prices are linked to changes in consumption behaviours, as well as changes in BMI. However, evidence of the relationship between food prices and BMI or obesity is weaker (Powell and Chaloupka, 2009), therefore we decided to 
model the effects fiscal interventions only through changes in consumption of fat and fruit and vegetables. Based on some of the most conservative estimates of the price elasticity of demand for foods high in fat and for fruit and vegetables, among the nine studies reviewed and discussed in a recent report issued by the French Government (Hespel and Berthod-Wurmser, 2008), it was estimated that a $10 \%$ change in price will produce, on average, a $2 \%$ change in consumption in the opposite direction. The health outcomes presented in this paper are based on the assumption that price elasticity is the same across population groups (this assumption was changed in the sensitivity analysis), which may slightly overestimate the responsiveness of low income groups to changes in the prices of fruit and vegetables, and correspondingly underestimate the responsiveness of high income groups. However, the health effects of the intervention appear to favour those in poorer socio-economic circumstances more than their better off counterparts. The financial burden of the tax, however, will also be significantly greater for poorer households.

97. Relatively few empirical studies have estimated the size of tax operating costs, which include costs borne by the public administration imposing the tax for the collection of revenues and enforcement of compliance (administrative costs) and costs borne by taxpayers, individuals and organisations, to comply with the requirements of the tax (compliance costs). Among these studies, even fewer have focused on administrative costs. Information on the administrative costs of specific taxes is very limited, partly because countries tend to assess these costs in aggregate, for all types of taxes. Empirical studies tend to provide estimates of operating costs as a proportion of total tax revenues, as some components of the former indeed vary with revenues. However, operating costs are determined by a broader range of factors (associated with the nature of the tax base or with characteristics of the tax) which makes it difficult to generalise existing estimates to new taxes or settings. A review of studies up to 2003 concluded that "studies that do address administrative costs suggest that they rarely exceed $1 \%$ of the revenue yield, and more usually come in well below 1\%" (Evans, 2003).

98. In modelling our "fiscal measures" intervention, we deliberately avoided to specify the detailed nature of the measures that governments may wish to use to cause a rise in the prices of foods high in fat and a fall in the prices of fruit and vegetables. Therefore, we only expect our estimates of the costs associated with the intervention to reflect a realistic average across a range of possible options. Using WHO standard costs, we modelled the (administrative) costs of fiscal measures to include basic administration, planning, monitoring and enforcement at the national level. The latter, in particular, accounts for most of the cost. The resulting estimate is $\$ 0.28$ per capita. Potential revenues from the tax, as well as expenditures originating from the subsidy, are not accounted for in the analysis, as they represent transfers rather than costs.

99. Interventions to influence food prices might rely on the infrastructure of existing agricultural policies. The overall cost of agricultural policies may be high. For instance, the policy-related transaction costs (administrative costs) of implementing the EU Common Agricultural Policy in the Netherlands were estimated to be approximately $€ 4.8$ per capita in 2009 (OECD, 2007). However, the additional administrative cost of incremental measures to influence the prices of selected foods is likely to be substantially lower. Alternatively, the prices of foods high in fat may be raised by imposing indirect taxes. If our modelling assumptions were applied to household expenditure data from the United Kingdom (Family Expenditure Survey 2007) it could be roughly estimated that a tax on foods high in fat leading to a $10 \%$ price increase and eliciting a $2 \%$ reduction in consumption would yield revenues in the region of $\$$ 1billion in the UK, while the estimated administrative cost of the tax, based on our modelling assumptions, would be up to $\$ 16.8$ million, or $1.6 \%$ of the total revenue yield of the tax.

\subsubsection{Food advertising regulation.}

100. Heavy marketing of fast food and energy-dense food is regarded as a potential causal factor in weight gain and obesity, particularly because of its impact on dietary habits in children and teenagers. 
Most advertising explicitly directed to children is broadcast on television. Some countries have already taken formal regulatory steps to limit food advertising to children. Furthermore, major international players in the food industry are adopting forms of self-regulation, which may be viewed as an alternative, or a complement, to government regulation.

101. Characteristics of the modelled intervention. The intervention is targeted to children between the ages of 2 and 18. The intervention is intended to limit children's exposure to food advertising on television, particularly in programmes primarily aimed at children and during times of the day when a large proportion of the audience is made up by children in the above age group. The best evidence currently available on the impact of restrictions on food advertising concerns the advertising of fast food (Chou et al., 2008), therefore the intervention designed for the analysis focused on this type of advertising. Two versions of the intervention were assessed in the analysis: the first involving formal government regulation introduced by law and enforced by communication authorities; the second involving self-regulation by the food industry and broadcasters, with the government acting only in a monitoring and supervisory role.

102. Effects of the intervention. The intervention will reduce children's BMI and fat consumption through changes in dietary habits. Chou et al. (2008) suggest that in the absence of fast food advertising to children, the number of overweight children would be reduced by $18 \%$ in the age group $3-11$ and by $14 \%$ in the age group 12-18. However, this effect was reduced in the analysis to account for children's residual exposure to a certain amount of advertising, either because they watch television programmes outside the hours in which restrictions are enforced, or because the industry may substitute television advertising with other forms of advertising to which children remain exposed. A recent evaluation of restrictions of food advertising to children enforced in 2007 by the regulatory agency OFCOM in the United Kingdom concluded that children aged 4-9 saw 39\% less advertising of foods high in fat, salt, or sugar, while children aged 10-15 saw 28\% less than they used to see before the policy was implemented. Changes in fat consumption were modelled on evidence drawn from a study by Bolton (1983). The effects of the intervention were assumed to persist into adult life in a reduced form. In the case of self-regulation, the effects of the intervention were assumed to be half of those produced by formal regulatory measures, because of possibly looser limitations self-imposed on advertising and a less than universal compliance to the voluntary arrangements.

103. The intervention involves basic administration and planning costs at the national and local levels, as well as monitoring and enforcement costs. In addition, minor training may be required for communication authority staff charged with the task of overseeing the implementation of the scheme. In the case of self-regulation, basic administration, facilitation and supervision costs will arise at the national level. Enforcement costs will be largely reduced, but there will remain a need for monitoring of compliance and effects.

\subsubsection{Food labelling}

104. Disclosure of the nutritional characteristics of food sold in stores through labels reporting easyto-read "nutrition facts" helps consumers choose healthier diets and may provide strong incentives for food manufacturers to decrease serving size and reformulate packaged food with healthier nutrients.

105. Characteristics of the modelled intervention. Although the intervention is intended to affect all consumers, empirical evidence suggests that only about two thirds of store customers actively read labels. The intervention entails the adoption of a mandatory food labelling scheme for food sold in stores. Labels will deliver information about nutrient contents and serving size. Retailers will post information about how to read labels and about the benefits of a healthy diet. The intervention does not involve other forms of communication. The accuracy of the information reported on labels is verified through an extensive programme of food inspection. 
106. Effects of the intervention. Food labelling helps conscious consumers in following a healthy diet. Evidence suggests that this would decrease fat consumption and increase the consumption of fruit and vegetables (Variyam, 2008) eventually leading to a small decrease of the body mass index (Variyam, 2006).

107. The costs of the intervention include basic administration, planning, enforcement, preparation and distribution of posters and, finally, resources needed to manage the program of food inspection. The program does not account for the additional packaging costs associated with designing and printing nutrition labels and for the potential cost associated with the reformulation of certain foods, likely to be borne by the private sector.

\subsection{Sensitivity analysis}

108. The CDP model is designed to produce estimates of cost-effectiveness and distributional impacts based on a wide range of input data derived from a variety of sources, and on assumptions regarding the relationships among such inputs and between model inputs and outputs. Similarly to other epidemiological and economic analysis models, the estimates produced by CDP are subject to a certain degree of uncertainty in relation to the following factors:

1. Input parameters are derived from heterogeneous sources. Although efforts were made to select the most reliable sources for each parameter, the need to combine parameters from different sources may lead to potential inconsistencies (e.g. the sources used may reflect the characteristics of diverse settings, or populations).

2. Parameter estimates are subject to measurement error, as they are often the result of stochastic assessments based on relatively small samples of individuals. Large studies, or meta-analyses, of the role of risk factors in disease processes, or the effectiveness of interventions to improve risk factors and health outcomes, are rare.

3. Estimates of the effectiveness of interventions are normally derived from studies involving a relatively short observation of outcomes. Studies providing assessments of the long-term sustainability (over several years) of the effects achieved by specific lifestyle interventions are lacking, therefore assumptions are required to estimate such effects.

4. Studies of the effectiveness of interventions tend to focus on interventions with (sometimes slightly) different characteristics. Direct comparisons of the findings of such studies may be difficult, and it is often preferable to extrapolate information on the effectiveness of a given intervention from a single study, rather than attempting a synthesis of effectiveness data based on potentially misleading comparisons across heterogeneous studies.

5. The disability weights assigned to the three sets of diseases explicitly modelled in the analysis are based on Global Burden of Disease estimates. These are predominantly based on expert judgement and do not reflect potential variations across geographical areas. Similarly, the discount rate used in the analysis for both costs and health outcomes (3\%) is based on standard practice within the WHO-CHOICE framework, which may not reflect local circumstances.

6. Estimates of the costs of treating risk factors and chronic diseases, as well as estimates of the costs of preventive interventions, are based on standard schedules of resource inputs derived from treatment protocols and experimental studies of the effectiveness of interventions. Unit costs were estimated for regional groupings of countries via regression analysis (Adam et al., 2003, 2006; Johns et al., 2006), and assigned to each resource item. Large-scale empirical cost analyses would provide more accurate and reliable cost estimates, but these were not available in the areas of interest for this analysis. 
7. The overall structure of the CDP model, the layers of risk factors and chronic diseases involved, and the relationships, static and dynamic, among those risk factors and diseases, provide a simplified representation of actual disease processes. It is possible that the exclusion of further concomitant risk factors, or interactions between risk factors, may lead to imprecise estimates of the impact of given preventive interventions.

8. Finally, the CDP model generates estimates based on a stochastic process involving the simulation of large numbers of individual lives. As the latter numbers become larger, model estimates tend to converge towards central values. However, a trade-off exists between the computational power required to undertake simulations based on large numbers of hypothetical individuals and the degree of confidence of the estimates produced.

109. We made efforts to address as many as possible of the likely sources of uncertainty illustrated above, and to assess the robustness of model estimates to assumptions built into the modelling process and potential variation in input parameters. We used the most accurate and reliable evidence available for each parameter. Whenever possible, we used the confidence intervals associated with individual parameter estimates to conduct sensitivity analyses. We made conservative assumptions regarding any parameters for which no empirical estimates were available, and tested such assumptions as extensively as possible. We were particularly careful in assessing the robustness of cost estimates, testing the effects of cost variations within given ranges on final model outputs. Using all available computational power, we were able to run simulations of intervention scenarios in which one modelled individual corresponded to 1,500 real individuals, for a total of 10 iterations for each scenario. Further sensitivity analyses were undertaken using the software MCLeague, based on Monte Carlo simulation, which provided the means to test the robustness of model outputs to alternative assumptions regarding mean estimates and distributions of input parameters. 
DELSA/HEA/WD/HWP(2009)6

\section{SECTION III. THE IMPACTS OF PREVENTIVE INTERVENTIONS}

\subsection{Introduction}

110. Using the methods and data illustrated in Section II, the CDP model was first run to compute the health outcomes associated with a baseline scenario reflecting the epidemiology of the relevant risk factors and chronic diseases in the absence of preventive interventions. Intervention scenarios were then developed, whose health outcomes were compared to those of the baseline scenario. The results of such comparisons are reported in this section in terms of effects on health and longevity (3.1); intervention costs and effects on health care costs (3.2); and cost-effectiveness (3.3). The impacts of possible combinations of interventions are also discussed (3.4). Selected results from a range of sensitivity analyses carried out to assess the robustness of model estimates are reported in section 3.5, while the distributional impact of preventive interventions is discussed in section 3.6.

\subsection{The effects of preventive interventions on health and longevity}

\subsubsection{Effects on obesity}

111. Most interventions were shown to have only a limited impact on the overall scale of the obesity problem. Figure 3 reports the proportional decrease in obesity achieved by each intervention at steady state, compared to the baseline scenario. Interventions modifying distal risk factors (e.g. school-based interventions and fiscal measures) such as diet and physical activity seem to have a somewhat smaller effect. The main cause of this is that they need more time to generate changes in body mass index. The situation is different when considering physical activity, as we modelled a stronger association between physical activity and BMI. In principle, we would expect to be able to observe a stronger effect for interventions such as worksite and mass media. However, worksite interventions cover, even at steady state, only a rather limited number of people (about $7 \%$ of the population), while mass media interventions have a broader coverage but generate a substantially smaller effect, equivalent to a $2.4 \%$ increase in the proportion of those doing sufficient physical activity.

112. The largest results, at the population level, are achieved by intensive primary care counselling (i.e. physician-dietician counselling). This intervention entails long and comprehensive sessions with a health specialist who tailors the intervention on the individual. Additionally, although this intervention covers only a small share of the total population, it focuses on people considered at risk and, among these, people with a BMI higher than 25. Therefore, the effects of the interventions are concentrated on those who may benefit the most. This last consideration holds also for the more basic version of the primary care counselling intervention. Restrictions on advertising produce a noteworthy reduction of obesity in young people while (on the basis of the assumptions made in this model) their effects fade as people get older. 
Figure 3. Decrease in obesity rates for 25 and 65 year olds and whole population

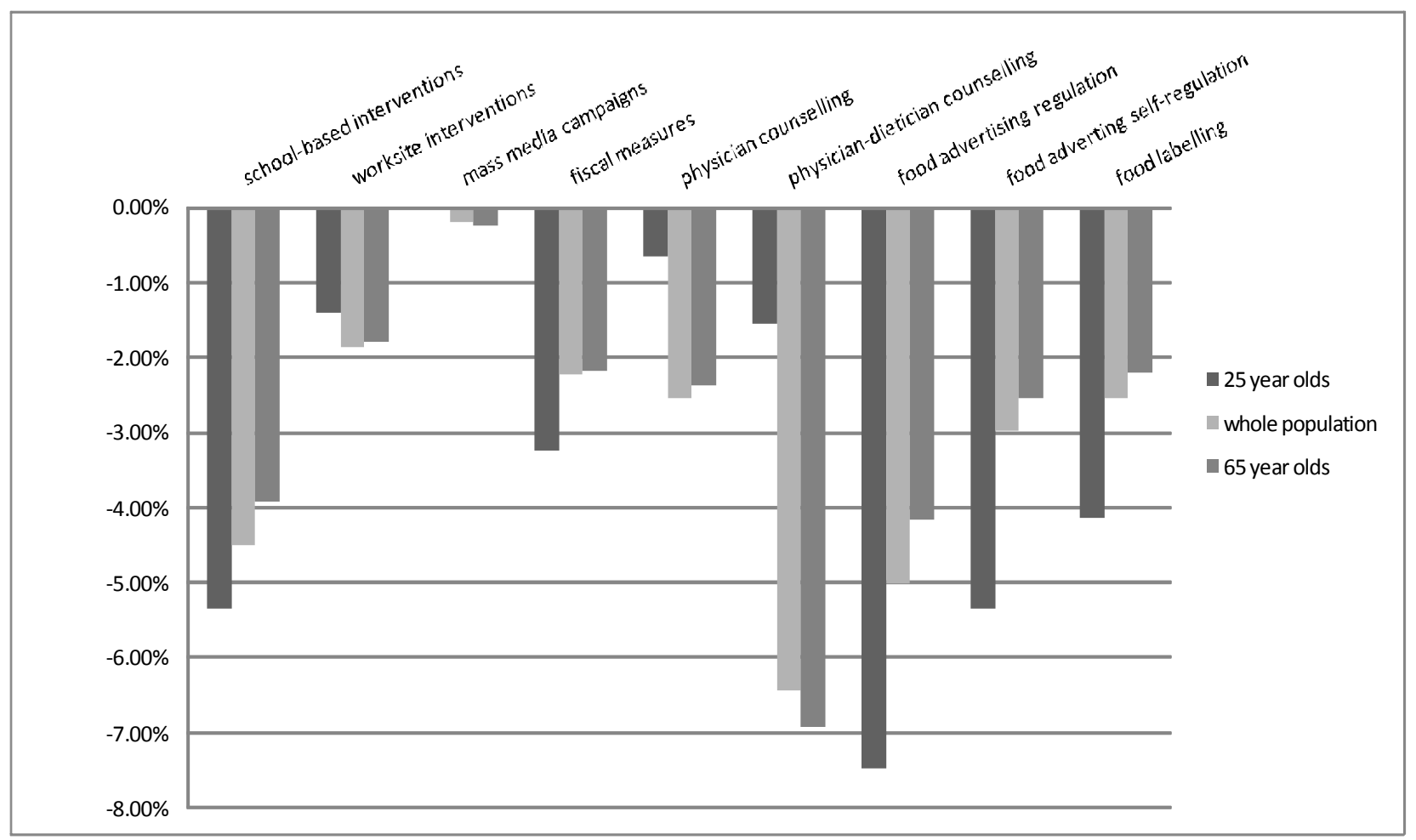

\subsubsection{Incidence of chronic diseases}

113. The incidence of the three groups of chronic diseases modelled in the analysis (ischaemic heart disease, stroke and cancer) is reduced by the preventive interventions investigated, although to a relatively small extent. Figure 4 shows the decrease in percentage points, in a 100 year time-perspective, between the incidences of the three diseases under the no-intervention scenario and with the interventions. A decrease of $0.1 \%$ means that an individual experiences a decrease of $0.1 \%$ in the yearly probability of developing the disease. Although the decrease can be considered rather limited, one should bear in mind that this graph shows the effect on the whole population, including individuals younger than 40 for whom the probability of developing a disease is naturally very low.

114. In general, interventions have larger effects on the incidence of ischaemic heart diseases and stroke. This is particularly true for interventions like counselling in primary care, which affects proximal risk factors (systolic blood pressure and cholesterol) directly linked with the onset of those diseases. On the other hand, the incidence of cancers is particularly affected by interventions which entail a significant increase in fruit and vegetables consumption. Physician-dietician counselling has the largest overall effect, decreasing ischaemic heart disease incidence rates by up to 1.36 percentage points (about 3.3 cases averted every year per 100,000 individuals). 
Figure 4. Decrease in disease incidence at the population level

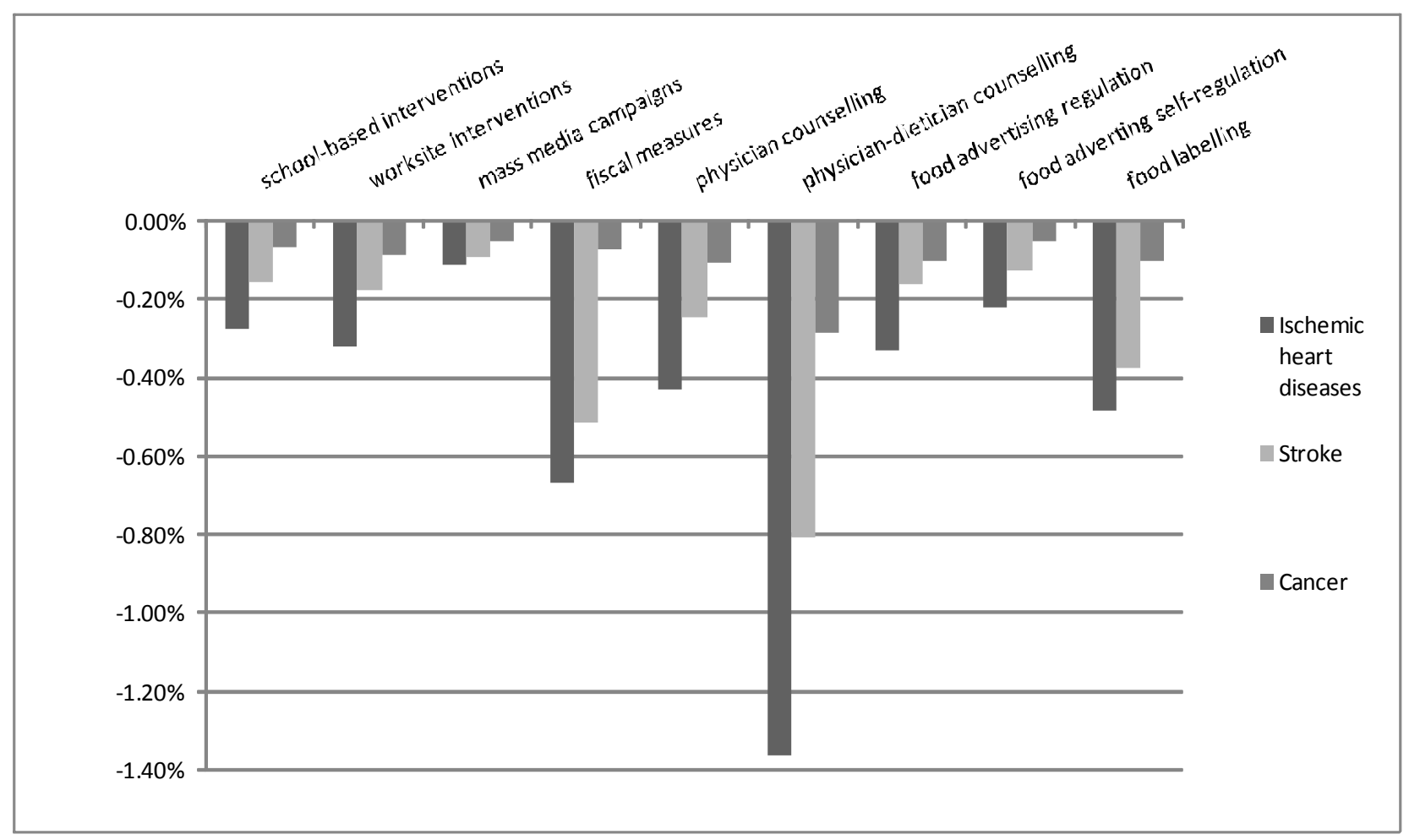

\subsubsection{Life years and disability-adjusted life years}

115. Figure 5 shows the increase in health outcomes (life years and disability-adjusted life years) for all interventions relative to the baseline scenario. Results are presented for the whole population. For all the interventions, with the exception of mass media campaigns, the gain in disability adjusted life years is higher than the gain in life years. In practical terms, this means that most interventions are more effective in reducing morbidity (by delaying the onset of chronic diseases) than in reducing mortality. One hundred percent of the morbidity observed in the simulation is caused by the diseases explicitly addressed in the model, while only $42 \%$ of total mortality is caused by the same diseases. As a consequence, $58 \%$ of mortality is not affected by the intervention and, in a real population, it is plausible that an increase in the number of deaths from other causes would be observed, even assuming a constant fatality rate (i.e. the fraction of people with a disease who dies because of the disease) only because the number of people at risk increases.

116. Intensive primary care counselling is the intervention providing the highest gain both in terms of disability-adjusted life years and life years. Overall, it generates a gain of 1 year of life every 12 individuals and 1 year of disability-adjusted life every 10 persons. On the other hand, mass media campaigns ranks lowest, generating a gain of 1 life year/disability-adjusted life year every 115/121 individuals. While all other programmes present a linear increase in their effectiveness on health outcome, physician/dietician counselling appears to be an outlier and presents, by far, the largest improvements. However, it should be remembered, that this is a particular intensive intervention targeting a specific group and providing tailored programmes. This is reflected also in the costs (§ section 3.2). 
Figure 5. Health outcomes at the population level

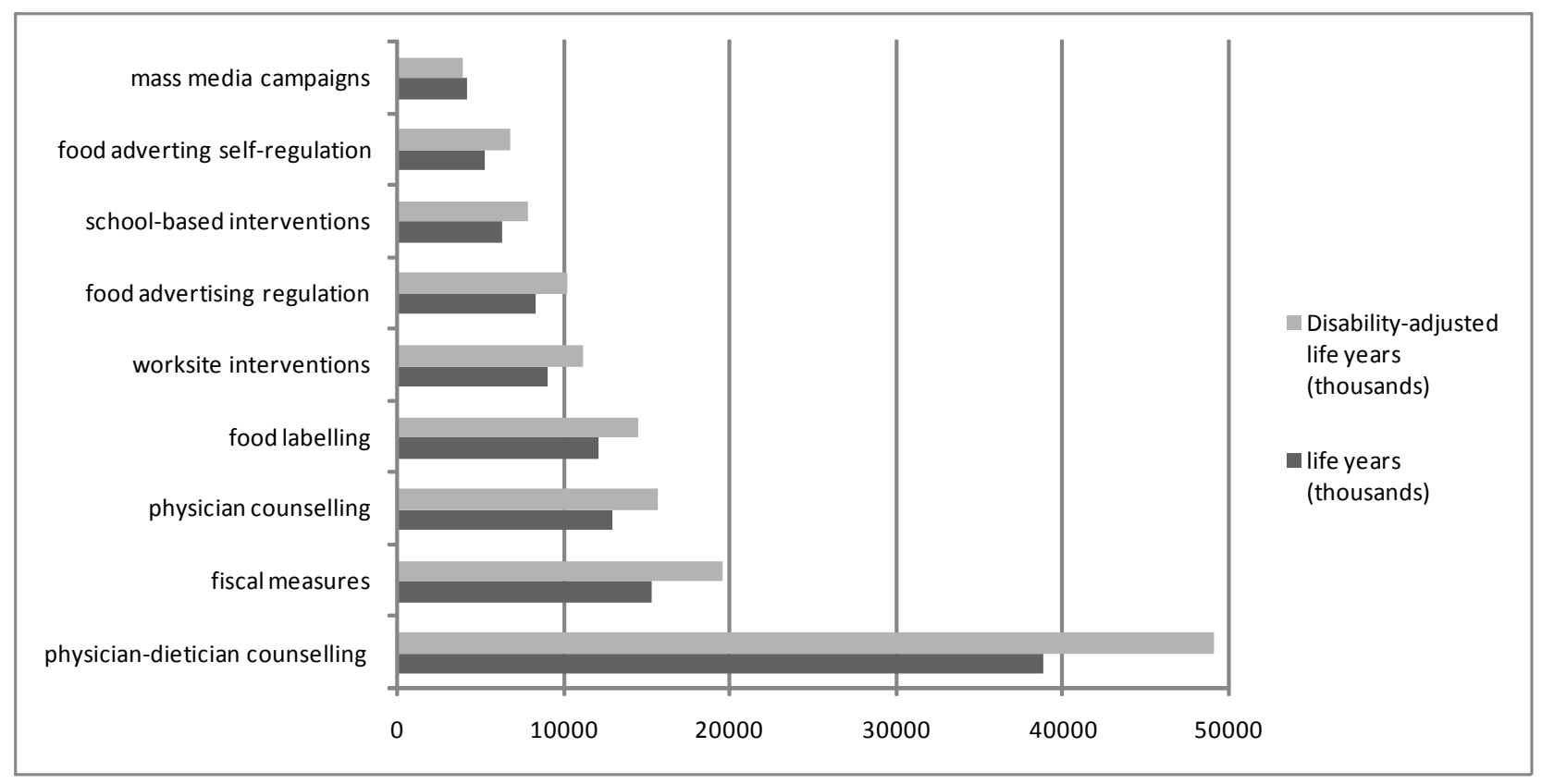

117. Figure 6 reports the gain in life years and disease adjusted life years by class of age. As expected, interventions show to have almost no effect on people less than 40 year old. Our model incorporates chronic diseases typically affecting middle-aged or old-aged individuals, therefore even if interventions decrease the prevalence of intermediate (i.e. BMI) and proximal risk factors (e.g. high blood pressure), the effects on diseases are not visible because the risk factors need time to cause the disease and, in any case, the incidence of the diseases is so low that the effect is not appreciable.

118. Additionally, it should be noted that gain in disability-adjusted life years is higher in the age group 41-80 while the gain in life years is usually higher in the age groups $81-100$. This is caused by the interaction between the nature of chronic diseases, generally entailing a slow course of the disease before death, and the effects of preventive interventions which delay the onset of the diseases. As a consequence, in the age group 40 to 80 , the decrease of new cases produce an higher gain in disability-adjusted life years (i.e. with no chronic diseases). As the population gets older, the incidence of the diseases increases and, consequently the impact on disease-adjusted life years weakens. At the same time, in the scenario without interventions people who are now 80 year olds and who had developed the disease when they were younger start dying while under the intervention scenario they only start developing the disease. Consequently there is an increase in life years and a relative decrease in disability-adjusted life years. 
Figure 6. Health outcomes at the population level by age group

School-based intervention

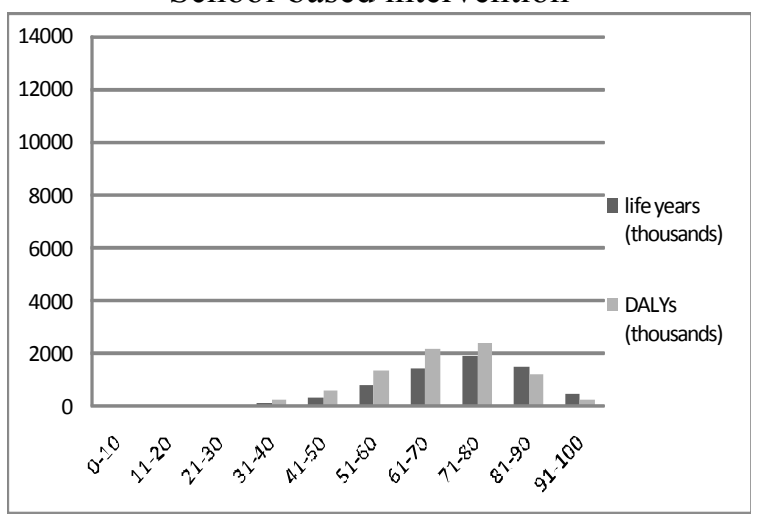

Mass media campaigns

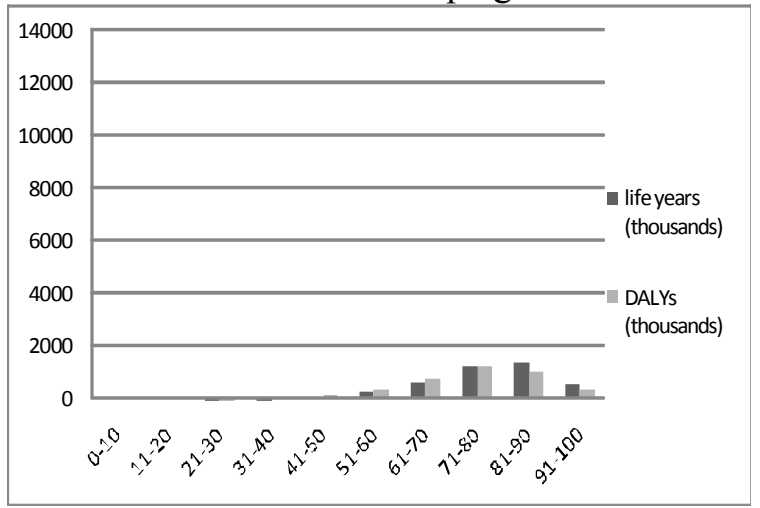

Physician counselling

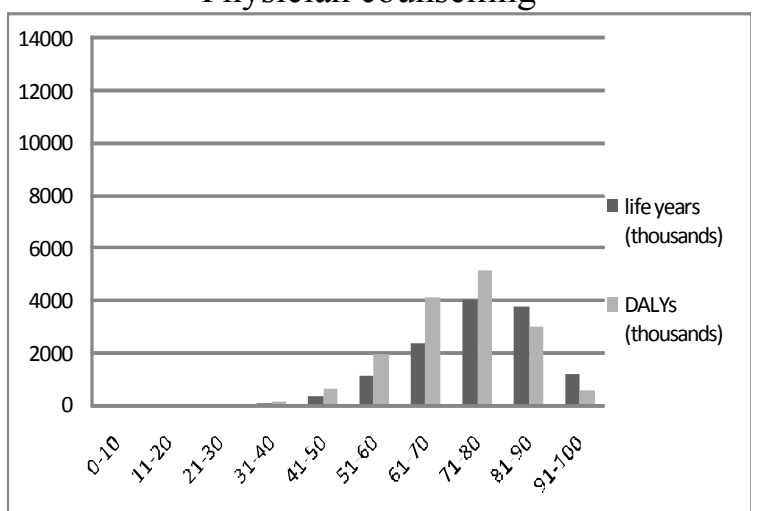

\section{Worksite interventions}

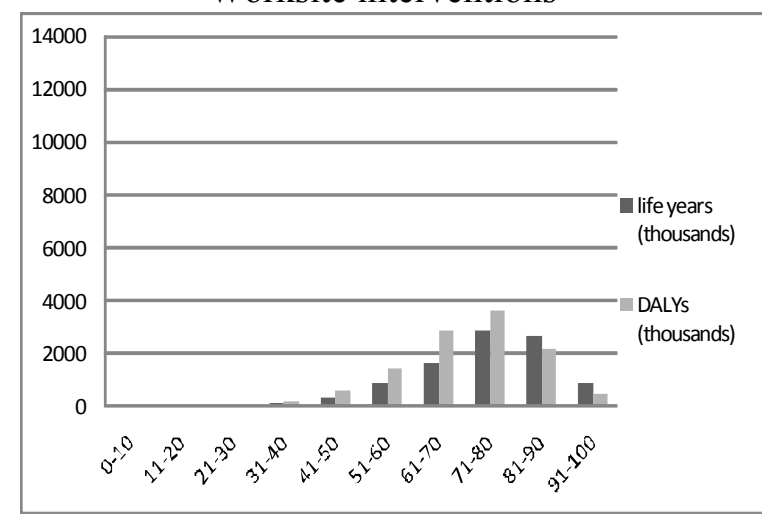

Fiscal measures

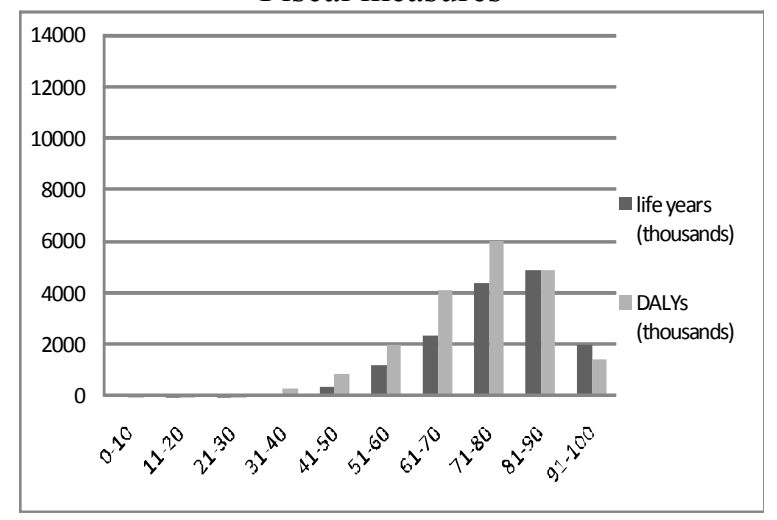

Physician-dietician counselling

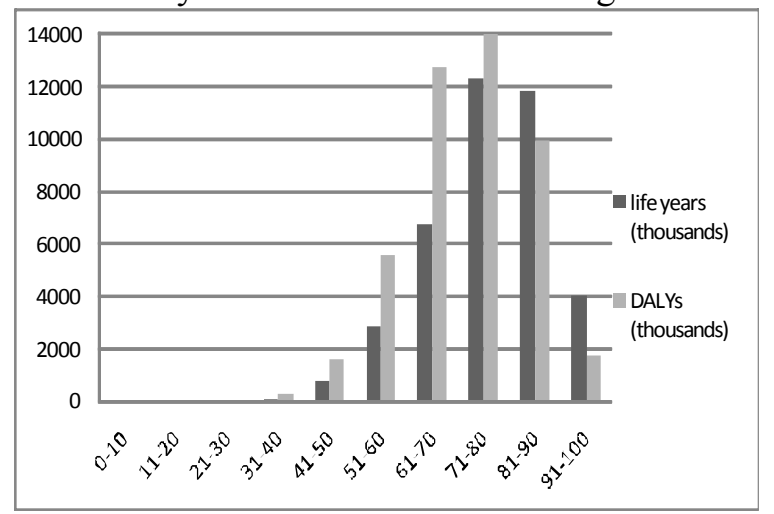



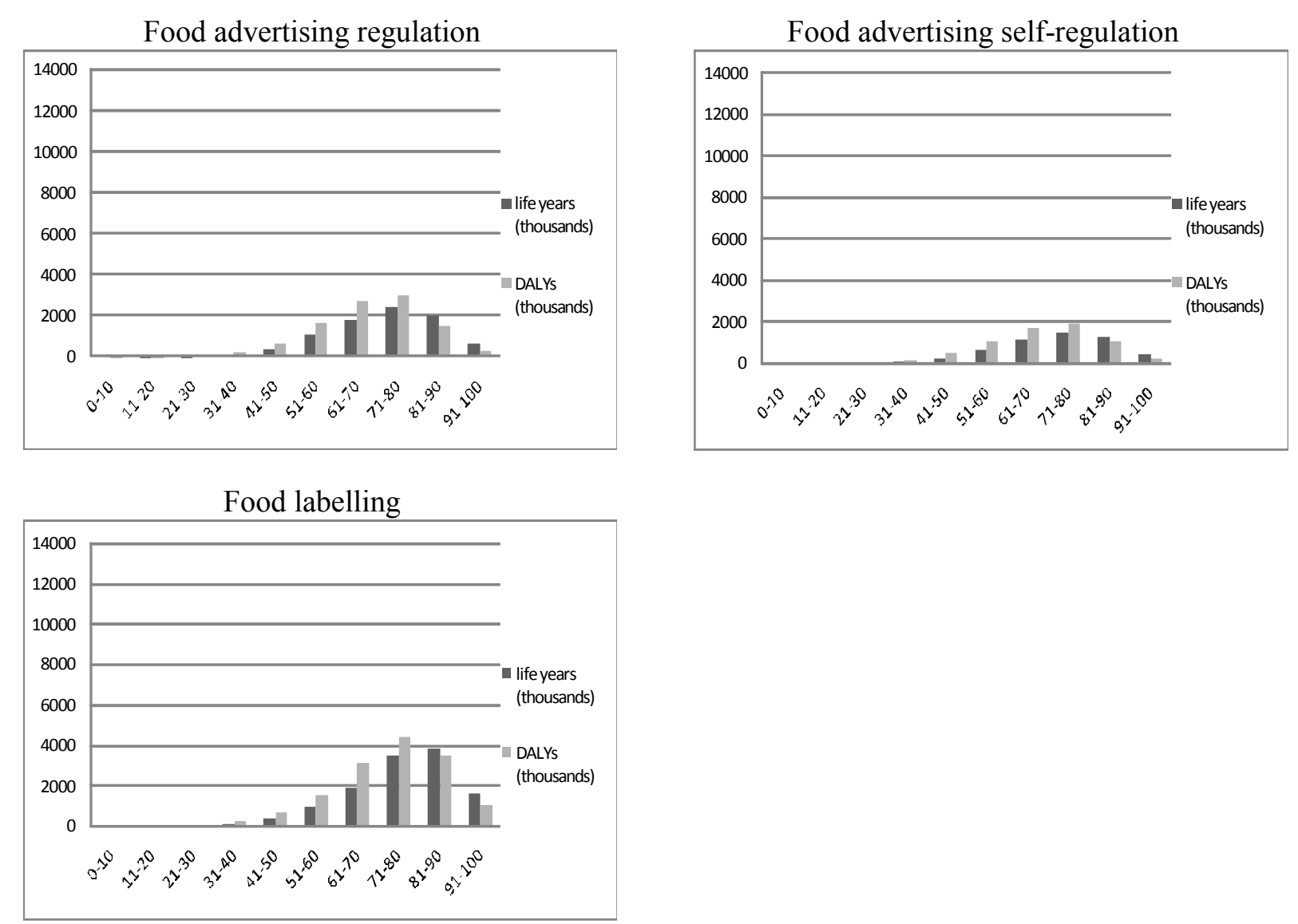

119. Table 3 presents a comparison of the effectiveness of the interventions at their steady state. The second column shows the yearly gain in disability-adjusted life years for 1 million individuals exposed to the intervention,. The third column illustrates the degree of population coverage at steady state (including the population currently exposed to the intervention plus the population previously exposed which still retains some benefit from the intervention). The fourth column four reports the yearly DALY gain for the whole population. 
Table 3. Disability-adjusted life years gained at steady state

\begin{tabular}{|lcccc|}
\hline \multicolumn{1}{|c}{ Intervention } & $\begin{array}{c}\text { Average effect (life } \\
\text { years per million } \\
\text { population) }\end{array}$ & Coverage & $\begin{array}{c}\text { Total effect } \\
\text { (life years) }\end{array}$ & $\begin{array}{c}\text { Years to } \\
\text { steady state }\end{array}$ \\
\hline School-based interventions & 685 & $91.3 \%$ & 214,198 & 91 \\
Worksite interventions & 4441 & $7.2 \%$ & 109,495 & 35 \\
Mass media campaigns & 113 & $79.4 \%$ & 30,723 & 1 \\
Physician counselling & 3357 & $9.7 \%$ & 111,617 & 35 \\
Physician-dietician counselling & 7090 & $9.7 \%$ & 235,853 & 35 \\
Food advertising regulation & 602 & $97.9 \%$ & 201,986 & 82 \\
Food adverting self-regulation & 439 & $97.9 \%$ & 147,217 & 82 \\
Fiscal measures & 735 & $100.0 \%$ & 251,914 & 1 \\
Food labelling & 850 & $67.9 \%$ & 197,763 & 1 \\
\hline
\end{tabular}

120. Figure 7 shows the cumulative effectiveness of interventions over time. The vertical axis reports the number of disease adjusted life years while the horizontal axis reports the time frame of our analysis. Disability-adjusted life years are discounted at a 3\% rate. In general, interventions targeting children (e.g. school-based interventions and regulation of food advertising) take longer to reach their steady state, therefore, their overall effectiveness, measured in a 100-year time perspective, is reduced accordingly.

121. Intensive primary care counselling is, by far, the most effective intervention. The second best performing intervention, primary care counselling, yields a total effect that is only a third of physiciandietician counselling. Fiscal measures, food labelling schemes and worksite interventions show similar effectiveness in the early years, but, in the long run, fiscal measures appear to have a larger impact. As noted in relation to previous figures, interventions targeting children yield significant results only after about 40 years. 
Figure 7. Cumulative disability-adjusted life years gained (millions) over time

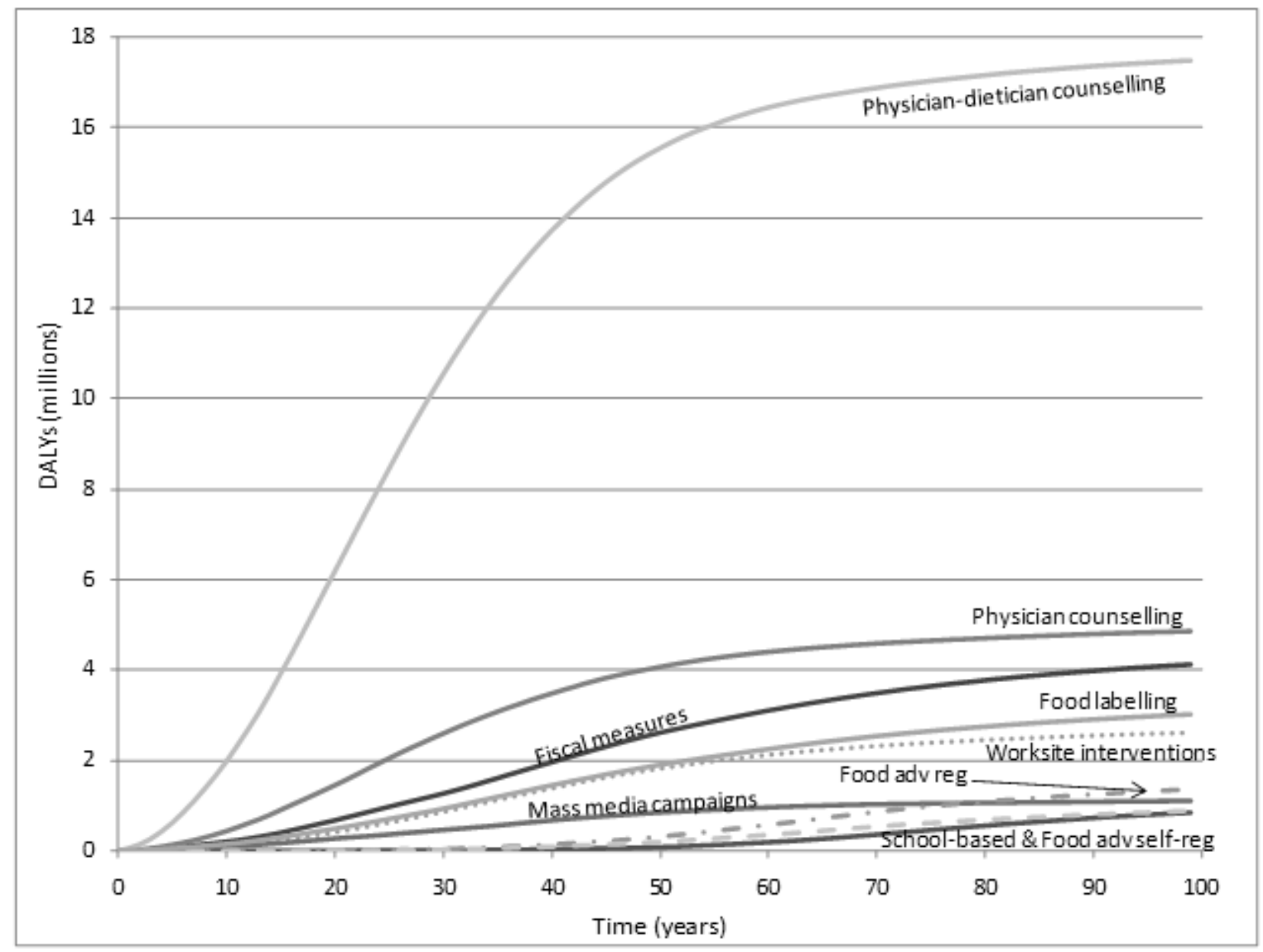

\subsection{Total costs}

122. Common beliefs about the potential impact of preventive interventions are often based on simplistic assumptions, which may lead to exceedingly optimistic expectations. Prevention produces multiple and sometimes interacting effects, which are difficult to predict. For instance, certain forms of prevention may substantially reduce future health care costs, but often this will not be the case. Prevention may reduce fatality rates associated with certain chronic diseases and extend life with those diseases, which may increase overall health care costs in the long run. Individuals who live longer as a result of prevention will also develop diseases other than those targeted by prevention, which may require treatment and increase health expenditure.

123. The preventive interventions assessed in the analysis reflect a wide variety of approaches and are based in diverse settings. The costs associated with those interventions may arise in different jurisdictions. Some of the costs are typically paid through public expenditure (e.g. the costs associated with regulatory measures), others typically not (e.g. most of the costs associated with worksite interventions). Some of the costs arise within the health sector (e.g. health care costs), others arise within other sectors of government intervention (e.g. most of the costs associated with school-based interventions). In principle, the costs associated with preventive interventions and with the treatment of risk factors and chronic diseases could be calculated at the national level, and the economic analysis could be set in the context of individual countries. However, as discussed in Section II, for practical reasons all analyses so far were undertaken at 
the regional level, with reference to a European region broadly reflecting the EUR-A WHO region, and the costs calculated reflect average conditions across the countries that make up that region.

124. Figure 8 describes the total financial impact of the interventions over 100 years. The diagram reports both the costs of the interventions and their impacts on health expenditure. All interventions decrease health expenditures for the conditions explicitly included in the model (cancer, IHD, stroke, diabetes, high cholesterol, high systolic blood pressure), therefore effects on health expenditure are reported with a negative sign. A breakdown of the latter by age can be found in Figure 9. Costs reported in Figures 8 and 9 are expressed, respectively, in billions and millions of dollars.

125. Physician/dietician counselling is the most expensive intervention with expected costs of about $\$ 540$ billion (before discounting) over 100 years, while self-regulated advertising restrictions is the least expensive intervention, costing about $\$ 3.7$ billion over 100 years. Both self-regulation of food advertising and fiscal measures generate reductions in health expenditure which more than offset intervention costs, thus leading to savings of about $\$ 6.3$ billion and $\$ 32.6$ billion.

Figure 8. Economic assessment of interventions at the population level

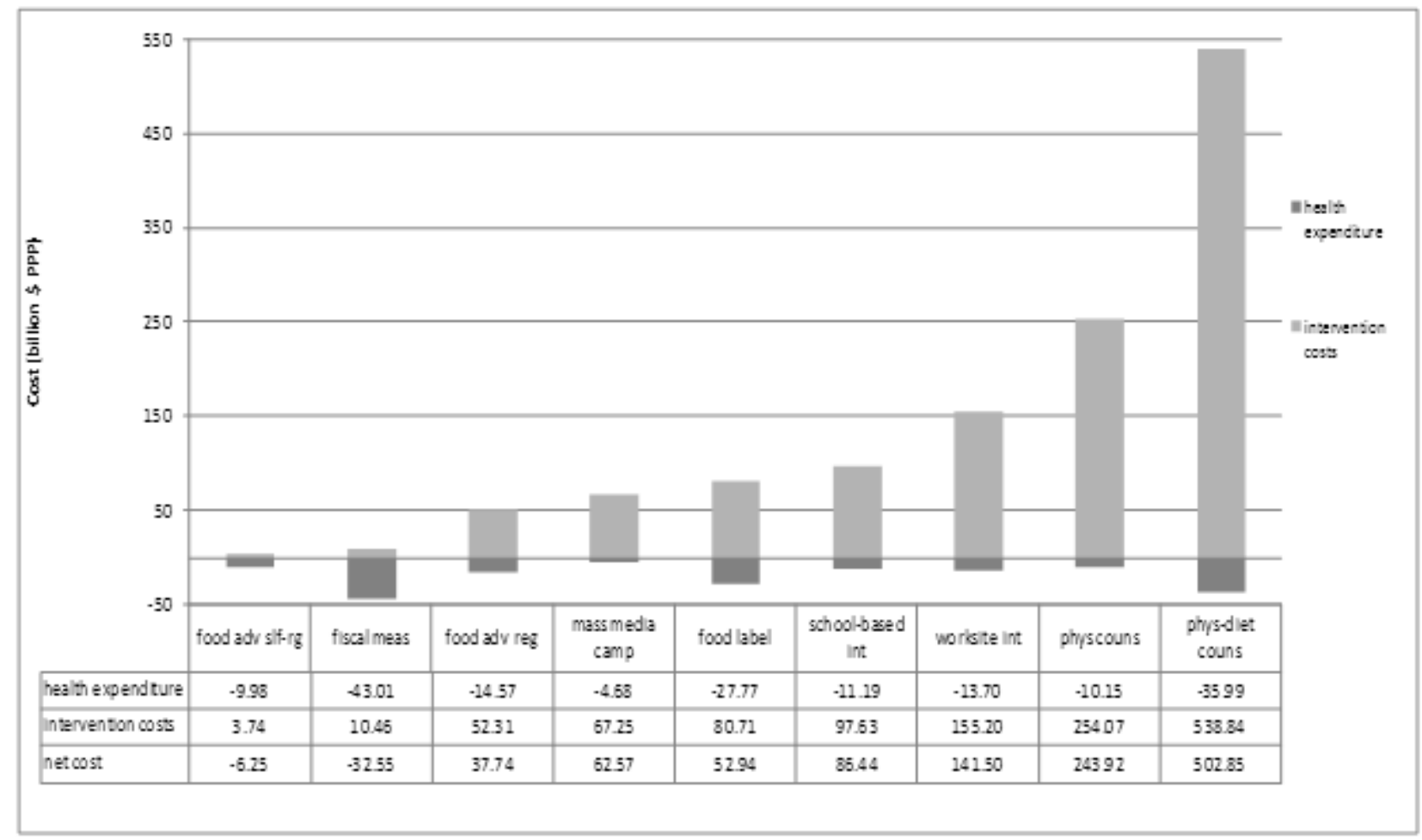

126. Figure 9 shows the potential savings due to the interventions in 100 years, and it can be directly compared with Figure 7 by considering that the sum of all age groups is equal to the result depicted in the right panel of Figure 7. In general, interventions generate savings in most age groups but become consistently more expensive than the baseline in the age group 90-100. The main cause of this is the increased life expectancy of the population: the number of individuals and, accordingly, the number of individuals with a disease is higher in the intervention scenario and, consequently, the costs for treating people affected increase as well. It is important to emphasise that the costs illustrated in Figure 8 reflect health care resources devoted to the treatment of the diseases and risk factors explicitly included in the model. If a broader definition of health care costs had been assumed, encompassing the treatment of all diseases, it is plausible that overall savings would have been smaller. 
Figure 9. Effects of interventions on health care costs by age group

School-based interventions

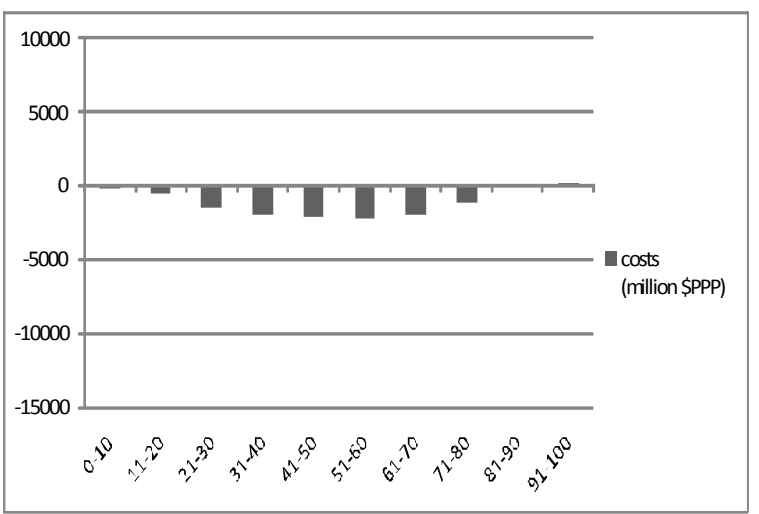

Mass media campaigns

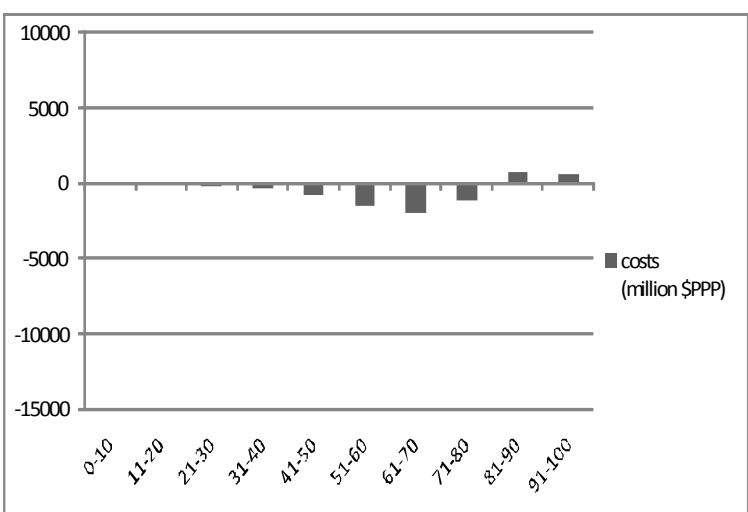

Physician counselling

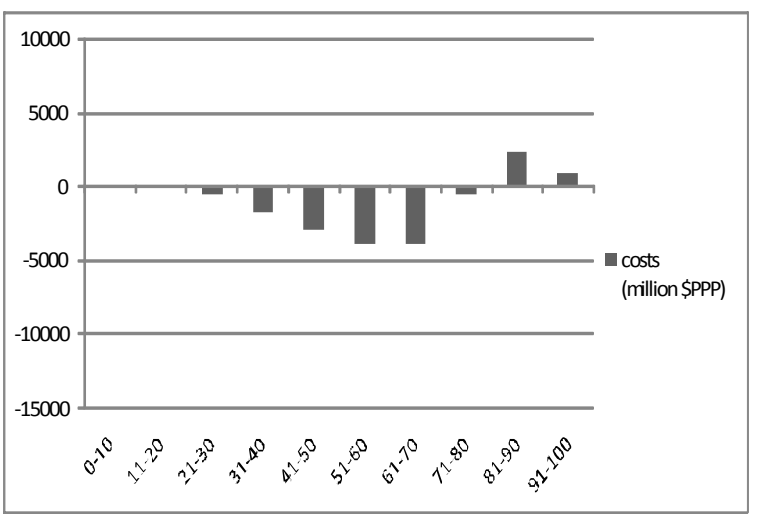

Worksite interventions

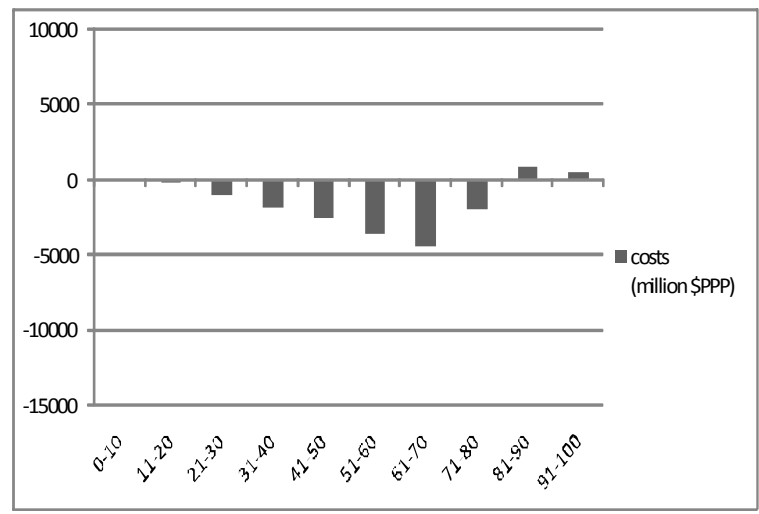

Fiscal measures

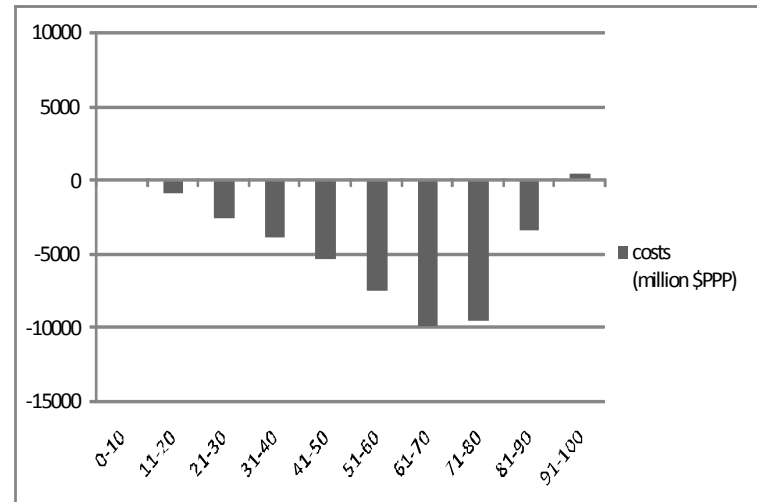

Physician-dietician counselling

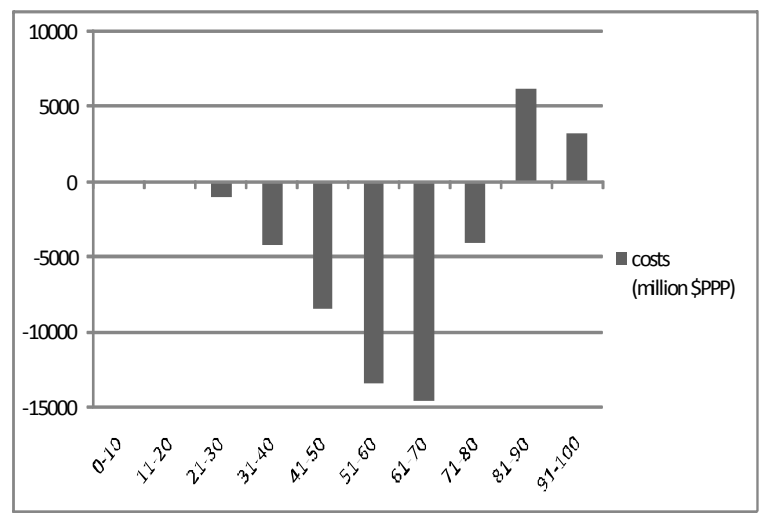


Figure 9. Effects of interventions on health care costs by age group

Food advertising regulation

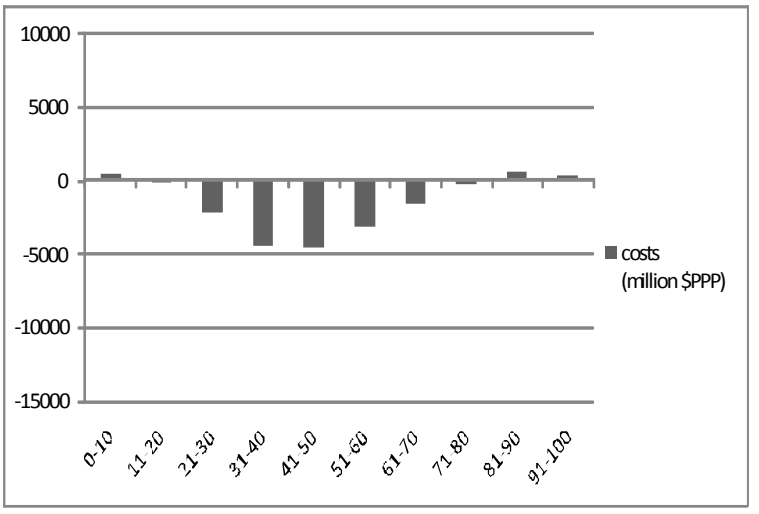

Food labelling

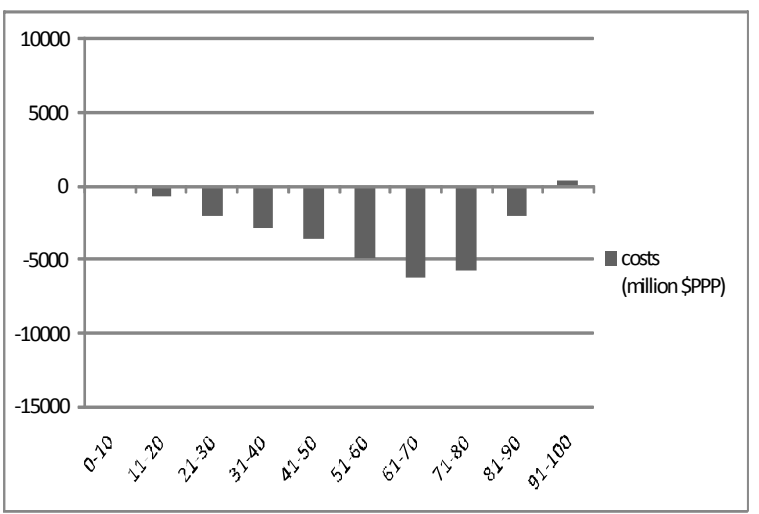

Food advertising self-regulation

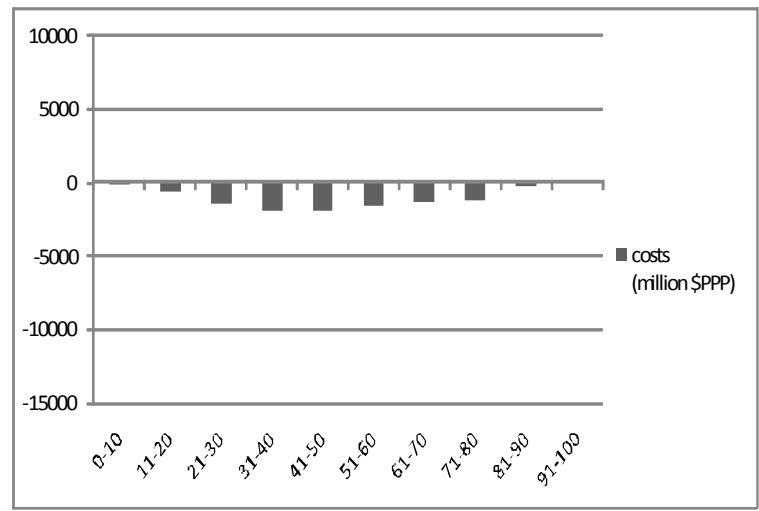

\subsection{Cost-effectiveness}

127. Figure 10 shows the cost-effectiveness ratios for each of the preventive interventions at different points in time over the 100 years of the simulation. Both costs and effectiveness are discounted at a $3 \%$ rate. Food labelling, mass media campaigns and physician-dietician counselling appear to have favourable cost-effectiveness ratio from the early years after their implementation. These three interventions are characterized either by a relatively small cost of implementation, about $\$ 2$ per capita, combined with effects influencing a large share of the population or, as in the case of physician-dietician counselling, very large effectiveness. A second group of interventions, including physician counselling, worksite intervention, self-regulation of food advertising, reaches a cost-effectiveness of $\$ 50,000$ after about 30 years from the initial implementation. School-based interventions and food advertising regulation need more than 60 years to reach similar values. Fiscal measures generate savings shortly after their implementation, while food advertising self-regulation does so after about 40 years. 
Figure 10. Cost-effectiveness of interventions over time (\$/DALY)

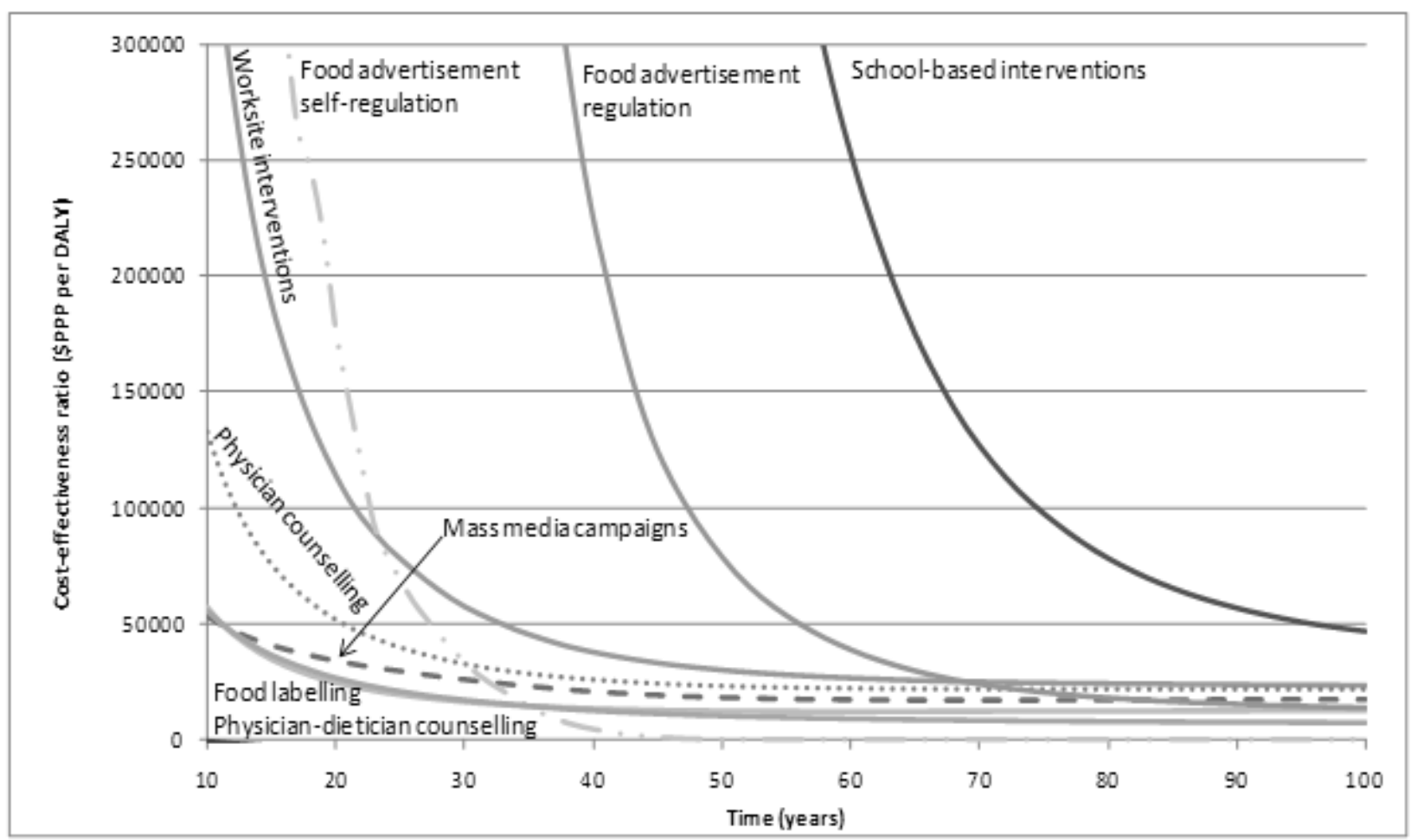

128. In the first 20-30 years of their implementation cost-effectiveness ratios tend to be extremely high. In general, the scale of the impact of individual interventions is limited by the difficulties involved in reaching a large proportion of the national population, either because only certain age groups are targeted by the intervention, in which case it may take many years before a large share of the population receives some exposure to the intervention, or because compliance rates are low, as is typically the case for several of the interventions examined, based on existing evidence.

129. Figure 11 shows the incremental cost-effectiveness ratio (ICER) per disability adjusted life year once interventions reach their steady state. Most interventions have cost-effectiveness ratios between 0 and $\$ 50,000$ with two interventions, namely fiscal measures and food advertising self-regulation, generating savings. 
Figure 11. Incremental cost-effectiveness of interventions at steady state

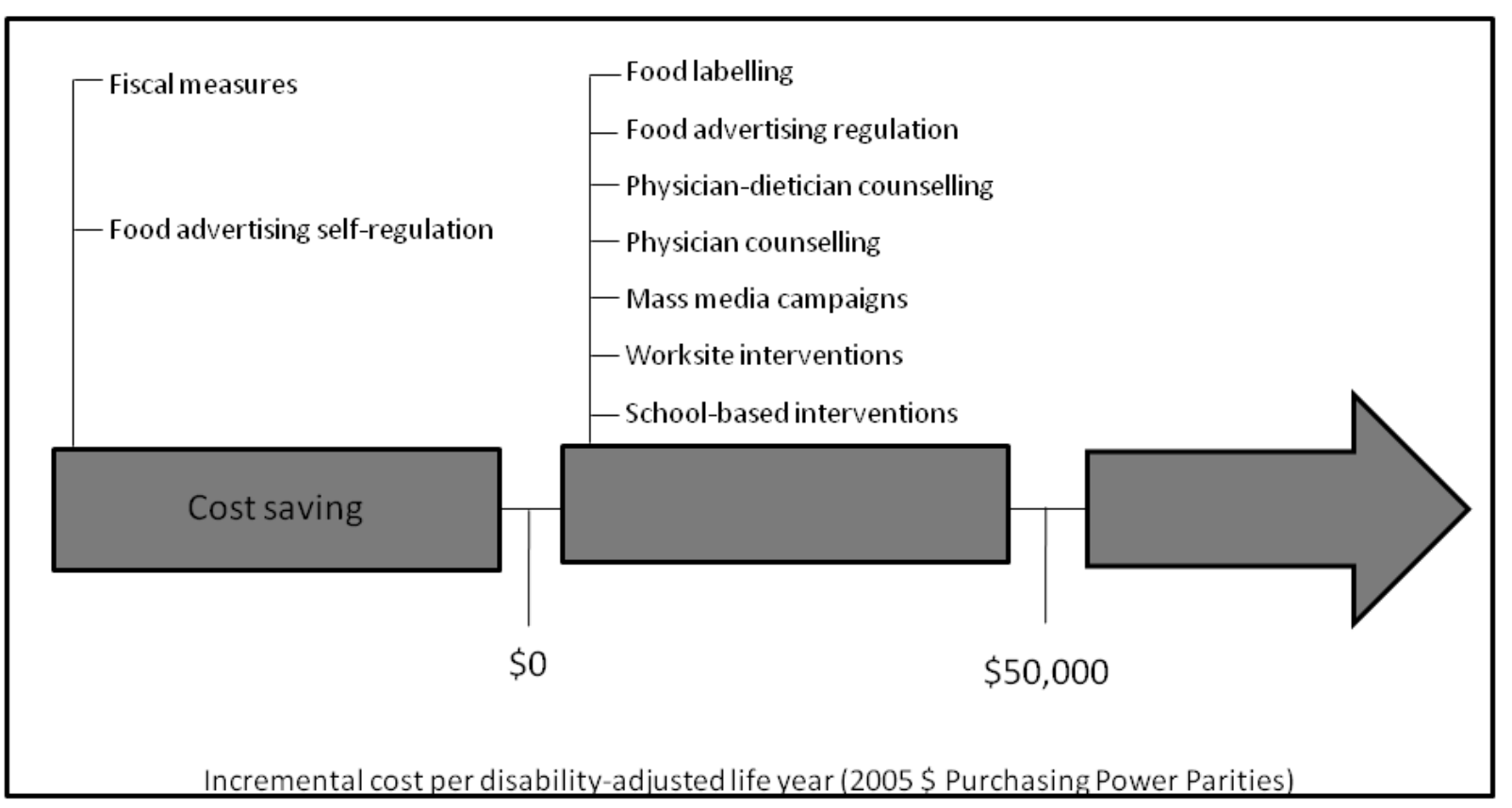

\subsection{Combinations of interventions}

130. We evaluated the effects of possible combinations of interventions designed to cover multiple age-groups with a mix of population-based and high-risk strategies. In particular we simulated three possible scenarios: (1) a combination of a school-based intervention, a mass media campaign and physician-dietician counselling; (2) fiscal measures, food advertising regulation and a worksite intervention; and, (3) a more extensive strategy entailing food labelling, self-regulation of food advertising, a school-based intervention, a mass media campaign and physician-dietician counselling. For all these combinations of interventions we assume that the combined effect is less than additive, relative to the effects of individual interventions. A fourth scenario was modelled including the same interventions as in multiple intervention 3 , but assuming additive effects.

131. Figure 12 shows health outcomes and impacts on health expenditure for the four combinations of interventions as well as for physician-dietician counselling alone. Results for the latter are reported for comparison purposes. As shown in the two figures, the approach used to calculate the combined effectiveness of multiple interventions does not significantly affect the results. All combinations of interventions, with the exception of multiple intervention 2, yield better results than physician-dietician counselling alone. However, it should be noted that multiple intervention 2 has a considerably larger impact on health expenditure than physician-dietician counselling, producing much larger savings. 
Figure 12. Health outcomes and impact on health expenditure for combinations of interventions
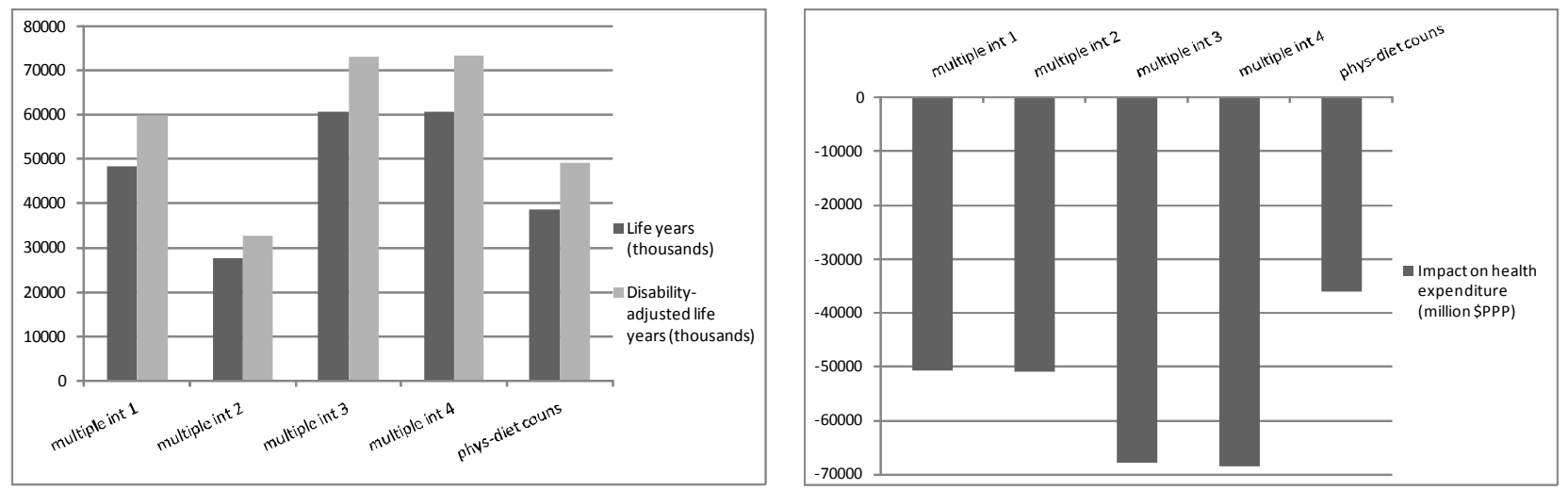

Note:

Multiple int 1 Multiple int 2

Multiple int 3

Multiple int 4
School-based int + mass media camp + physician-dietician couns Fiscal measures + food advert reg+worksite int Food label+food advert self-reg+school-based int+mass media camp+physician-dietician couns Food label+food advert self-reg+school-based int+mass media camps+physician-dietician couns (diff assumpt)

132. Figure 13 shows the cost-effectiveness of combinations of interventions over time, along with the cost-effectiveness of physician-dietician counselling for comparison. All combinations of interventions have cost-effectiveness ratio in the same order of magnitude as physician-dietician counselling thoughout the simulation, with slightly higher ratios for multiple intervention 2 in the early years. Nonetheless, at steady state, the cost-effectiveness of multiple intervention 2 reaches a value of about \$10,000/DALY compared to a value of $\$ 15,000 / \mathrm{DALY}$ for the other interventions. 
Figure 13. Cost-effectiveness of combinations of interventions over time (\$/DALY)

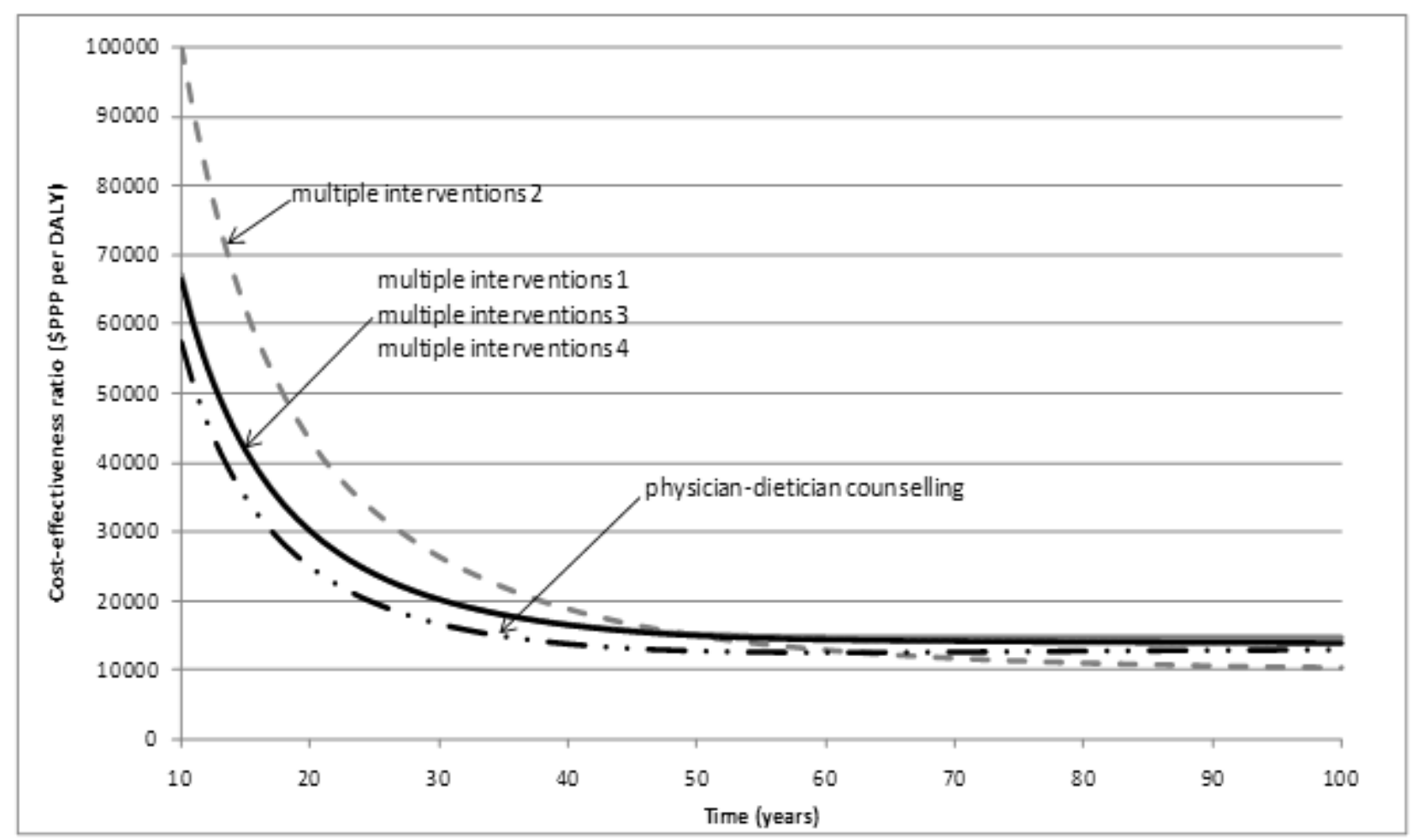

Note:

Multiple int 1

Multiple int 2

Multiple int 3

School-based int + mass media camp+physician-dietician couns

Fiscal measures+food advert reg+worksite int

Food label+food advert self-reg+school-based int+mass media camp+physician-dietician couns

Multiple int 4

Food label+food advert self-reg+school-based int+mass media camps+physician-dietician couns (diff assumpt)

\subsection{Sensitivity analysis}

133. Existing evidence suggests that the effectiveness of preventive interventions may vary significantly depending on the settings in which interventions are implemented and on the ways in which they are implemented. Therefore, as part of the sensitivity analysis, we tested the impact of possible variations in the effectiveness of the modelled interventions by first assuming a $30 \%$ increase in the effectiveness and coverage of the interventions and then assuming a decrease of the same amount. Columns in Figure 14 represent the effects on health outcomes and health expenditure of the average intervention while the error bars show the results due to the increased/decreased effectiveness. In general, a $30 \%$ variation in effectiveness would produce remarkable effects on both health outcomes and health expenditure. 
Figure 14. Sensitivity analysis of health outcomes and impact on health expenditure for selected interventions

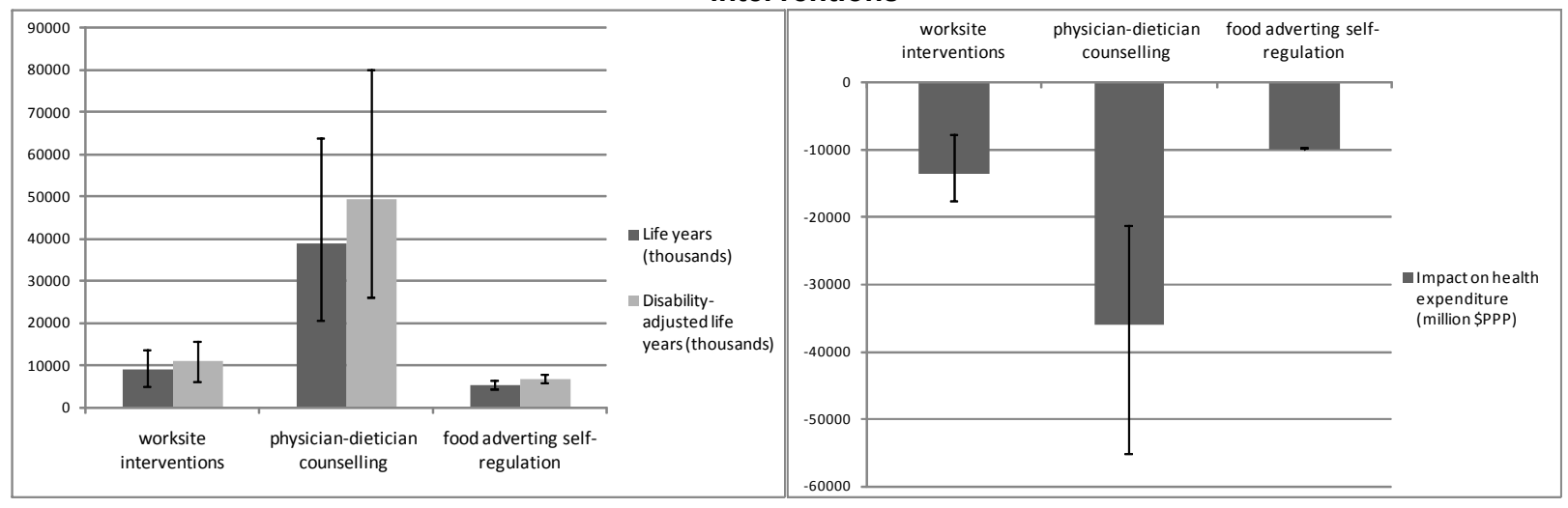

Note: impact on health expenditure is limited to costs for the treatment of diseases explicitly included in the model

134. Figure 15 reports the results of the sensitivity analysis on cost-effectiveness ratios of a selection of two interventions (intensive counselling in primary care and worksite intervention). The costeffectiveness ratio of the intervention originally modelled in the analysis is depicted by the solid line, whereas the extreme-value interventions ( $\pm 30 \%$ of effectiveness) are illustrated by the dashed lines. While the two interventions had markedly different cost-effectiveness profiles in the original analysis, the picture is less clear after the introduction of the extreme-value bounds. For example, the lower effectiveness bound of the physician/dietician counselling intervention generates a cost-effectiveness profile similar to the highest effectiveness bound of worksite interventions.

Figure 15. Sensitivity analysis: cost-effectiveness of interventions over time (thousands \$/DALY)

Worksite intervention

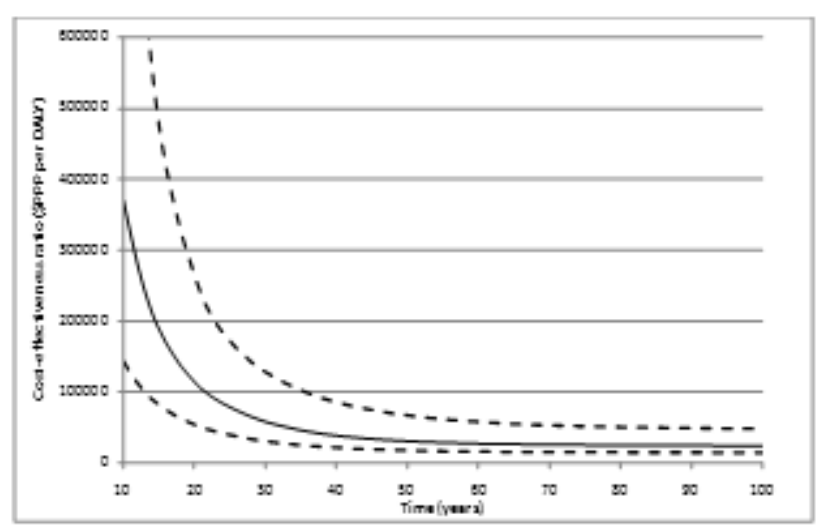

Physician-dietician counselling

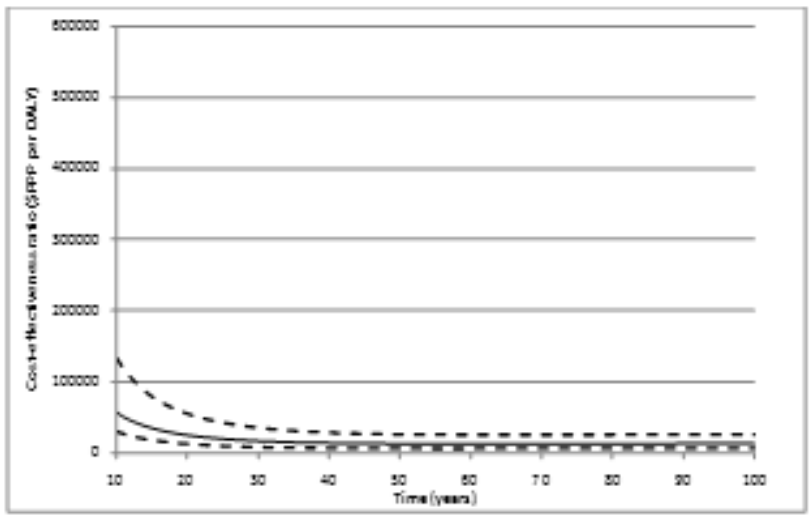

135. Figure 16 shows the results of the sensitivity analysis assuming that the three interventions that we suppose to have long term effects on the behaviour of children have an effectiveness of $20 \%$ instead of a baseline effectiveness estimated at 50\%. To allow a better comparison between the two assumptions, the three panels report the health gain and the impact on health expenditure for both the scenarios with bars in dark grey (those produced by assuming an impact on behaviours at $50 \%$ equals to figures 5 and 8 ). As expected, assuming a reduced effectiveness after the accomplishment of the intervention causes a decrease in the overall impact of the interventions. 
Figure16. Sensitivity analysis: alternative assumptions about the long-term effects of interventions targeting children)

Life years (thousands)

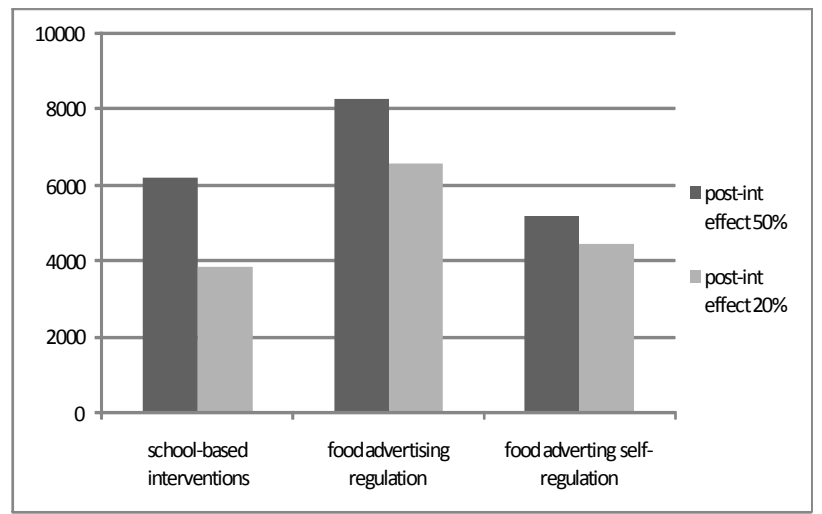

Impact on health expenditure ( $\$$ /million)
Disability-adjusted life years (thousands)

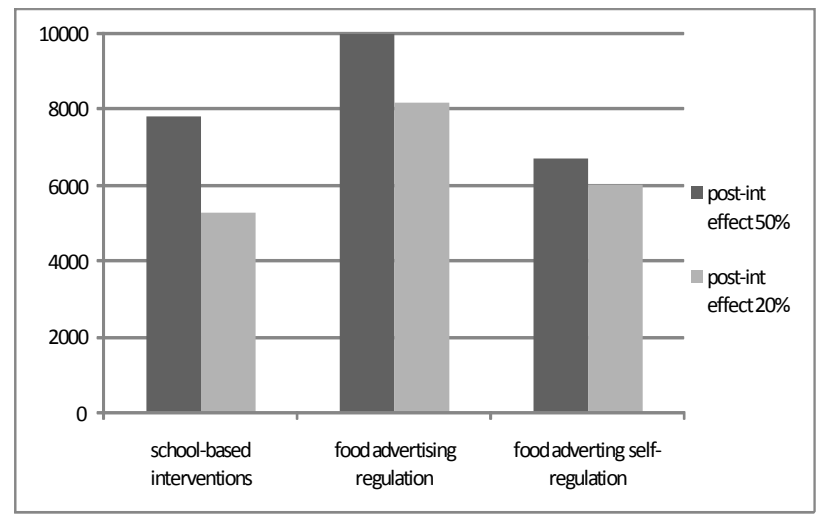

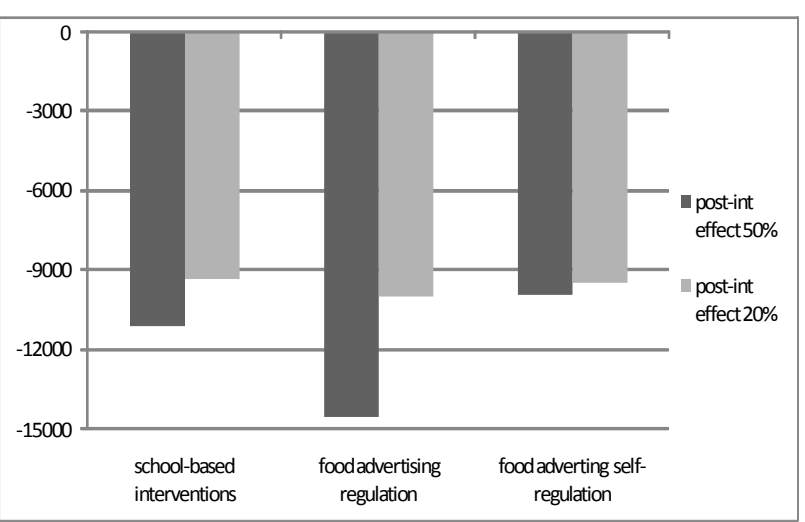

136. Figure 17 shows the results of a probabilistic sensitivity analysis undertaken using the software MCLeague. The analysis identifies "clouds" of stochastic points, reflecting possible combinations of costs and effects, for each intervention. Essentially, the clouds of points shown in Figure 17 for each intervention reflect the dispersion around the point estimates of cost-effectiveness ratios shown in Figure 10, respectively, 20 and 100 years after the initial implementation of the interventions. The points (i.e. costeffectiveness estimates) in the clouds in Figure 17 are generated by assuming that the costs and health effects of each intervention are drawn from normal distributions. Thus, for instance in the case of physician-dietician counselling at year 20, figure 10 shows a cost-effectiveness ratio of about $\$ 25,000$ per DALY. This ratio derives from an average cost of $\$ 80$ billion and an average effectiveness of 3 million DALYs. In calculating panel 1 of figure 17 we assume that these values are the means of two normal distributions (one for costs and one for effectiveness) with a standard deviation equal to $15 \%$ of the mean. The diagonal line in the figures delimits the threshold of $\$ 50,000 / \mathrm{DALY}$, which is often referred to as a possible value to discriminate between efficient and inefficient interventions. Clouds below the horizontal axis correspond to interventions that generate savings in health expenditures which more than offset intervention costs; clouds above the horizontal axis and lying to the right of the dotted line have a favourable cost-effectiveness ratio; while interventions lying completely to the left of the line have a high (less favourable) cost-effectiveness ratio. In the first panel, corresponding to 20 years after the initial implementation, the clouds for most interventions straddle the dotted line with only school-based interventions and regulation of food advertising clearly positioned to the left while physician-dietician 
counselling and fiscal measures are positioned to the right of the threshold. The picture becomes clearer in the second panel (100 years after the initial implementation) where most of the interventions clearly lie to the right of the line. School-based interventions remain the only ones falling across the threshold line, while fiscal measures and food-advertising self-regulation generate savings. 
Figure 17. Probabilistic sensitivity analysis of the cost-effectiveness of interventions at 10 and 100 years)

Cost-effectiveness after 20 years

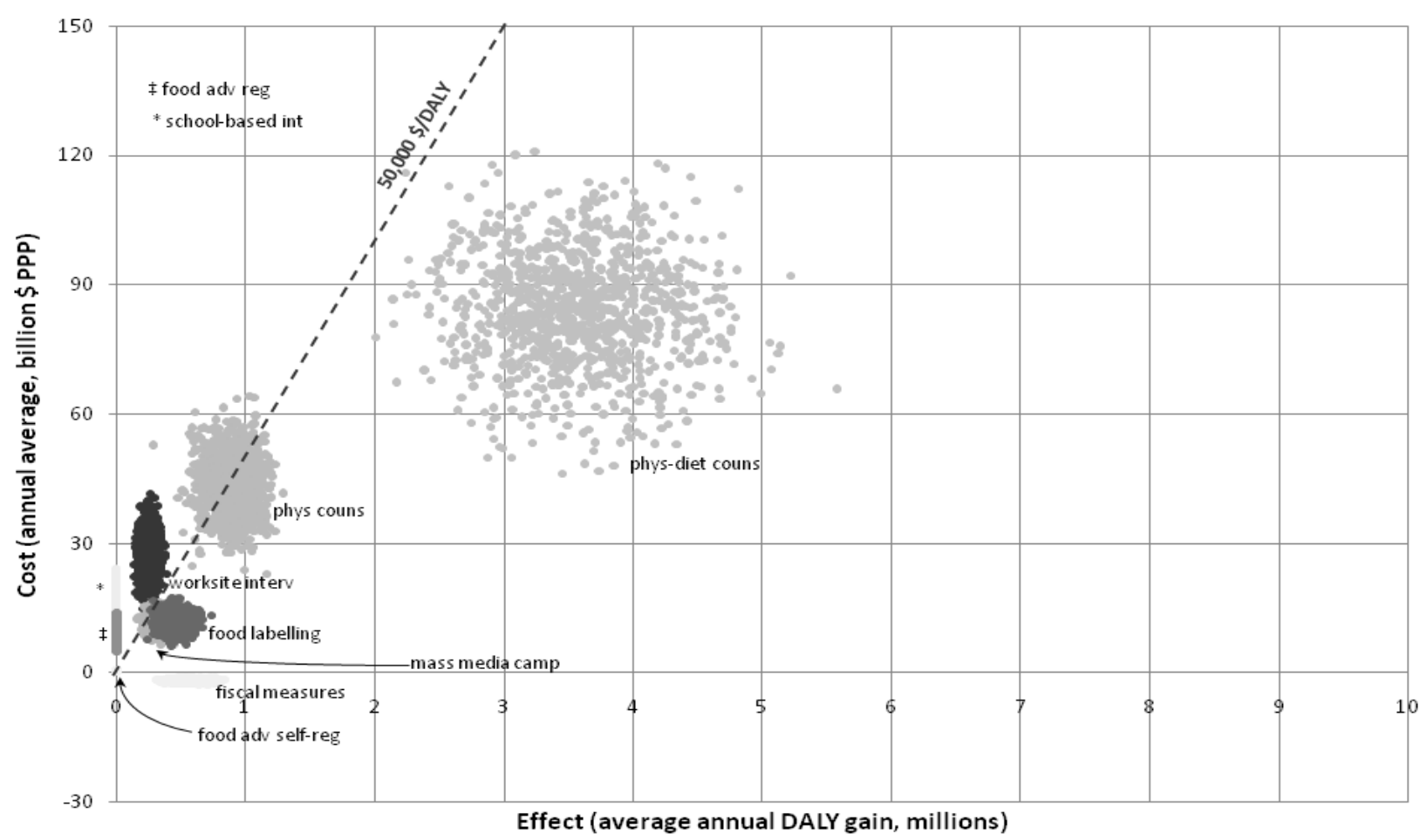

Cost-effectiveness after 100 years

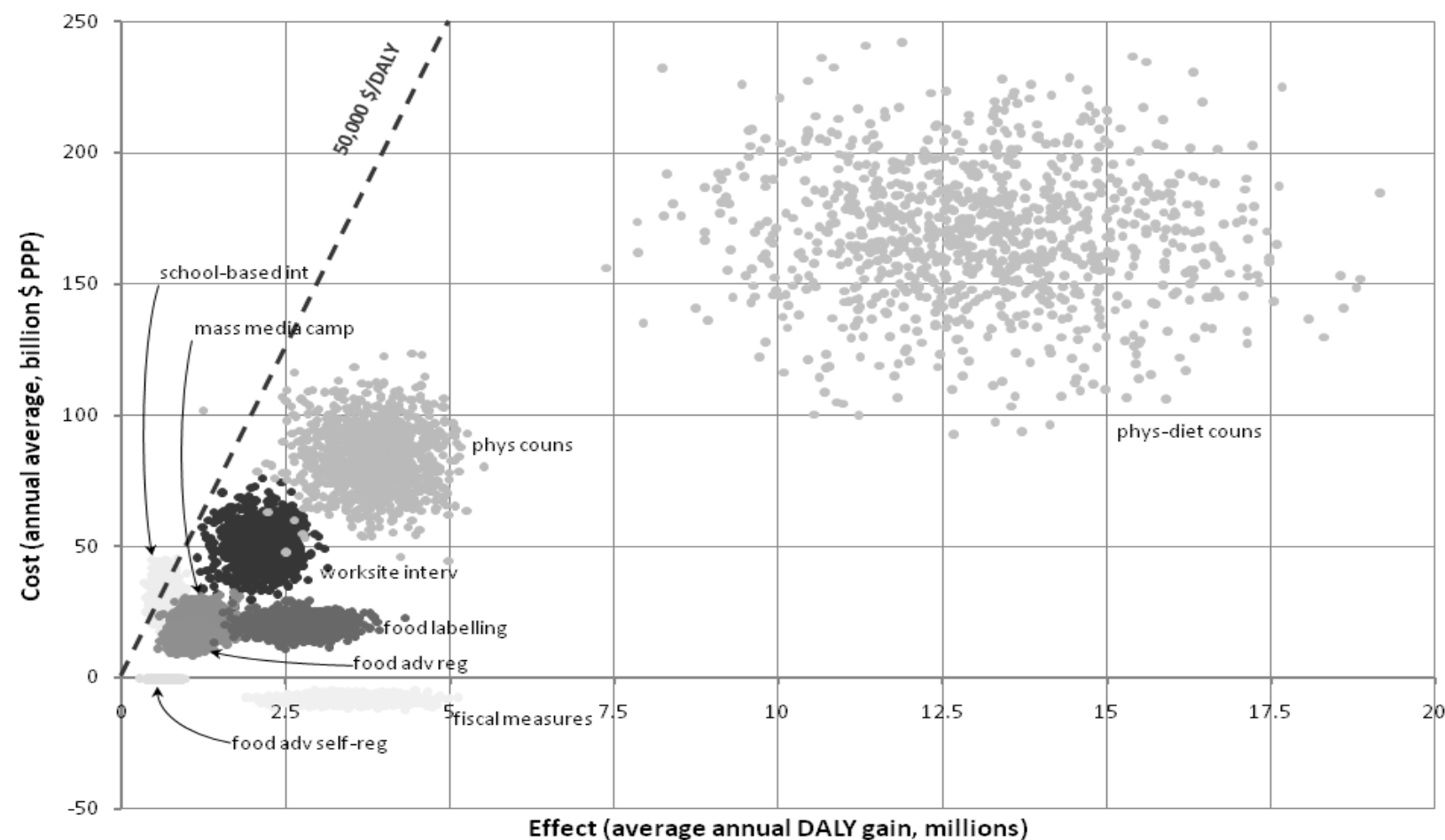




\subsection{Distributional impact}

137. Interventions have larger health effects on individuals in poorer socio-economic circumstances than on their better-off counterparts. This is shown in Figure 18, which depicts the gain in life years produced in different socio economic groups by class of age. The figure shows that gains are proportionally larger at older ages and among the less well-off, except in the oldest age-group. However, it should be noted that the health outcomes presented in this paper are based on the assumption that the effectiveness and the coverage of interventions is the same across population groups, which may slightly misrepresent the response of low-income and high-income groups to some interventions. For instance, in the case of fiscal measures, there is at least some evidence that the two socio-economic groups may have a different reaction to changes in the prices of fruit and vegetables, although studies provide conflicting evidence as to which group has the largest response (Allais et al., 2008; Mytton et al., 2007).

Figure 18. Life-year gain for different socio-economic groups

School-based interventions

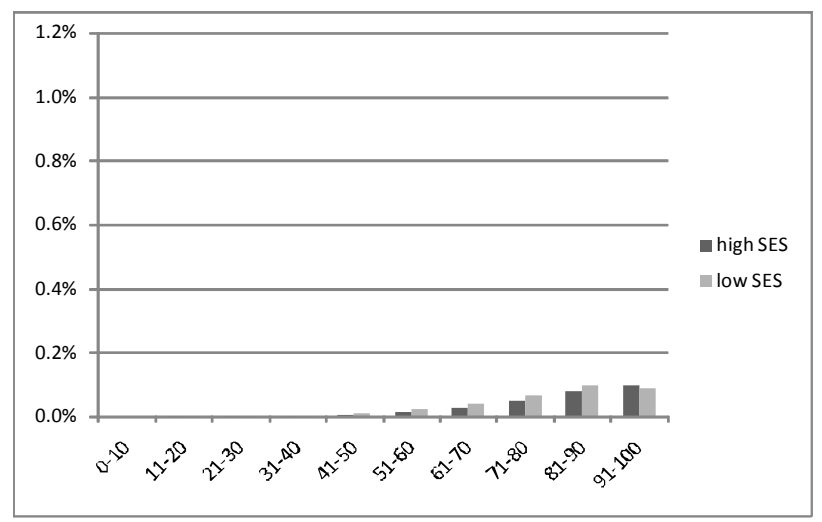

Mass media campaigns

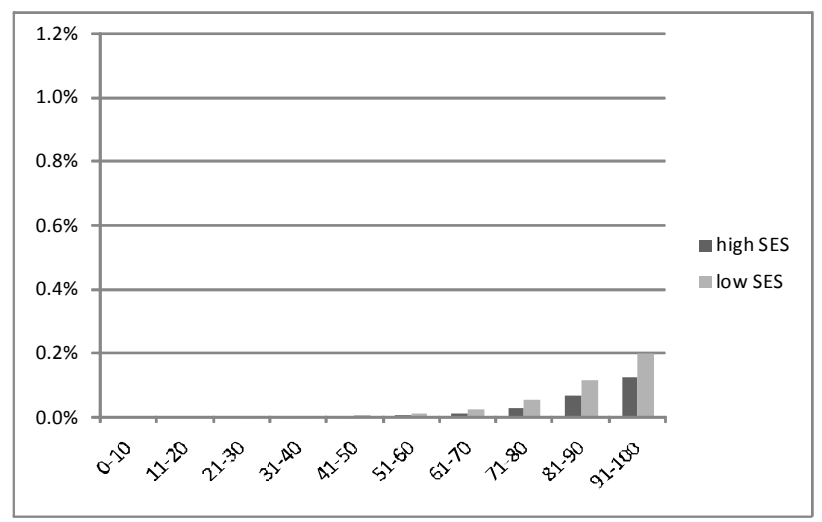

Worksite intervention

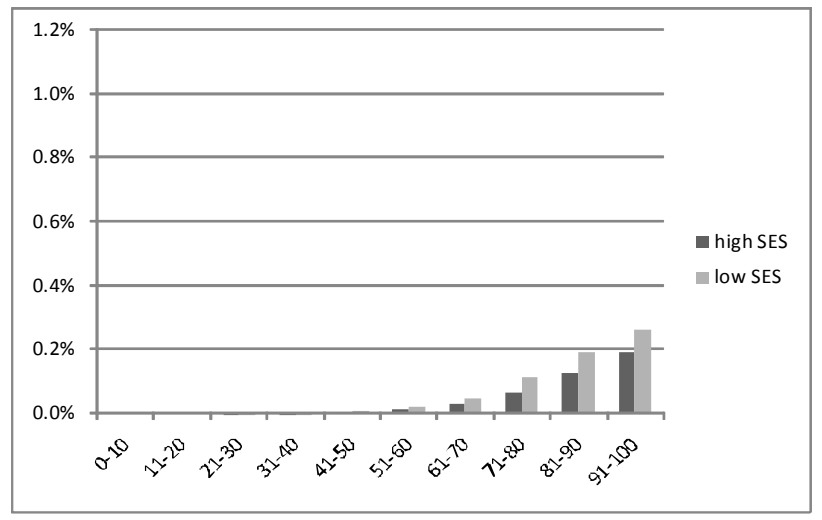

Fiscal measures

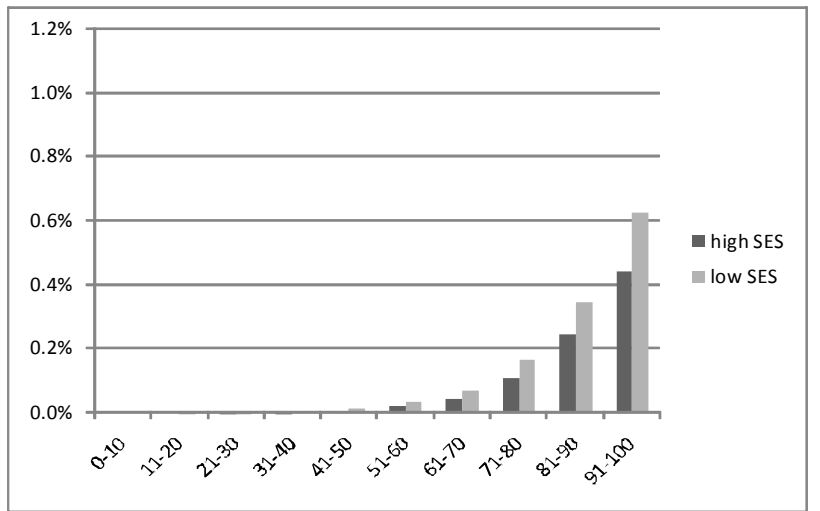


Physician counselling

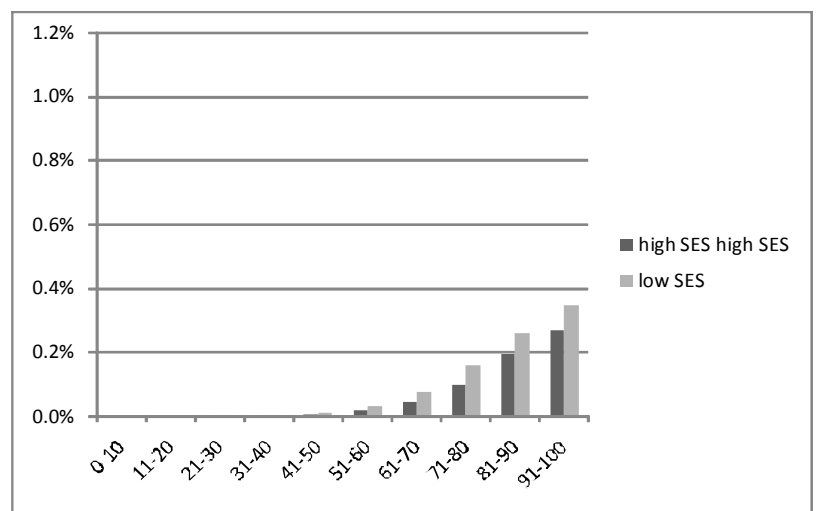

Food advertising regulation

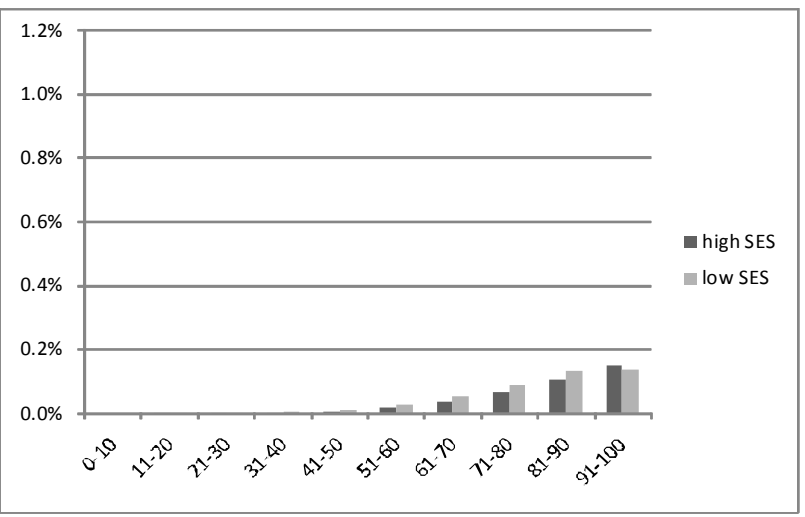

Food labelling

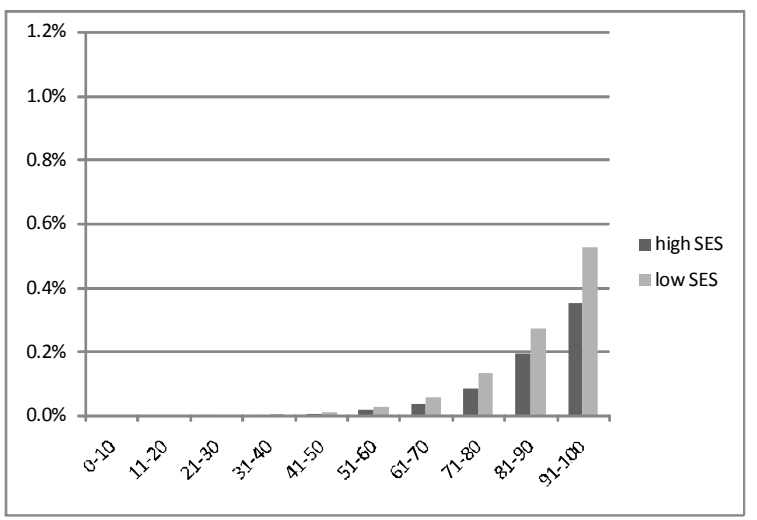

Physician and dietician counselling

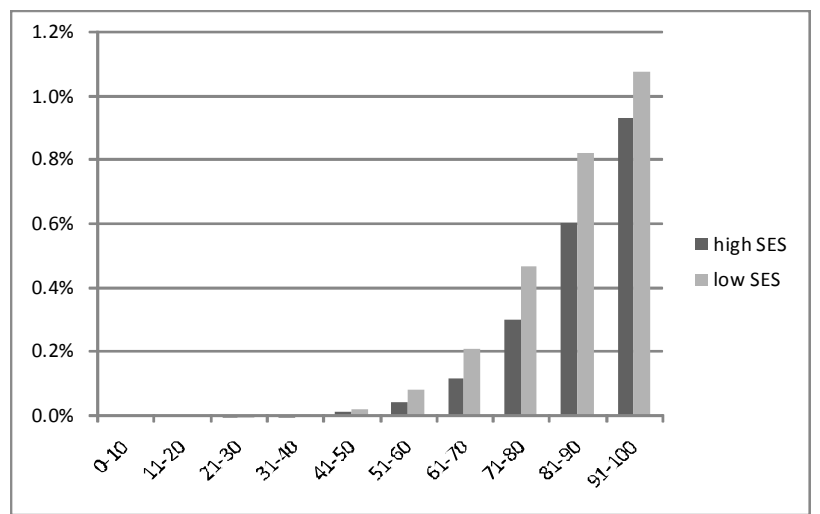

Food advertising self-regulation

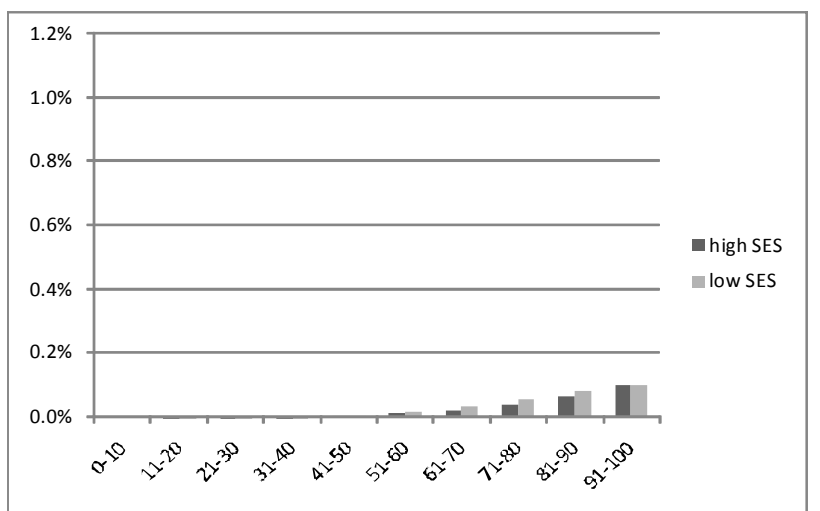

138. Figure 19 reports the results of a sensitivity analysis carried out on the effectiveness of fiscal measures by employing different elasticities for high and low SES groups. Alternative sets of elasticity figures were retrieved from from two studies (Allais et al., 2008; Mytton et al., 2007) suggesting opposite relative effects of fiscal measures for individuals in high and low socioeconomic conditions. While Allais et al. (2008) report a larger effect of price changes in high SES individuals, Mytton et al. (2007) reach the opposite conclusion.. The first panel reports the results of the baseline assumption (equal elasticity for high 
and low SES) while the other two panels show the life-year gain under the two alternative sets of assumptions. Adopting different elasticities does not appear to significantly affect results, as in all three scenarios the less well-off enjoy a larger life-year gain than the better-off.

Figure 19. Sensitivity analysis: life-year gain for different socio-economic groups (fiscal measures)

Elasticity high SES $=2 \%$

Elasticity low $\mathrm{SES}=2 \%$
Elasticity high SES $=2.34 \%$

Elasticity low $\mathrm{SES}=1.71 \%$
Elasticity high SES $=1.56 \%$ Elasticity low SES $=2.38 \%$

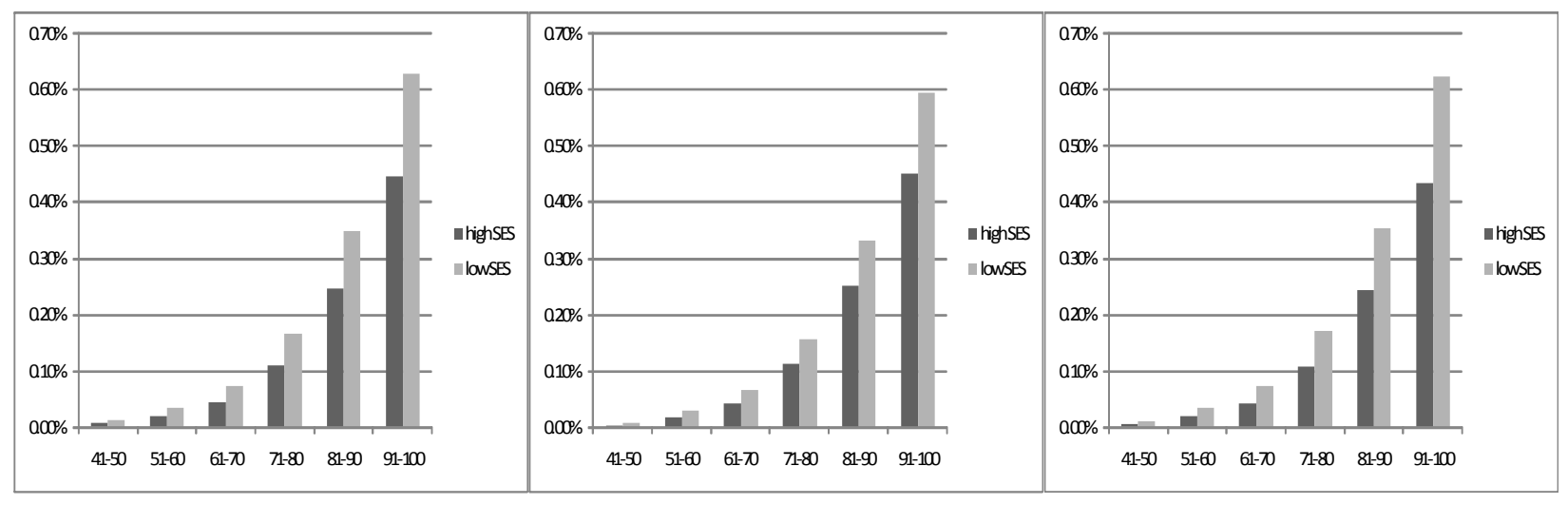

139. Figure 20 illustrates the effect of interventions on overall inequalities in life expectancy and disability-adjusted life expectancy, measured by the Gini coefficient for life years and disability-adjusted life years. All interventions have a favourable, albeit small, effect on health equity. The figures should be read in the following way: the horizontal axis represents the Gini coefficient for the baseline scenario (i.e. no intervention). This means that the Gini coefficient for life years is 0.10373 , whereas the one for disability-adjusted life years is 0.10664 . The bars in the histograms show by how much each intervention reduces the Gini coefficient. Physician/dietician counselling has the largest effect both when considering life years and disability-adjusted life years, while mass media campaigns and worksite interventions produce the lowest decrease of health inequality.

Figure 20. Decrease in the Gini coefficient for life years and disability-adjusted life years due to interventions

Life years

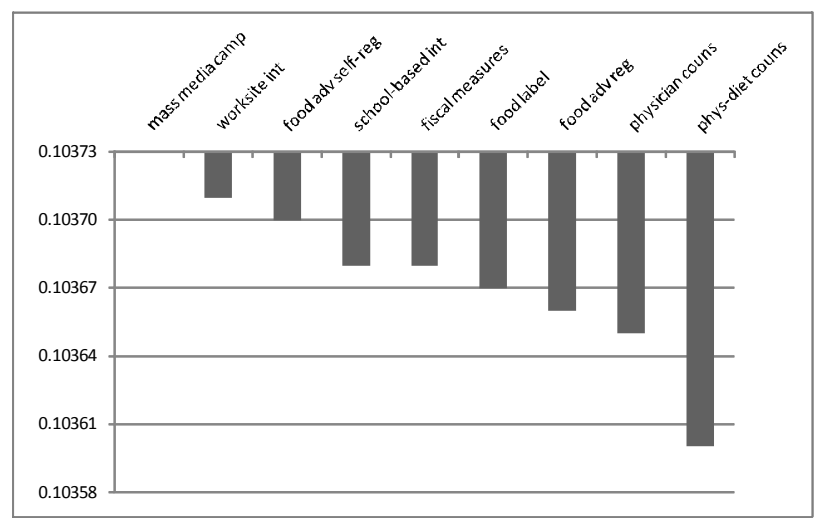

Disability-adjusted life years

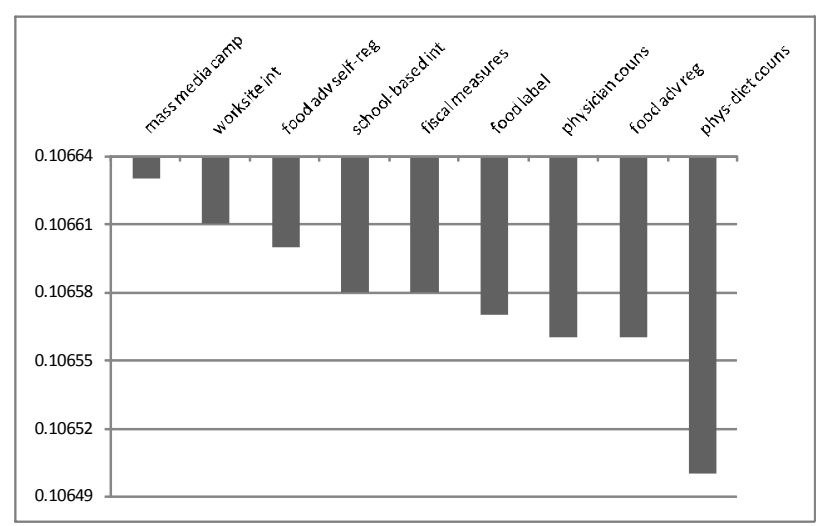


DELSA/HEA/WD/HWP(2009)6

\section{SECTION IV. CONCLUSIONS}

140. Most OECD governments have undertaken actions to curb the recent rise in obesity and related chronic diseases. However, there is only limited evidence concerning the effectiveness and efficiency of doing so. The OECD joined forces with the WHO in an effort to generate new evidence on the efficiency and distributional impact of a range of interventions aimed at preventing chronic diseases linked to unhealthy diets and sedentary lifestyles. A micro-simulation modelling approach was adopted in the analysis, based on the best existing evidence of the epidemiology of the relevant risk factors and chronic diseases, and of the effectiveness of possible actions to modify those risk factors.

141. The evidence base concerning the efficiency (cost-effectiveness) of interventions to improve diet and increase physical activity prior to this analysis was limited to a relatively small number of studies based on highly heterogeneous methodological approaches and outcome measures. This small body of evidence appears to indicate that interventions in at least four areas may present favourable cost effectiveness ratios: counselling of individuals at risk in a primary care setting; community-based counselling; school-based interventions; interventions on the physical environment.

142. A modelling approach provides the most reliable means of assessing health interventions that do not lend themselves to testing within experimental settings. However, the advantages offered by a microsimulation model are inevitably associated with certain limitations, chiefly the need to combine input data from heterogeneous sources and the need to translate all relationships among risk factors, diseases and health outcomes into a mathematical form, with obvious simplifications. Further simplifying assumptions were required due to the nature of the input data available. In particular, the effectiveness of the interventions evaluated had to be assumed constant across individuals of different age, gender, and socioeconomic condition. Due to the absence of long-term follow-up data, critical assumptions also had to be made concerning behaviour changes following the completion of interventions.

143. Most of the preventive interventions evaluated as part of the project appear to have favourable cost-effectiveness ratios. Therefore, those interventions may be regarded as efficient uses of resources when their benefits are measured in terms of life years, or disability-adjusted life years, gained relative to a scenario in which no systematic prevention is undertaken and chronic diseases are treated once they emerge. However, cost-effectiveness ratios do not provide information on the scale of the overall effects and costs associated with preventive interventions. Since the determinants of obesity are multi-factorial and affect all age groups and social strata, interventions tackling individual determinants or narrowly targeted to one groups of individuals will have a limited impact at the population level, and will not reduce significantly the scale of the obesity problem.

144. Among the most important reasons for the limited overall impact of some interventions, when considered in isolation, are the difficulties involved in reaching large sectors of national populations and in securing active participation in such programmes. In fact, the interventions that are capable of reaching the largest numbers of individuals (e.g. mass media campaigns, or fiscal measures), are among those that appear to have the largest impacts, even if their effects are smaller at the individual level. Interventions that target younger age groups are unlikely to have any significant health effects at the population level for many years. The cost-effectiveness profiles of such interventions may be favourable in the long-term, but may remain unfavourable for several decades at the start of the interventions. 
145. Although the most efficient interventions appear to be outside the health sector, health care systems can make the largest impact on obesity and related chronic conditions by selecting individuals at high risk and by using existing facilities, particularly in primary care, to deliver effective counselling. However, it is also possible that the outcomes of primary-care-based interventions appear superior to those of other interventions because a more detailed assessment of their impact on risk factors could be made in a clinical setting.

146. Preventive interventions do not always generate reductions in health expenditure, even when the analysis is limited to a set of diseases that are more directly affected by diet, physical activity and obesity. Individuals may live longer with chronic diseases, as a result of prevention, and may survive long enough to experience unrelated diseases which they would not have experienced otherwise. Most of the interventions assessed in the economic analysis generate a requirement for additional resources to be made available within the health sector, in other areas of government intervention, or within the private sector. Interventions appear to be efficient uses of such resources, however, a large part of those resources would need to be made available upfront, while health returns are often delayed. Governments should determine what level of resources (budgets) they are willing and able to assign to prevention, and they may use the findings of this economic analysis to assess what portfolio of interventions would make the best use of such budgets.

147. The cost-effectiveness ratios resulting from the economic analysis are generally favourable, but subject to a certain degree of uncertainty because of the heterogeneity and relatively wide confidence intervals of the estimates of effectiveness used as inputs in the modelling work. Although a range of sensitivity analyses confirmed that model estimates are robust, the range of variation in potential inputs suggests that interventions need to be very carefully designed in order to achieve at least the same levels of effectiveness recorded in the studies referred to in the economic analysis, at no greater cost. Given the degree of heterogeneity observed among interventions documented in the existing literature aimed at tackling the same health-related behaviours in the same settings, and the variation in the outcomes observed, it is likely that the ways in which interventions are designed and implemented may significantly affect their results.

148. The distributional impact of preventive interventions appears generally favourable, with improvements both in overall inequalities in age at death and in inequalities in life expectancy and disability-adjusted life expectancy between socio-economic groups. However, inequalities in age at death appear to be reduced only to a small extent, whereas the extent to which inequalities between socioeconomic groups may be reduced depends crucially on possible differences in the effectiveness of interventions between the relevant groups. When equal effectiveness is assumed, interventions generate a greater equality of health outcomes between socio-economic groups, but responses to interventions by different socioeconomic groups may well vary in certain settings. 
ANNEX 1. EVIDENCE OF THE COST-EFFECTIVENESS OF INTERVENTIONS

DELSA/HEA/WD/HWP(2009)6

\begin{tabular}{|c|c|c|c|c|c|c|c|c|c|}
\hline REF & $\begin{array}{l}\text { Year of } \\
\text { publication }\end{array}$ & Classification & Domain & Country & $\begin{array}{l}\text { Intervention and } \\
\text { description }\end{array}$ & Comparator & $\begin{array}{l}\text { Interv/ } \\
\text { f-up length }\end{array}$ & Results & Target population \\
\hline 1 & 2001 & $\begin{array}{l}\text { Community } \\
\text { Counseling }\end{array}$ & Diet & $A U$ & $\begin{array}{l}\text { Interactive computer- } \\
\text { based } \\
\text { telecommunication } \\
\text { system }\end{array}$ & do nothing & $26 / 26$ & $\$ 1464$ for one serve of fruit/veg & $\begin{array}{l}\text { Members of a } \\
\text { multisite, } \\
\text { multispecialty } \\
\text { practice }\end{array}$ \\
\hline 2 & 1998 & $\begin{array}{l}\text { Community } \\
\text { Counseling }\end{array}$ & $\begin{array}{l}\text { Physical } \\
\text { activity }\end{array}$ & GB & 10 week program & do nothing & $10 / 34$ & $\$ 3268$ to move one person to recommended PA level & $\begin{array}{l}45-74 \text { y olds } \\
\text { inactive people }\end{array}$ \\
\hline 3 & 2000 & $\begin{array}{l}\text { Community } \\
\text { Counseling }\end{array}$ & $\begin{array}{l}\text { Physical } \\
\text { activity }\end{array}$ & US & Small group meetings & $\begin{array}{l}\text { month free } \\
\text { gym } \\
\text { membership }\end{array}$ & $26 / 104$ & $\begin{array}{l}\$ 91 / \mathrm{Kg} \text { lost for counseling, } \$ 170 / \mathrm{Kg} \text { lost for gym } \\
\text { memb at } 52 \mathrm{wk} ; \$ 398 / \mathrm{kg} \text { lost fo counseling, weight } \\
\text { increase for gym memb at } 104 \mathrm{wk}\end{array}$ & $\begin{array}{l}35-60 \text { y olds \& } \\
140 \% \text { body weight } \\
\& \text { low expenditure } \\
\text { value }\end{array}$ \\
\hline 23 & 2008 & $\begin{array}{l}\text { Community } \\
\text { counseling }\end{array}$ & $\begin{array}{l}\text { Physical } \\
\text { activity }\end{array}$ & US & $\begin{array}{l}\text { Promotion of walking } \\
\text { using media }\end{array}$ & do nothing & life/life & ICER $\$ 15,259 / Q A L Y$ & $\begin{array}{l}25-64 \text { in good } \\
\text { health }\end{array}$ \\
\hline 23 & 2008 & $\begin{array}{l}\text { Community } \\
\text { counseling }\end{array}$ & $\begin{array}{l}\text { Physical } \\
\text { activity }\end{array}$ & US & $\begin{array}{l}\text { Personal trainers and } \\
\text { counseling sessions }\end{array}$ & do nothing & life/life & ICER $\$ 31,786 /$ QALY & $\begin{array}{l}25-64 \text { in good } \\
\text { health }\end{array}$ \\
\hline 23 & 2008 & $\begin{array}{l}\text { Community } \\
\text { counseling }\end{array}$ & $\begin{array}{l}\text { Physical } \\
\text { activity }\end{array}$ & US & $\begin{array}{l}\text { Newsletter and group } \\
\text { activities }\end{array}$ & do nothing & life/life & ICER $\$ 42,394 / Q A L Y$ & $\begin{array}{l}25-64 \text { in good } \\
\text { health }\end{array}$ \\
\hline 23 & 2008 & $\begin{array}{l}\text { Community } \\
\text { counseling }\end{array}$ & $\begin{array}{l}\text { Physical } \\
\text { activity }\end{array}$ & US & $\begin{array}{l}\text { Health education } \\
\text { through media }\end{array}$ & do nothing & life/life & ICER $\$ 73,227 / Q A L Y$ & $\begin{array}{l}25-64 \text { in good } \\
\text { health }\end{array}$ \\
\hline
\end{tabular}


DELSA/HEA/WD/HWP(2009)6

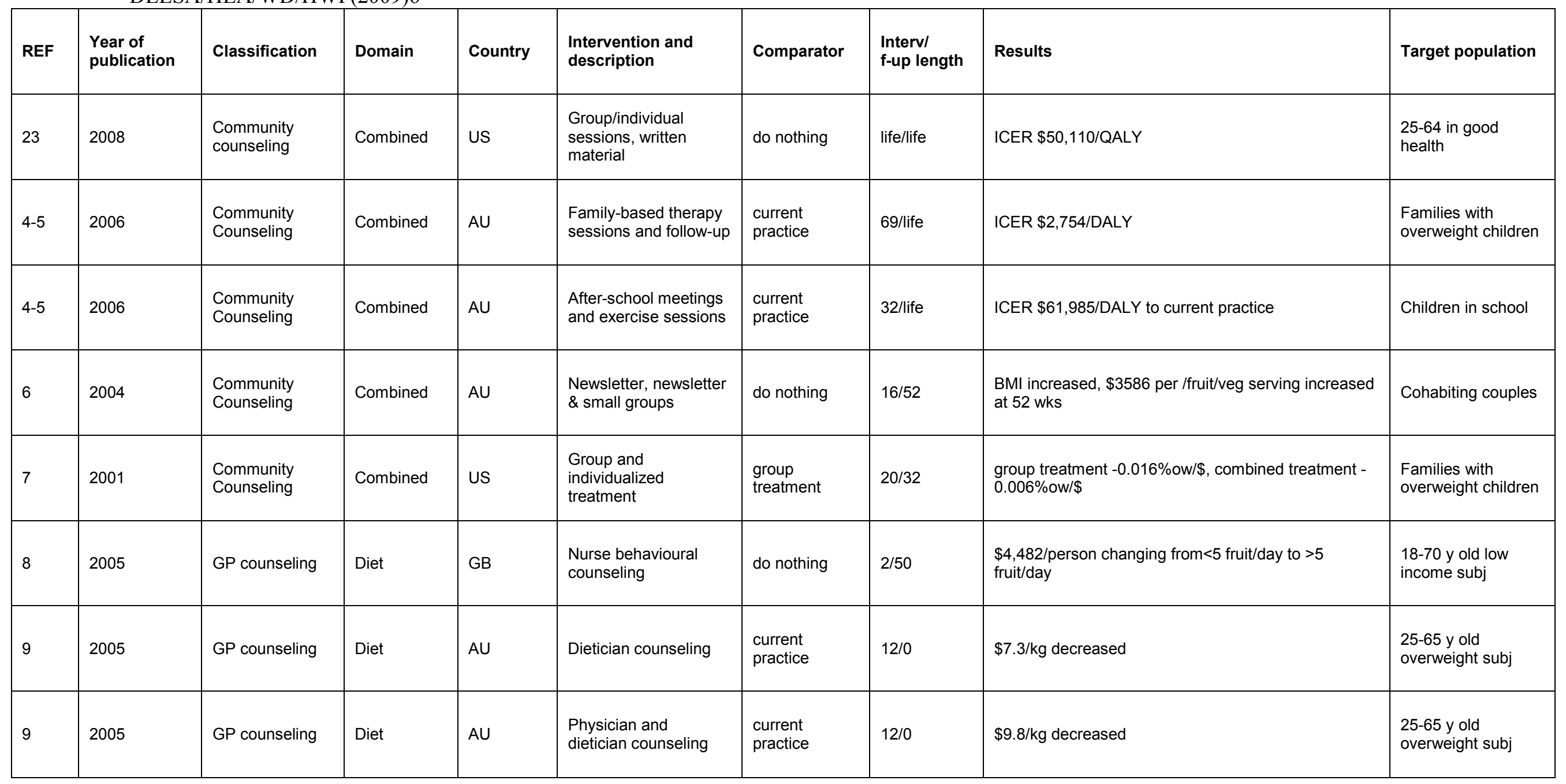


DELSA/HEA/WD/HWP(2009)6

\begin{tabular}{|c|c|c|c|c|c|c|c|c|c|}
\hline REF & $\begin{array}{l}\text { Year of } \\
\text { publication }\end{array}$ & Classification & Domain & Country & $\begin{array}{l}\text { Intervention and } \\
\text { description }\end{array}$ & Comparator & $\begin{array}{l}\text { Interv/ } \\
\text { f-up length }\end{array}$ & Results & Target population \\
\hline 10 & 2005 & GP counseling & Diet & DK & $\begin{array}{l}\text { General practitioner } \\
\text { counseling }\end{array}$ & do nothing & 52/life & ICER $\$ 889 /$ life year gained & $\begin{array}{l}\text { BMI>30, waist } \\
\text { circumference } \\
\text { (men>102, women } \\
>88 \mathrm{~cm} \text { ), } \\
\text { dyslipidemia, type } 2 \\
\text { diabetes }\end{array}$ \\
\hline 10 & 2005 & GP counseling & Diet & DK & Dietician counseling & Do nothing & 52/life & dietician $\$ 6,495 /$ life year gained & $\begin{array}{l}\text { BMI>30, waist } \\
\text { circumference } \\
\text { (men>102, women } \\
>88 \mathrm{~cm} \text { ), } \\
\text { dvelinidomis tyno? }\end{array}$ \\
\hline 11 & 1999 & GP counseling & $\begin{array}{l}\text { Physical } \\
\text { activity }\end{array}$ & $A U$ & $\begin{array}{l}\text { PA prescription and } \\
\text { counseling }\end{array}$ & $\begin{array}{l}\text { current } \\
\text { practice }\end{array}$ & $-/ 5$ & ICER $\$ 22,605 /$ QALY & Inactive patients \\
\hline 11 & 1999 & GP counseling & $\begin{array}{l}\text { Physical } \\
\text { activity }\end{array}$ & $\mathrm{AU}$ & $\begin{array}{l}\text { Counseling by a } \\
\text { physiologist }\end{array}$ & $\begin{array}{l}\text { informational } \\
\text { pamphlet }\end{array}$ & $26 / 26$ & ICER $\$ 25,76 /$ QALY on 15 years & $\begin{array}{l}>60 \text { y old inactive } \\
\text { patients }\end{array}$ \\
\hline 12 & 2004 & GP counseling & $\begin{array}{l}\text { Physical } \\
\text { activity }\end{array}$ & $\mathrm{NZ}$ & $\begin{array}{l}\text { Verbal and written } \\
\text { prescription and } \\
\text { follow-up on phone }\end{array}$ & do nothing & $13 / 39$ & $\begin{array}{l}\$ 7 / \mathrm{Kcal} \text { spent in PA/Kg/day, } \$ 1,094 / \text { additional sub } \\
\text { became active }\end{array}$ & $40-79$ year olds \\
\hline $4-5$ & 2006 & GP counseling & Combined & $A U$ & $\begin{array}{l}\text { Family therapy by } \\
\text { psychiatrist }\end{array}$ & $\begin{array}{l}\text { current } \\
\text { practice }\end{array}$ & 12/life & ICER $\$ 22,039 / D A L Y$ & $\begin{array}{l}\text { Families with } \\
\text { overweight/obese } \\
\text { children }\end{array}$ \\
\hline $4-5$ & 2006 & School setting & Diet & $A U$ & $\begin{array}{l}\text { Classes to reduce the } \\
\text { consumption of } \\
\text { carbonated drinks }\end{array}$ & $\begin{array}{l}\text { current } \\
\text { practice }\end{array}$ & 26/life & ICER $\$ 2,066 / D A L Y$ on life course & $7-11$ year olds \\
\hline
\end{tabular}


DELSA/HEA/WD/HWP(2009)6

\begin{tabular}{|c|c|c|c|c|c|c|c|c|c|}
\hline REF & $\begin{array}{l}\text { Year of } \\
\text { publication }\end{array}$ & Classification & Domain & Country & $\begin{array}{l}\text { Intervention and } \\
\text { description }\end{array}$ & Comparator & $\begin{array}{l}\text { Interv/ } \\
\text { f-up length }\end{array}$ & Results & Target population \\
\hline $4-5$ & 2006 & School setting & $\begin{array}{l}\text { Physical } \\
\text { activity }\end{array}$ & $A U$ & $\begin{array}{l}\text { Classes to reduce TV } \\
\text { viewing }\end{array}$ & $\begin{array}{l}\text { current } \\
\text { practice }\end{array}$ & 43/life & ICER $\$ 2,066 /$ DALY on life course & $\begin{array}{l}\text { Children in primary } \\
\text { school (grade } 3 \text { and } \\
\text { 4) }\end{array}$ \\
\hline $4-5$ & 2006 & School setting & $\begin{array}{l}\text { Physical } \\
\text { activity }\end{array}$ & $A U$ & $\begin{array}{l}\text { School session }+ \\
\text { events to increase PA } \\
*\end{array}$ & $\begin{array}{l}\text { current } \\
\text { practice }\end{array}$ & 4/life & ICER $\$ 179,068 / D A L Y$ on life course & $\begin{array}{l}\text { Children in primary } \\
\text { school (grade } 5 \text { and } \\
6 \text { ) }\end{array}$ \\
\hline $4-5$ & 2006 & School setting & $\begin{array}{l}\text { Physical } \\
\text { activity }\end{array}$ & $\mathrm{AU}$ & Walking school bus * & $\begin{array}{l}\text { current } \\
\text { practice }\end{array}$ & 43/life & ICER $\$ 0.53 \mathrm{M} / \mathrm{DALY}$ on life course & $\begin{array}{l}\text { Children in primary } \\
\text { school }\end{array}$ \\
\hline $4-5$ & 2006 & School setting & Combined & $\mathrm{AU}$ & $\begin{array}{l}\text { Classes + increased } \\
\text { PA * }\end{array}$ & $\begin{array}{l}\text { current } \\
\text { practice }\end{array}$ & 156/life & ICER $\$ 4,821 / D A L Y$ on life course & $\begin{array}{l}\text { Children in primary } \\
\text { school }\end{array}$ \\
\hline $4-5$ & 2006 & School setting & Combined & $\mathrm{AU}$ & Classes & $\begin{array}{l}\text { current } \\
\text { practice }\end{array}$ & 104/life & ICER $\$ 9,642 / D A L Y$ on life course & $\begin{array}{l}\text { Children in primary } \\
\text { school }\end{array}$ \\
\hline $4-5$ & 2006 & School setting & Combined & $\mathrm{AU}$ & Classes & $\begin{array}{l}\text { current } \\
\text { practice }\end{array}$ & 12/life & ICER $\$ 2,066 / D A L Y$ on life course & $\begin{array}{l}\text { Overweight 7-10 } \\
\text { year old children }\end{array}$ \\
\hline 13 & 2003 & School setting & Combined & US & $\begin{array}{l}\text { Classes + increased } \\
\text { PA * }\end{array}$ & do nothing & 104/life & ICER $\$ 4,629 / Q A L Y$ on life course & $\begin{array}{l}\text { Pupils in middle } \\
\text { school }\end{array}$ \\
\hline $4-5$ & 2006 & $\begin{array}{l}\text { Environment } \\
\text { modification }\end{array}$ & Diet & $\mathrm{AU}$ & $\begin{array}{l}\text { Banning TV } \\
\text { advertising }\end{array}$ & $\begin{array}{l}\text { current } \\
\text { practice }\end{array}$ & $-/$ life & ICER \$2.5/DALY on life course & $\begin{array}{l}\text { General pop ( }>15 \% \\
\text { audience }<14 \text { years } \\
\text { old) }\end{array}$ \\
\hline 14 & 2004 & $\begin{array}{l}\text { Environment } \\
\text { modification }\end{array}$ & $\begin{array}{l}\text { Physical } \\
\text { activity }\end{array}$ & US & $\begin{array}{l}\text { Build/manage a cycle } \\
\text { trial }\end{array}$ & no comparator & $1 / 0$ & $\$ 930 /$ person cycling with the purpose of losing weight & General pop \\
\hline 15 & 2002 & $\begin{array}{l}\text { Environment } \\
\text { modification }\end{array}$ & $\begin{array}{l}\text { Physical } \\
\text { activity }\end{array}$ & NO & $\begin{array}{l}\text { Build/manage a cycle } \\
\text { trial }\end{array}$ & no comparator & $-/-$ & CB ratio $3: 1$ to $14: 1$ & General pop \\
\hline 16 & 2007 & $\begin{array}{l}\text { Environment } \\
\text { modification }\end{array}$ & $\begin{array}{l}\text { Physical } \\
\text { activity }\end{array}$ & GB & $\begin{array}{l}\text { Build/manage a cycle } \\
\text { trial }\end{array}$ & no comparator & $-/-$ & CB ratio $1.4: 1$ to $7: 1$ & General pop \\
\hline
\end{tabular}


DELSA/HEA/WD/HWP(2009)6

\begin{tabular}{|c|c|c|c|c|c|c|c|c|c|}
\hline REF & $\begin{array}{l}\text { Year of } \\
\text { publication }\end{array}$ & Classification & Domain & Country & $\begin{array}{l}\text { Intervention and } \\
\text { description }\end{array}$ & Comparator & $\begin{array}{l}\text { Interv/ } \\
\text { f-up length }\end{array}$ & Results & Target population \\
\hline 23 & 2008 & $\begin{array}{l}\text { Environmental } \\
\text { modifications }\end{array}$ & $\begin{array}{l}\text { Physical } \\
\text { activity }\end{array}$ & US & $\begin{array}{l}\text { Bike paths, fitness } \\
\text { facilities, events }\end{array}$ & do nothing & life/life & ICER $\$ 30,493 /$ QALY & $\begin{array}{l}25-64 \text { in good } \\
\text { health }\end{array}$ \\
\hline 24 & 2008 & $\begin{array}{l}\text { Environmental } \\
\text { modifications }\end{array}$ & $\begin{array}{l}\text { Physical } \\
\text { activity }\end{array}$ & US & $\begin{array}{l}\text { Sponsored access to } \\
\text { fitness centers }\end{array}$ & do nothing & $2 / 0$ & $\$-534$ in total health care costs & $>65$ year olds \\
\hline 18 & 1995 & Other & Diet & US & $\begin{array}{l}\text { Diet regimen with } \\
\text { medical check-up }\end{array}$ & do nothing & $76 / 0$ & $\$ 1,958 / \mathrm{lb}$ & Obese subj \\
\hline 19 & 2005 & Other & Diet & US & Low carbohydrate diet & $\begin{array}{l}\text { standard } \\
\text { weight loss } \\
\text { diet }\end{array}$ & $26 / 26$ & No statistical difference & $\begin{array}{l}\text { Severely obese } \\
\text { subj }\end{array}$ \\
\hline 20 & 1988 & Other & $\begin{array}{l}\text { Physical } \\
\text { activity }\end{array}$ & US & Jogging & do nothing & $1560 / 0$ & ICER $\$ 19,273 /$ QALY & 35 y old men \\
\hline 21 & 2001 & Other & Combined & US & $\begin{array}{l}\text { Correspondence } \\
\text { behavioral programme }\end{array}$ & do nothing & $-/-$ & $\$ 11 / \mathrm{kg}$ lost & General pop \\
\hline 22 & 2006 & Other & Combined & US & $\begin{array}{l}\text { Three component } \\
\text { intervention of diet, } \\
\text { exercise, behaviour } \\
\text { modification * }\end{array}$ & $\begin{array}{l}\text { current } \\
\text { practice }\end{array}$ & 52/life & $\$ 13800 /$ QALY & $\begin{array}{l}\text { ow/obese women } \\
>35 \text { year olds }\end{array}$ \\
\hline
\end{tabular}




\section{ANNEX 2. LIST OF ARTICLES AND PUBLICATIONS ON THE COST-EFFECTIVENESS AND COST-BENEFIT OF INTERVENTIONS TO TACKLE OVERWEIGHT AND OBESITY THROUGH DIET AND PHYSICAL ACTIVITY}

(1) Dalziel, K. et al. (2005), "Risk Factor Study: How to Reduce the Burden of Harm from Poor Nutrition, Tobacco Smoking, Physical Inactivity and Alcohol Misuse: Cost-utility Analysis of 8 Nutrition Interventions", Center for Health Economics Research Paper 2005(4).

(2) Stevens, W. et al. (1998), "Cost-effectiveness of a Primary Care Based Physical Activity Intervention in 45-74-year-old Men and Women: a Randomized Controlled Trial. Br J Sports Med 1998; 32:236241

(3) Sevick MA, Dunn AL, Morrow MS, Marcus BH, Chen GJ, Blair SN, 2000: Cost-effectiveness of lifestyle and structured exercise interventions in sedentary adults. Am J Prev Med. 2000;19(1):1-8

(4) ACE 2006, Haby MM, Vos T, Carte, R, Moodie M, Markwick A, Magnus A, Tay-Teo K-S, Swinburn B, 2006: Pediatric new perspective: A new approach to assessing the health benefit from obesity interventions in children and adolescents: the assessing cost-effectiveness in obesity project. International Journal of Obesity. 2006

(5) ACE-Obesity 2006: Assessing Cost-effectiveness of obesity interventions in children and adolescents Summary of results

(6) Dzator JA, Hendrie D, Burke V, Gianguilio N, Gillam HF, Beilin LJ, Houghton S, 2004: A randomized trial of interactive group sessions achieved greater improvements in nutrition and physical activity at a tiny increase in cost. Journal of Clinical Epidemiology 2004;57:610-619

(7) Goldfied GS, Epstein LH, Kilanowski CK, Paluch RA, Kogut-Bossler B, 2001: Cost-effectiveness of group and mixed family-based treatment for childhood obesity. International Journal of Obesity 2001; 25:1843-1849

(8) Dalziel K, Segal L, Mortimer D, 2005: Risk factor study: How to reduce the burden of harm from poor nutrition, tobacco smoking, physical inactivity and alcohol misuse: cost-utility analysis of 8 nutrition interventions. Center for Health Economics Research paper 2005(4) p. 90

(9) Dalziel K, Segal L, Mortimer D, 2005: Risk factor study: How to reduce the burden of harm from poor nutrition, tobacco smoking, physical inactivity and alcohol misuse: cost-utility analysis of 8 nutrition interventions. Center for Health Economics Research paper 2005(4) p. 4

(10) Olsen J, Willaing I, Ladelund S, Jørgensen T, Gundgaard J, Sørensen J, 2005: Cost-effectiveness of nutritional counselling for obese patients and patients at risk of ischemic heart disease. International Journal of Technology Assessment in Health Care 2005; 21(2):194-202

(11) Dalziel K, Segal L, Mortimer D, 2005: Risk factor study: How to reduce the burden of harm from poor nutrition, tobacco smoking, physical inactivity and alcohol misuse: cost-utility analysis of 4 
physical inactivity interventions. Center for Health Economics Research paper 2005(3) p. 4 [this reference is used twice]

(12) Elley R, Kerse N, Arroll B, Swinburn B, Ashton T, Robinson E, 2004: Cost-Effectiveness of physical counselling in general practice. The New Zealand Medical Journal. 2004 Dec;117(1207)

(13) Wang LY, Yang Q, Lowry R, Wechsler H, 2003: Economic Analysis of a school-based obesity prevention program. Obes Res. 2003;11:1313-1324

(14) Wang G, Macera CA, Scudder-Soucie B, Schmid T, Pratt M, Buchner D, 2004: Cost effectiveness of a bicycle/pedestrian trail development in health promotion. Preventive Medicine. 2004;38:237-242

(15) Saelesminde K, 2002: Walking and cycling track networks in Norwegian cities - Cost-benefit analyses including health effects and external costs of road traffic. TØI report 2002

(16) Rutter H, 2007: Valuing the benefits of cycling: A report to Cycling England. 2007 May

(17) Dalziel K, Segal L, Mortimer D, 2005: Risk factor study: How to reduce the burden of harm from poor nutrition, tobacco smoking, physical inactivity and alcohol misuse: cost-utility analysis of 8 nutrition interventions. Center for Health Economics Research paper 2005(4) p. 99

(18) Martin LF, Tan TL, Horn JR Bixler EO, Kauffman GL, Becker DA, Hunter SM, 1995: Comparison of the costs associated with medical and surgical treatment of obesity. Surgery. 1995;118:599-607

(19) Tsai AG, Glick HA, Shera D, Stern L, Samaha FF, 2005: Cost-effectiveness of a low-carbohydrate diet and a standard diet in severe obesity. Obesity Research. 2005 Oct;13(10)

(20) Hatziandreu EI, Koplan JP, Weinstein MC, Caspersen CJ, Warner KE, 1988: A cost-effectiveness analysis of exercise as a health promotion activity. Am J Public Health. 1988;78:1417-1421

(21) Latner JD, 2001: Self-help in the long-term treatment of obesity. Obesity Reviews. 2001;2:87-97

(22) Roux L, Kuntz KM, Donaldson C, Goldie SJ, 2006: Economic evaluation of weight loss interventions in overweight and obese women. Obesity. 2006 June;14(6):1093-1103

(23) Roux L, Pratt M, Tengs TO, Yore MM, Yanagawa TL, Van Den Bos J, Rutt C, Brownson RC, Powell KE, Heath G, Kohl HW 3rd, Teutsch S, Cawley J, Lee IM, West L, Buchner DM. Cost effectiveness of community-based physical activity interventions. Am J Prev Med. 2008 Dec;35(6):578-88.

(24) Nguyen HQ, Ackermann RT, Maciejewski M, Berke E, Patrick M, Williams B, LoGerfo JP. Managed-Medicare health club benefit and reduced health care costs among older adults. Prev Chronic Dis. 2008 Jan;5(1):A14. Epub 2007 Dec 15. 


\section{ANNEX 3. LIST OF ARTICLES AND PUBLICATIONS ON PARAMETERS OF THE EPIDEMIOLOGICAL MODEL}

Arrich J, Lalouschek W, Müllner M. Influence of socioeconomic status on mortality after stroke: retrospective cohort study. Stroke. 2005 Feb;36(2):310-4

Batty GD, Shipley MJ, Jarrett RJ, Breeze E, Marmot MG, Davey Smith G. Obesity and overweight in relation to disease-specific mortality in men with and without existing coronary heart disease in London: the original Whitehall study. Heart. 2006 Jul;92(7):886-92

Boshuizen HC, Lanti M, Menotti A, Moschandreas J, Tolonen H, Nissinen A, Nedeljkovic S, Kafatos A, Kromhout D. Effects of past and recent blood pressure and cholesterol level on coronary heart disease and stroke mortality, accounting for measurement error. American Journal of Epidemiology. 2007 Feb 15;165(4):398-409

Bull FC, Armstrong TP, Dixon T, Ham S, Neiman A, Pratt M. Physical inactivity. In: Ezzati M, Lopez AD, Rodgers A, Murray CJL. Comparative Quantification of Health Risks. Global and Regional Burden of Diseases Attributable to Selected Major Risk Factors. World Health Organization, Geneva, 2004

Calle EE, Rodriguez C, Walker-Thurmond K, Thun MJ. Overweight, obesity, and mortality from cancer in a prospectively studied cohort of U.S. adults. New England Journal of Medicine 2003 Apr 24;348(17):1625-38

FAOSTAT, http://faostat.fao.org. Accessed on 02/12/2008

Flegal KM, Graubard BI, Williamson DF. Cause-specific excess deaths associated with underweight, overweight, and obesity. The Journal of American Medical Association 2005,293(15):1861

Forssas EH, Keskimäki IT, Reunanen AR, Koskinen SV. Coronary heart disease among diabetic and nondiabetic people - socioeconomic differences in incidence, prognosis and mortality. Journal of diabetes and its complications. 2008 Jan-Feb;22(1):10-7

Haan M, Kaplan GA, Camacho T. Poverty and health. Prospective evidence from the Alameda County Study. American Journal of Epidemiology. 1987 Jun;125(6):989-98.

Hart CL, Hole DJ, Smith GD. Risk factors and 20-year stroke mortality in men and women in the Renfrew/Paisley study in Scotland. Stroke. 1999 Oct;30(10):1999-2007

Hart CL, Hole DJ, Smith GD. The contribution of risk factors to stroke differentials, by socioeconomic position in adulthood: the Renfrew/Paisley Study. American Journal of Public Health. 2000 Nov;90(11):1788-91

Hu G, Jousilahti P, Qiao Q, Katoh S, Tuomilehto J. Sex differences in cardiovascular and total mortality among diabetic and non-diabetic individuals with or without history of myocardial infarction. Diabetologia. 2005a May;48(5):856-61 
Hu G, Jousilahti P, Sarti C, Antikainen R, Tuomilehto J. The effect of diabetes and stroke at baseline and during follow-up on stroke mortality. Diabetologia. 2006 Oct;49(10):2309-16

Hu G, Sarti C, Jousilahti P, Peltonen M, Qiao Q, Antikainen R, Tuomilehto J. The impact of history of hypertension and type 2 diabetes at baseline on the incidence of stroke and stroke mortality. Stroke. 2005b Dec;36(12):2538-43

IARC/WHO. WHO Mortality database on cancer. 2008

Jakovljević D, Sarti C, Sivenius J, Torppa J, Mähönen M, Immonen-Räihä P, Kaarsalo E, Alhainen K, Kuulasmaa K, Tuomilehto J, Puska P, Salomaa V. Socioeconomic status and ischemic stroke: The FINMONICA Stroke Register. Stroke. 2001 Jul;32(7):1492-8

James WPT, Jackson-Leach R, Mhurchu CN, Kalamara E, Shayeghi M, Rigby NJ, Nishida C, Rodgers A. Overweight and Obesity (High body mass index). Ezzati M, Lopez AD, Rodgers A, Murray CJL. Comparative Quantification of Health Risks. Global and Regional Burden of Diseases Attributable to Selected Major Risk Factors. World Health Organization, Geneva, 2004

Jansen MC, Bueno-de-Mesquita HB, Buzina R, Fidanza F, Menotti A, Blackburn H, Nissinen AM, Kok FJ, Kromhout D. Dietary fiber and plant foods in relation to colorectal cancer mortality: the Seven Countries Study. International Journal of Cancer. 1999 Apr 12;81(2):174-9

Kaplan GA, Keil JE. Socioeconomic factors and cardiovascular disease: a review of the literature. Circulation 1993 Oct;88(4 Pt 1):1973-98

Kuper H, Adami HO, Theorell T, Weiderpass E. The socioeconomic gradient in the incidence of stroke: a prospective study in middle-aged women in Sweden. Stroke. 2007 Jan;38(1):27-33

Lawes CMM, Vander Horn S, Law MR, Elliot P, Mac Mahon S, Rodgers A. High blood pressure. in: Ezzati M, Lopez AD, Rodgers A, Murray CJL. Comparative Quantification of Health Risks. Global and Regional Burden of Diseases Attributable to Selected Major Risk Factors. World Healt Organization, Geneva, 2004a

Lawes CMM, Vander Horn S, Law MR, Rodgers A. High Cholesterol. in: Ezzati M, Lopez AD, Rodgers A, Murray CJL. Comparative Quantification of Health Risks. Global and Regional Burden of Diseases Attributable to Selected Major Risk Factors. World Health Organization, Geneva, 2004b

Lim SS, Gaziano TA, Gakidou E, Reddy KS, Farzadfar F, Lozano R, Rodgers A. Prevention of cardiovascular disease in high-risk individuals in low-income and middle-income countries: health effects and costs. Lancet. 2007 Dec 15;370(9604):2054-62.

Lock K, Pomerleau J, Causer L, McKee M. Low fruit and vegetable consumption. In: Ezzati M, Lopez AD, Rodgers A, Murray CJL. Comparative Quantification of Health Risks. Global and Regional Burden of Diseases Attributable to Selected Major Risk Factors. World Health Organization, Geneva, 2004

Lock K, Pomerleau J, Causer L, Altmann DR, McKee M. The global burden of disease attributable to low consumption of fruit and vegetables: implications for the global strategy on diet. Bulletin of the World Health Organization. 2005 Feb;83(2):100-8

Logue EE, Jarjoura D. Modeling heart disease mortality with census tract rates and social class mixtures. Social Science \& Medicine. 1990;31(5):545-50 
Lopez AD, Mathers CD, Ezzati M, Jamison DT, Murray CJL. Global Burden of Disease and risk factors.

Oxford University Press/the World Bank. New York, 2006

Mackenbach JP, Kunst AE, Cavelaars AE, Groenhof F, Geurts JJ. Socioeconomic inequalities in morbidity and mortality in western Europe. The EU Working Group on Socioeconomic Inequalities in Health. Lancet. 1997 Jun 7;349(9066):1655-9

Menotti A, Lanti M. Coronary risk factors predicting early and late coronary deaths. Heart. 2003 Jan;89(1):19-24

Pardo Silva MC, De Laet C, Nusselder WJ, Mamun AA, Peeters A. Adult obesity and number of years lived with and without cardiovascular disease. Obesity (Silver Spring). 2006 Jul;14(7):1264-73

Parkin DM, Whelan SL, Ferlay J, Storm H. Cancer Incidence in Five Continents, vol VIII updated. IARC CancerBase. Lyon, 2005

Pierce JP, Natarajan L, Caan BJ, Parker BA, Greenberg ER, Flatt SW, Rock CL, Kealey S, Al-Delaimy WK, Bardwell WA, Carlson RW, Emond JA, Faerber S, Gold EB, Hajek RA, Hollenbach K, Jones LA, Karanja N, Madlensky L, Marshall J, Newman VA, Ritenbaugh C, Thomson CA, Wasserman L, Stefanick ML. Influence of a diet very high in vegetables, fruit, and fiber and low in fat on prognosis following treatment for breast cancer: the Women's Healthy Eating and Living (WHEL) randomized trial. Journal of the American Medical Association. 2007 Jul 18;298(3):289-98

Ringback Weitoft G, Eliasson M, Rosen M. Underweight, overweight and obesity as risk factors for mortality and hospitalization. Scandinavian Journal of Public Health 2008,36(2):169-76

Skuladottir H, Tjoenneland A, Overvad K, Stripp C, Olsen JH. Does high intake of fruit and vegetables improve lung cancer survival? Lung Cancer 2006 Mar;51(3):267-73

Salomaa V, Niemelä M, Miettinen H, Ketonen M, Immonen-Räihä P, Koskinen S, Mähönen M, Lehto S, Vuorenmaa T, Palomäki P, Mustaniemi H, Kaarsalo E, Arstila M, Torppa J, Kuulasmaa K, Puska P, Pyörälä K, Tuomilehto J. Relationship of socioeconomic status to the incidence and prehospital, 28day, and 1-year mortality rates of acute coronary events in the FINMONICA myocardial infarction register study. Circulation 2000 Apr 25;101(16):1913-8

Stamler J, Daviglus ML, Garside DB, Dyer AR, Greenland P, Neaton JD. Relationship of baseline serum cholesterol levels in 3 large cohorts of younger men to long-term coronary, cardiovascular, and allcause mortality and to longevity. Journal of the American Medical Association. 2000;284(3):311318

Stevens RJ, Coleman RL, Adler AI, Stratton IM, Matthews DR, Holman RR. Risk factors for myocardial infarction case fatality and stroke case fatality in type 2 diabetes: UKPDS 66. Diabetes Care. 2004 Jan;27(1):201-7

van Baal PH, Polder JJ, de Wit GA, Hoogenveen RT, Feenstra TL, Boshuizen HC, Engelfriet PM, Brouwer WB. Lifetime medical costs of obesity: prevention no cure for increasing health expenditure. PLoS Medicine 2008 Feb;5(2):e29

van Loon AJ, Brug J, Goldbohm RA, van den Brandt PA. Differences in cancer incidence and mortality among socio-economic groups. Scandinavian Journal of Social Medicine. 1995 Jun;23(2):110-2 
Wannamethee SG, Shaper AG, Lennon L. Cardiovascular disease incidence and mortality in older men with diabetes and in men with coronary heart disease. Heart. 2004 Dec;90(12):1398-403

WHO-CHOICE website, www.who.int/choice. Accessed on 2/12/08

Wild S, Roglic G, Green A, Sicree R, King H. Global prevalence of diabetes: estimates for the year 2000 and projections for 2030. Diabetes Care. 2004 May;27(5):1047-53 


\section{ANNEX 4. STRUCTURE OF MICRO-SIMULATION MODEL FOR ECONOMIC ANALYSIS}

\section{Introduction}

149. The main features of the epidemiological model are described in the main text in section 2.2. In this annex, we describe in more detail the risk factors and diseases featuring in the CDP model. We also describe the basic conceptual structure (i.e. "assumptions") of the model. The definition of the risk factors, as well as the thresholds used to identify individuals at risk, is largely based on data provided by the WHO publication "Comparative quantification of health risks" (Ezzati et al., 2004).

\section{Detailed description of the causal web}

150. Figure A4.1 shows the overall structure of the CDP model and the interactions (represented by arrows) between risk factors and between risk factors and diseases.

151. There are a total of eight classes of risk factor. Three risk factors are associated with healthrelated behaviours (causally distal), one is linked with body mass (causally intermediate) and three are related to alterations in physiological parameters (causally proximal). Physical activity level and two dimensions of diet (levels of fat and fibre) are the distal risk factors. Body mass is the intermediate risk factor. The three proximal risk factors are levels of blood pressure, blood sugar (i.e. "diabetes") and blood cholesterol. Three diseases are modelled: stroke, ischaemic heart disease, and cancer (an aggregate category consisting of lung, colorectal and breast cancer).

152. For all risk factors and diseases, when no interaction is modelled, the risk factors/diseases are assumed to be independent. The causal web shown in Figure A4.1 can be further distinguished by analysing it in terms of its static and dynamic components.

\section{Static causal web}

153. The static component of the causal web refers to that part of the general causal web shown in Figure A4.1 that affects an individual's health state before model time begins, in other words, at initialization. The initialization of an individual's health state requires the assignment of starting values for all individual level variables: for example, sex, age and disease and risk factor status. For validity, the static component of the causal web must reproduce the observed population values of the modeled variables in cross section. This component of the web is called "static" because it determines the value of variables before model time is "turned on"; thus, it does not refer to the probability of an individual's making a (time-dependent) transition between risk factors (say, moving from a state of low socioeconomic status and high fibre diet to a state of low socioeconomic status and low fibre diet) but rather refers to the probability of an individual's having a given risk factor profile (e.g. low socioeconomic status and low fibre diet) at the start of model time.

154. The assignment of risk factor status at model initialization is done with reference both to the observed values of risk factor prevalence in the population as well as the assumptions used to specify the interactions in the static causal web. The assignment of risk factor status at initialization thus depends directly on the interaction relationships posited in static causal web. 
155. When enough of these interactions are quantitatively known, they, together with the observed values of risk factor prevalence in the population, completely determine the joint distribution of risk factors in all population subgroups. The static causal web, in other words, specifies the distribution of individuals across risk factor states at the start of model simulation.

156. The static causal web is represented here as a series of boxes denoting the risk factor states included in the model; static interactions are represented by arrows connecting the boxes (Figure A4.1). In the static causal web, the presence of an interaction is equivalent to saying that there is a relative risk, greater than (lesser than) 1, denoting the factor by which the probability is increased (decreased) of having, at the start of the simulation, both the condition depicted at the start of the arrow and the condition depicted at the end of the arrow denoting the interaction.

157. The observed values of population prevalence for the risk factors, together with the values of relative risk describing the interactions, which are usually obtained from epidemiological studies, specify a system of linear equations. When a sufficient number of parameters (relative risk and prevalence) are observed, the system of equations has a unique solution determining the joint distribution of the population across risk factor states at simulation start.

158. Notice that in Figure A4.1, interactions operate in a hierarchical fashion: socioeconomic status affects the probability of having a given fat diet, fibre diet and physical activity level at simulation start. These three risk factors in turn affect the probability of having a given body mass status at initialization. Body mass status in turn affects the probability of having a given level of blood sugar, blood pressure and cholesterol at time zero.

159. The values of an individual's risk factor variables are thus assigned starting values in accordance with the joint probability distribution found by solving the system of risk factor prevalences and relative risks.

\section{Dynamic causal web: risk factor transitions and disease events}

160. The dynamic causal web refers to interactions occurring during the simulation, in other words, interactions that affect the probability of an individual's making a transition between risk factor or disease states.

161. The dynamic causal web can be considered as consisting of two parts: one part reflecting interactions between various risk factors only and one part reflecting interactions between risk factors and disease events. This is not a substantive difference reflected in the technical aspects of model implementation, such as that between the static and dynamic causal web, but merely a conceptual distinction made for convenience.

\section{Risk factors}

162. The dynamic causal web for risk factors is depicted in Figure A4.2. Note that here the strict hierarchical principle no longer applies: for example, the level of fat diet affects both the probability of an individual's making a transition between levels of body mass as well as the probability of an individual's making a transition between levels of the proximal risk factor for blood sugar. Similarly, physical activity affects both transitions between levels of body mass and between levels of the proximal risk factors.

163. In CDP, dynamic effects between risk factors are, for simplicity, modelled by means of a single parameter for each of the distal risk factors for physical activity and fat diet. The use of a single parameter is equivalent to a claim that the effect (in relative terms) of, for example, the level of fat diet on transitions between levels of blood sugar, blood pressure and cholesterol is the same for each of the risk factors for 


\section{DELSA/HEA/WD/HWP(2009)6}

blood sugar, blood pressure and cholesterol. A further simplification is made which claims that the magnitude of the effect of this parameter on risk factor incidence, on the one hand, and risk factor remission, on the other, are multiplicative inverses. "Multiplicative inverse" means that, if "RR1" is the effect of the risk factor on incidence, the effect of that risk factor on remission is equal to $1 / R R 1$.

164. Also for the sake of simplicity, it is further assumed that the interaction between the effects of the two distal risk factors is multiplicative and exponential in levels of the risk factor. "Multiplicative" means that the effect of both the medium fat diet (e.g. RR1) and the low physical activity level (e.g. RR2) on the transition between, for example, bodymass levels, is assumed to be equal to RR1 x RR2. Moreover, "exponential in levels of the risk factor" means that the effect of the fat diet "high fat" is assumed to be equal to RR1 x RR1.

\section{Diseases}

165. The dynamic causal web assumed for the effect of risk factors on transitions to disease states is shown in Figure A4.3. In this figure, disease states are represented by rectangular boxes while risk factor states are represented by boxes with rounded corners.

166. Here again, a strict hierarchy of levels does not apply: the probability of a disease event (i.e. incidence, remission or fatality) for cancer is affected by both the distal risk factor for fibre diet as well as by the medial risk factor for body mass. Similarly, the probability of a disease event for stroke or for ischaemic heart disease is affected by all three proximal risk factors (blood sugar, blood pressure and cholesterol) as well as by the medial risk factor for body mass.

167. In contrast with the dynamic causal web for risk factors, the dynamic causal web for diseases allows for either a multiplicative or an additive interaction. As before, "multiplicative" means that the effect of both the medium fat diet (e.g. RR1) and the low physical activity level (e.g. RR2) on the incidence of, for example, stroke or ischaemic heart disease, is assumed to be equal to RR1 $x$ RR2. An "additive" interaction, however, means that the joint effect is assumed to be equal to RR1 + RR2 - 1 (which is equivalent to "additive in excess risk", where "excess risk" is equal to relative risk minus 1).

168. In general, far fewer parameters can be expected to be observed for the dynamic causal web than for the static causal web. In practice, only the magnitude of the interactions in the web (which are here called relative rates) will be known, as well as the total transition rate for the risk factor or disease (i.e. incidence, remission or mortality).

\section{Intervention analysis}

169. We consider interventions that act to improve population health status. In a typical intervention, it is assumed that the distribution of the population in the different risk factor subgroups is changed, i.e. from a "risky" distribution that may be currently observed to a "less risky", typically counterfactual, distribution. Implicit in this concept is the assumption that the transition rates for disease states corresponding to individual population subgroups defined by risk factor status are not themselves changed. Accordingly, an intervention lowers the total population disease rate by shifting the distribution of population from subgroups with higher disease rates to those with lower disease rates.

170. Indeed, the total population disease rate is merely the weighted average of the disease rates for the population subgroups, where the weights are the population prevalence rates for the different subgroups. A typical intervention thus achieves its effect by shifting the distribution of population between risk groups. 
171. In order to uniquely specify disease rates for each of the subgroups (whose size was previously determined by analysis of the static causal web), it is not in general enough to know merely the magnitude of the relative rates for each of the risk factors and the total population disease rate: additional information is typically required about how relative rates combine in joint risk groups. In the CDP model, this information comes in the form of an explicit assumption that relative rates combine either additively or multiplicatively for the joint risk groups. On the basis of one or the other such an assumption, it is possible to solve for a unique set of disease rates for all population subgroups, so long as the magnitude of the interactions (i.e. relative rates) is known and the total disease rate is also known.

Figure A4.1: The static causal web for risk factor prevalences implemented in the CDP model

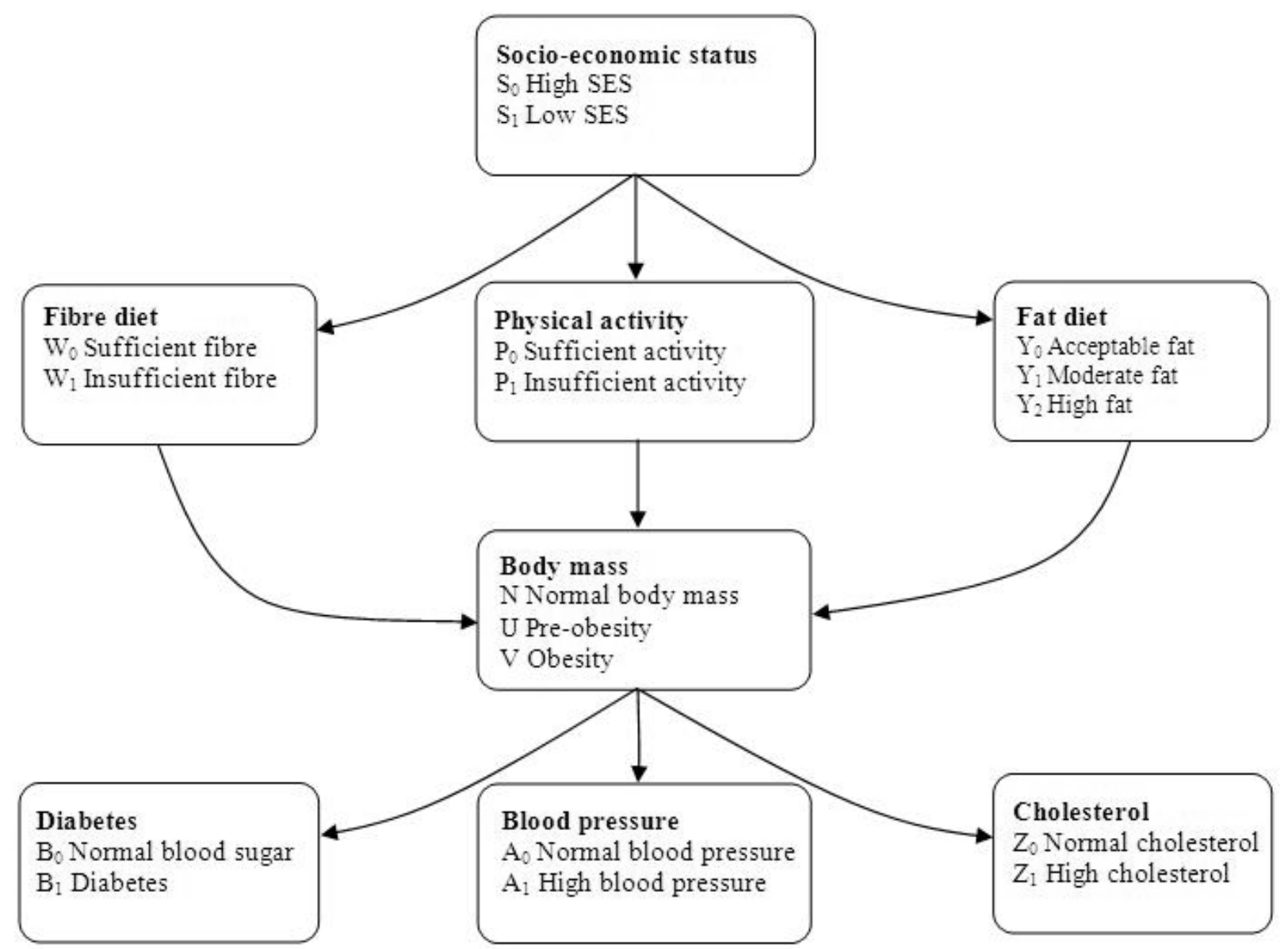


Figure A4.2: The dynamic causal web for risk factor transitions implemented in the CDP model .

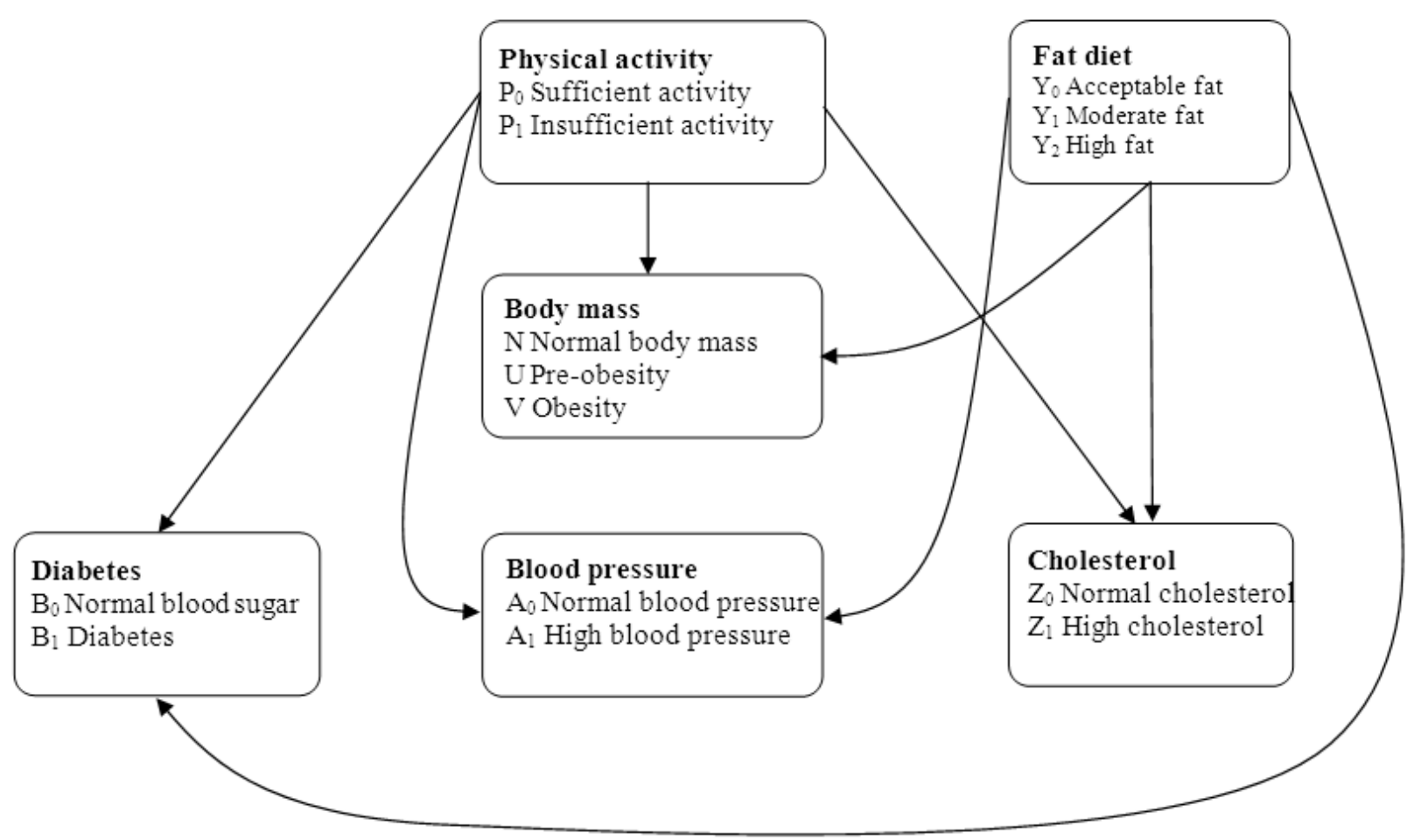


Figure A4.3: The dynamic causal web for disease events implemented in the CDP model .

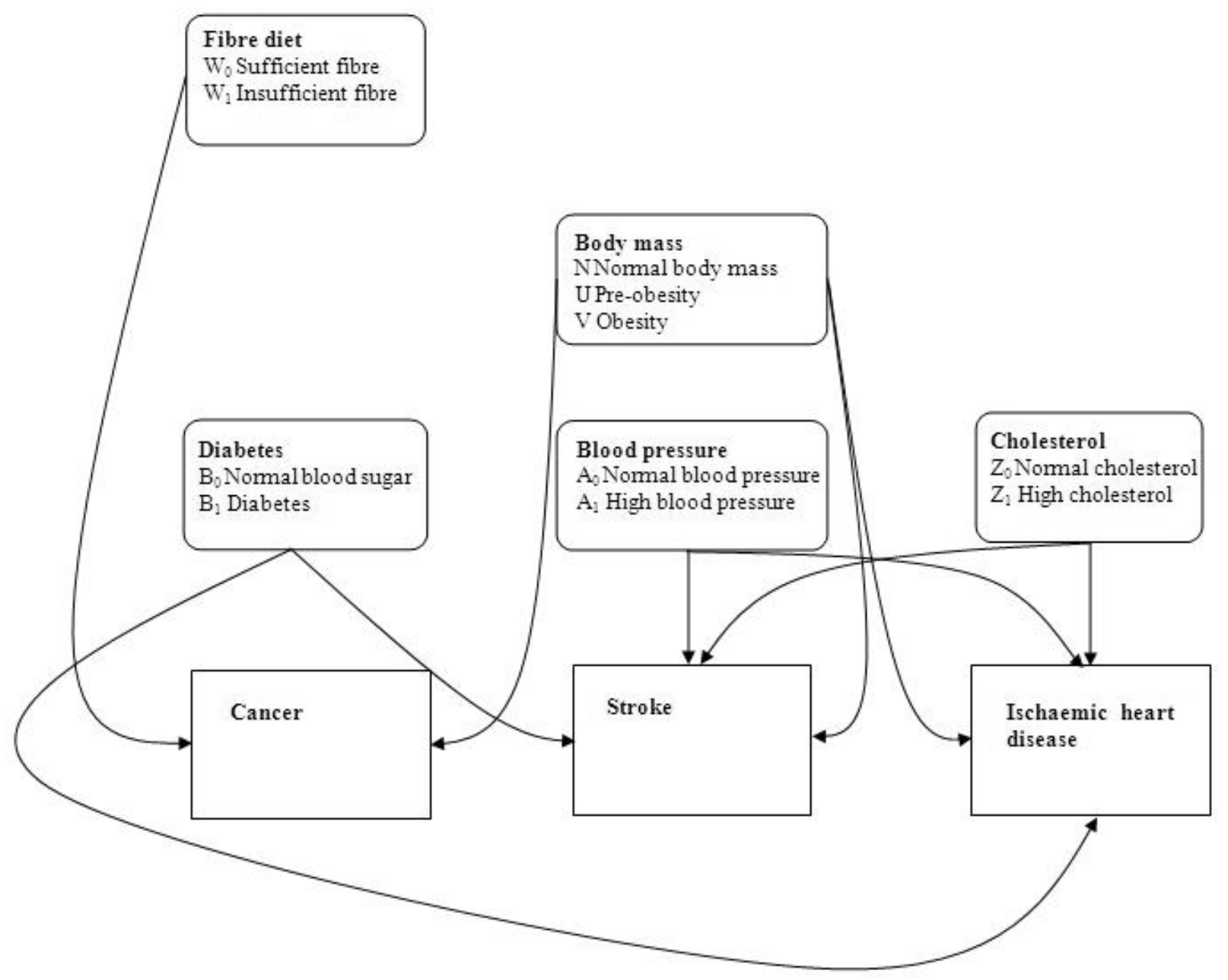




\section{ANNEX 5. EVIDENCE OF THE EFFECTIVENESS OF INTERVENTIONS}

172. The main source in our search for effectiveness evaluations was a comprehensive review undertaken by the WHO, published under the title of "Interventions on diet and physical activity: what works" (WHO, 2009). This is one of the outputs of the WHO global strategy on diet, physical activity \& health and is designed to provide a framework of "best practice" interventions for diet and physical activity, aimed at reducing risks of chronic non-communicable diseases. The studies included in the WHO review were identified through the following literature databases: Medline, Cochrane Library, Embase, National Research Register, HSRProj database, CDSR, CRD ongoing review-DARE, PsycINFO, restricting the year of publication between 1995 and (June) 2006. The studies identified evaluated group, community, or population level interventions, with an additional emphasis on disadvantaged settings. Studies of individual level interventions were not included, unless individual components were part of a population-based approach. In order to satisfy inclusion criteria, studies should have targeted apparently healthy adults and children or specific subpopulations at risk, such as overweight persons. However, not all of the effectiveness evidence used to model interventions (see section II) was derived from the above review. We retrieved and used a number of additional studies which were not covered in the review because of one or more of the following reasons: (i) they were published after June 2006; (ii) they were not indexed in the literature databases used in the above review; and, (iii) the relevant interventions were out of the scope of the review.

173. In order to facilitate comparisons across studies, we grouped interventions into the eight macroareas defined in the taxonomy of preventive interventions proposed in Sassi and Hurst (2008). These are: interventions on the broader economic and social environment; interventions on the physical environment and transport system; interventions on the work or school environment; interventions on the supply of lifestyle commodities; educational interventions; health sector interventions; interventions on social and community networks; interventions aimed at directly influencing lifestyle choices.

174. The reminder of this section will cover the main findings of our review. As in the section concerning the cost-effectiveness of interventions, we will present the different groups one by one, describing the common features shared by interventions in the same groups, target populations and key results.

175. In total, 108 interventions extrapolated from 152 studies were reviewed. Of these, 48 aimed at promoting dietary changes, 26 aimed at increasing physical activity and 32 adopted a combined approach. The numbers of interventions per area and domain are shown in Figure A5.2. Educational interventions are clearly the ones that have been investigated the most. However, this group may be divided into two subgroups based on different approaches. Part of the interventions involved only a strictly educational approach where individuals, either still in school or selected among the population are taught principles of healthy living or educated in how to improve their behaviours. Interventions in a second sub-group combined the approach previously described with environmental changes, such as improvements in the food served in local canteens. Distribution by country is heavily imbalanced: 66 studies $(61 \%)$ were undertaken in the US, 11 in the UK, 9 in Australia or New Zealand, 6 in Canada, 10 in other OECD countries. Finally, 6 studies were undertaken in developing countries. 
Figure A5.2. Numbers of interventions per area and domain

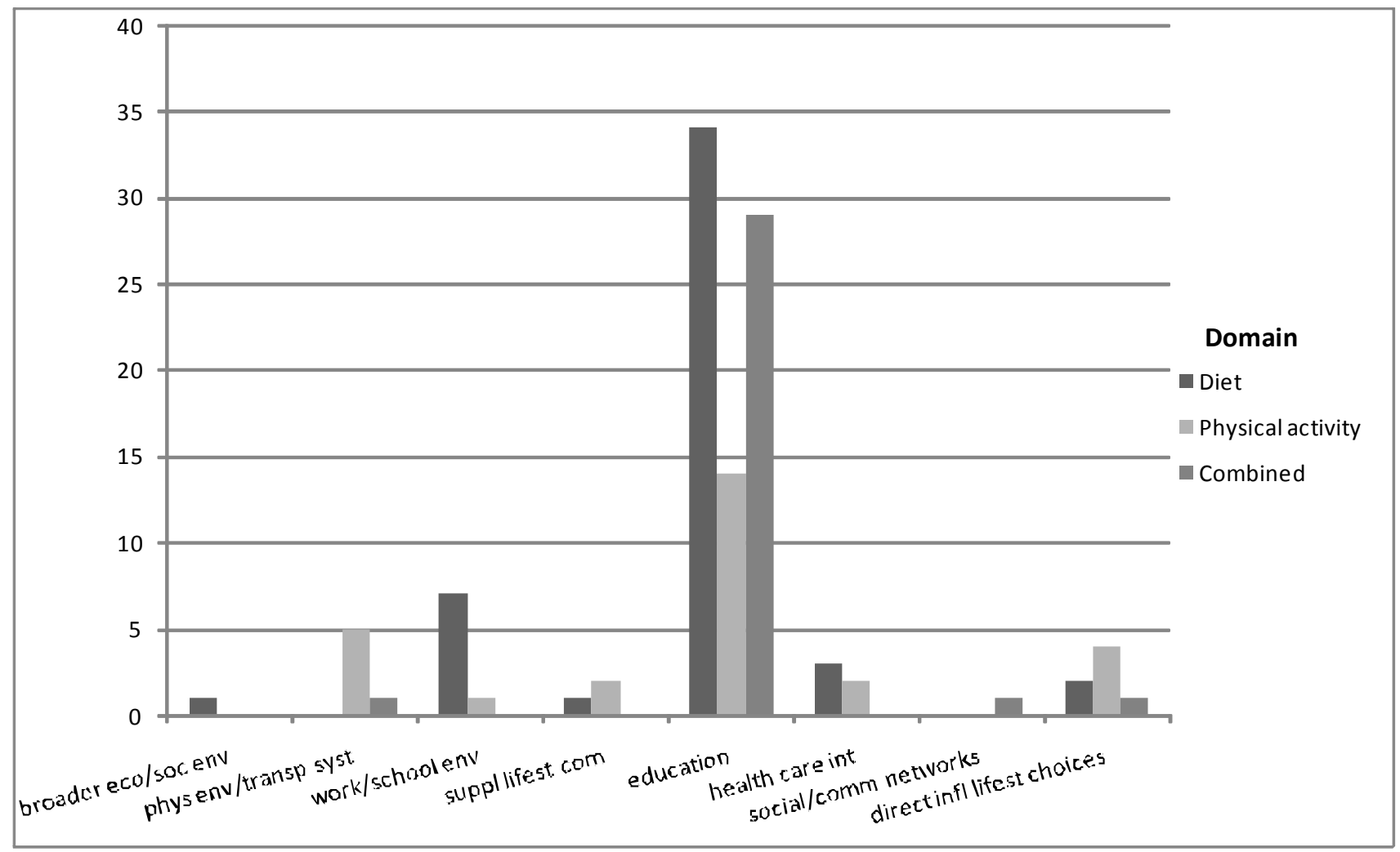

176. The group defined as "interventions on the broader economic and social environment" gathers all those interventions implying modification of policies at national (e.g. general fiscal policies) and international (e.g. international trade agreements) level. In the only study falling in this category we were able to find, researchers assessed the effects of a policy of free fruit and vegetables delivered at home for low income elderly. Results would suggest a significant increase in the number of servings eaten daily and a related $50 \%$ increase in the individuals eating at least five portions a day.

177. The group of interventions under the name "physical environment and transport system" includes policies undertaken by government offices at the national and local levels involving changes in aspects such as the urban environment, means of transportation, housing conditions. Most of the studies in this area focus on interventions aimed at increasing physical activity, for instance, by encouraging walking and cycling to work and to school, by increasing the safety of trails, or by organizing public events such as banning car circulation on certain roads during the week-ends. In general, the target of such interventions is not limited to any subgroup, but some studies focus their efforts on evaluating results in particular population groups such as employees or school children. Additionally, in no study the maximum age of individuals is set above the threshold of 69 years. Given the large number of individuals involved, studies usually report results as percentage variations in people doing exercise (e.g. after improving the safety of trails, children cycling to school increased by $114 \%$ ).

178. Seven interventions on diet and one intervention on physical activity fall in the category "interventions on the work or school environment". Investigations in this category involve a range of modifications of the work environment to facilitate healthier choices. Although most studies in this area assessed interventions which included an educational component, their primary outcomes were environmental changes. Interventions generally targeted workers, with some additionally focusing on subgroups such as males, low-income or sedentary individuals. In some cases, interventions targeted whole 
groups of individuals, while in other cases participation was voluntary and individuals were asked to sign up to specific programmes. An example of the latter is a study investigating the effects of the use of pedometers. Interventions are very different in their design and implementation. Most studies in this area investigated the effectiveness of improving the quality of food in terms of basic nutrients, or increasing the provision of healthy foods, for example fruit and vegetables, in canteens or cafeterias. In many cases, interventions were not just on food, but also on the environment in which the food was delivered. For example, in one experiment staff working in the canteen was taught how to better present food and posters showing the composition of a correct meal were displayed. Results are generally expressed in quantities of fruit and vegetables consumed or variations in sales of healthy foods. In three cases other parameters such as fat intake or BMI changes are reported.

179. The three interventions labelled as "supply of lifestyle commodities" work essentially by modifying the availability of certain commodities, access to some facilities, or the composition of food. Target populations and methods of intervention are very different according to the domains concerned. In the case of diet, the only study available investigated the effects of changing the composition of cooking oil involving a decrease in the intake of saturated fatty acids. In the case of physical activity, two studies report the effects of providing free access to physical activity sessions for seniors in different socioeconomic conditions. In terms of results, changing oil components would significantly decrease both cholesterol blood levels and the estimated intake of saturated fats in males and females, while granting free utilization of sports centres would result in a decrease in systolic blood pressure.

180. "Educational interventions" are by far the largest group. Most of the seventy-seven interventions falling into this category are addressed to students at different stages of their school education. A number of interventions in this group were aimed at increasing awareness of the benefits of healthy lifestyles in the general population, or in specific subgroups. About one third of the interventions evaluated, mainly those delivered in closed environments such as schools, adopted combined approaches associating education with environmental changes. The latter interventions are labelled in the table below as "education + interventions on the work or school environment". Target populations vary according to the approaches used. Interventions that were merely educational targeted broader groups of individuals, generally children older than six and adults, with some studies targeting specific sub-groups believed to be at risk, such as postmenopausal women or individuals in disadvantaged socioeconomic conditions. Combined interventions tended to target younger groups, even though a small number of interventions were still addressed to adults at work. Teaching is usually aimed at promoting healthy diets, or diet and physical activity, rather than physical activity alone. The approach is typically through individual or group sessions, more often school classes. In some cases, new forms of communication of health and lifestyle messages, such as telephone calls or multimedia campaigns, were compared to traditional methods such as booklets or newsletters. When environmental modifications are included, the latter include improvements in the direct provision of foods, or in access to facilities for physical activity.

181. Results are reported in different ways depending on selected objectives. In general three different types of results can be found: most of the studies assessed outcomes in terms of self-reported or measured variations in parameters used as proxies for a healthy life. Examples are numbers of servings of fruit and vegetables eaten in a day, minutes of physical activity undertaken, quantities of fibre or fat consumed, or calories spent. Some studies report changes in the level of physiological parameters such as blood cholesterol, BMI, weight, etc. Finally, some studies report differences in proportions of overweight or obese individuals.

182. At this stage, we chose to categorize in the "health care interventions" group only interventions delivered by health professionals. These generally target the adult population, and often consider groups at risk, for example individuals with high levels of cholesterol or relatives of people who experienced heart problems. Interventions usually involve an initial health check-up, in one case limited only to blood tests, 
followed by oral counselling and occasionally supported by written information. Results are generally expressed in terms of variations of physiological components of blood levels (e.g. cholesterol); additional outcomes reported in the studies include variations in BMI, blood pressure or variation in the intake of fruit and vegetables.

183. Only one intervention is labelled as "interventions on social and community networks". This is a multilevel intervention that, at least for a component, entailed community partnerships and involvement. Its main aim was to improve health behaviours through a combined approach. The target population was individuals older than nineteen years, without distinction. Results for this evaluation were not yet available.

184. The last group of interventions is "direct interventions on lifestyle choices". This class comprises interventions that try to directly influence choices for example by implementing policies inducing people towards healthier habits. These studies usually target the population in general with school students being the most represented. Interventions range from reducing the choice of calorie dense food in canteens to putting signs stating that the use of the stairs is more beneficial the elevator and inviting to do exercise. Results are generally expressed in terms of sale variation of food or number of individuals preferring the use the stairs.

185. As noted for the review of cost-effectiveness studies, educational interventions are the ones most often evaluated in the existing literature. A large number of the studies reviewed here focused on interventions taking place either in schools or workplaces. In fact, these two environments appear particularly suitable for the types of interventions examined in our review. Target populations are relatively small, easy to reach and to monitor. Unlike the cost-effectiveness studies review earlier in this paper, only few effectiveness studies focused on interventions delivered in general practice settings $(5 \%$ of the studies, compared with $26 \%$ of the cost-effectiveness analyses). 
DELSA/HEA/WD/HWP(2009)6

\begin{tabular}{|c|c|c|c|c|c|c|}
\hline OECD class & Domain & Country & Intervention and description & $\begin{array}{l}\text { Intervention } \\
\text { Length } / \\
\text { Follow-up } \\
\text { length } \\
\end{array}$ & Results & Target population \\
\hline $\begin{array}{l}\text { Intervention on the broader } \\
\text { economic and social } \\
\text { environment }\end{array}$ & Diet & US & $\begin{array}{l}\text { policy of free fruit/vegetable at } \\
\text { home }\end{array}$ & $22 / 0$ & $\begin{array}{l}\text { increase of } 1.04 \text { servings of fruit/veg, } \% \text { of elderly having }>5 \\
\text { servings a day from } 22 \% \text { to } 39 \%\end{array}$ & low income seniors \\
\hline $\begin{array}{l}\text { Intervention on the physical } \\
\text { environment and transport } \\
\text { system }\end{array}$ & $\begin{array}{l}\text { Physical } \\
\text { activity }\end{array}$ & US & $\begin{array}{l}\text { evaluation of the use of walking } \\
\text { trials }\end{array}$ & $-/-$ & beneficial in promoting PA in some groups & gen pop \\
\hline $\begin{array}{l}\text { Intervention on the physical } \\
\text { environment and transport } \\
\text { system }\end{array}$ & $\begin{array}{l}\text { Physical } \\
\text { activity }\end{array}$ & Colombia & influence on PA of sport events & $-/-$ & $\begin{array}{l}\text { women who participate in ciclovia are } 7 \text { times more likely to be } \\
\text { physically active }\end{array}$ & women 18-69 \\
\hline $\begin{array}{l}\text { Intervention on the physical } \\
\text { environment and transport } \\
\text { system }\end{array}$ & $\begin{array}{l}\text { Physical } \\
\text { activity }\end{array}$ & Finland & $\begin{array}{l}\text { evaluation of the benefits of } \\
\text { walking/biking to work }\end{array}$ & $20 / 0$ & $\begin{array}{l}\text { VO2 max }+4.5 \% \text {, cycle time }+10.5 \%, \mathrm{HDL}+5 \% \text {; heart rate }- \\
2.5 \% \text { compared to control }\end{array}$ & employee \\
\hline $\begin{array}{l}\text { Intervention on the physical } \\
\text { environment and transport } \\
\text { system }\end{array}$ & $\begin{array}{l}\text { Physical } \\
\text { activity }\end{array}$ & US & $\begin{array}{l}\text { improving safety in walk/cycle } \\
\text { trials }\end{array}$ & $104 /-$ & $\begin{array}{l}\text { number of students walking }+64 \% \text {, biking }+114 \% \text {, car use }- \\
39 \% \text {, carpooling }+91 \%\end{array}$ & school pupils \\
\hline $\begin{array}{l}\text { Intervention on the physical } \\
\text { environment and transport } \\
\text { system }\end{array}$ & $\begin{array}{l}\text { Physical } \\
\text { activity }\end{array}$ & Australia & $\begin{array}{l}\text { organization of community walking } \\
\text { events, campaign on PA, } \\
\text { multimedia }\end{array}$ & $104 /-$ & inactive women decreased (22\% vs. $15 \%)$ & $20-50$ y old women \\
\hline $\begin{array}{l}\text { Intervention on the physical } \\
\text { environment and transport } \\
\text { system }\end{array}$ & Combined & US & $\begin{array}{l}\text { funding the establishment of } \\
\text { community garden }\end{array}$ & $-/ 0$ & fruit/veg +0.34 servings/day, PA +0.3 sessions/week & gen pop \\
\hline $\begin{array}{l}\text { Interventions on the work, or } \\
\text { school, environment }\end{array}$ & Diet & US & $\begin{array}{l}\text { education }+ \text { multimedia }+ \\
\text { environment modification }\end{array}$ & $52 / 52$ & $\begin{array}{l}\text { fruit/veg intake }+0.3 \text { servings/day total, }+0.16 \text { servings/day in } \\
\text { cafeterias }\end{array}$ & workers \\
\hline $\begin{array}{l}\text { Interventions on the work, or } \\
\text { school, environment }\end{array}$ & Diet & Belgium & $\begin{array}{l}\text { education + multimedia + } \\
\text { environment modification }\end{array}$ & $13 /-$ & $\begin{array}{l}\text { BMI +0.258, energy intake }-142 \mathrm{Kcal} / \text { day, cholesterol intake - } \\
16.5 \mathrm{mg} / \mathrm{day}\end{array}$ & male workers \\
\hline $\begin{array}{l}\text { Interventions on the work, or } \\
\text { school, environment }\end{array}$ & Diet & Denmark & $\begin{array}{l}\text { canteen staff better present } \\
\text { fruits/vegetables }\end{array}$ & $34 / 17$ & average increase $95 \mathrm{~g} /$ customer of fruit/veg & workers \\
\hline $\begin{array}{l}\text { Interventions on the work, or } \\
\text { school, environment }\end{array}$ & Diet & US & $\begin{array}{l}\text { prevention + environmental } \\
\text { changes + education vs. } \\
\text { education + multimedia vs. family } \\
\text { involvement }\end{array}$ & $86 /-$ & fruit/veg intake $+19 \%$ in group $3,+7 \%$ in group 2 & low-income workers \\
\hline $\begin{array}{l}\text { Interventions on the work, or } \\
\text { school, environment }\end{array}$ & Diet & US & $\begin{array}{l}\text { education + environment } \\
\text { modification }\end{array}$ & $104 /-$ & $\begin{array}{l}\text { energy from fat }-2.3 \% \mathrm{Kcal} \text { vs. }-1.5 \% \text { in control, fruit/veg intake } \\
+10 \% \text { vs. }+4 \% \text { in control }\end{array}$ & workers \\
\hline $\begin{array}{l}\text { Interventions on the work, or } \\
\text { school, environment }\end{array}$ & Diet & US & $\begin{array}{l}\text { environmental mod at work vs. } \\
\text { peer groups }\end{array}$ & $77 / 26$ & fruit/veg intake +0.41 servings/day & low-income workers \\
\hline $\begin{array}{l}\text { Interventions on the work, or } \\
\text { school, environment }\end{array}$ & Diet & US & $\begin{array}{l}\text { education + environment } \\
\text { modification }\end{array}$ & $104 /-$ & $\begin{array}{l}\text { energy from fat }-0.37 \% \text { Kcal, fiber intake }+0.13 \mathrm{~g} / 1000 \mathrm{Kcal} \text {, } \\
\text { fruit/veg intake }+0.18 \mathrm{serv} / \text { day }\end{array}$ & workers \\
\hline $\begin{array}{l}\text { Interventions on the work, or } \\
\text { school, environment }\end{array}$ & $\begin{array}{c}\text { Physical } \\
\text { activity }\end{array}$ & Canada & use of a pedometer + education & $12 /-$ & decrease BMI, weight, heart rate, +3451 steps/day & sedentary workers \\
\hline $\begin{array}{l}\text { Interventions on supply of } \\
\text { lifestyle commodities }\end{array}$ & Diet & Mauritius & $\begin{array}{l}\text { reduction palm oil and increase } \\
\text { soy oil }\end{array}$ & $260 / 0$ & $\begin{array}{l}\text { total cholesterol fell by } 0.79 \mathrm{mmol} / \mathrm{L} \text { in men } \& 0.82 \text { in women } \\
(p<0.001) \text {. Estimated intake of saturated fats decreased by } \\
3.5 \% \& 3.6 \% \text { in men \& women, respectively }\end{array}$ & gen pop \\
\hline
\end{tabular}


DELSA/HEA/WD/HWP(2009)6

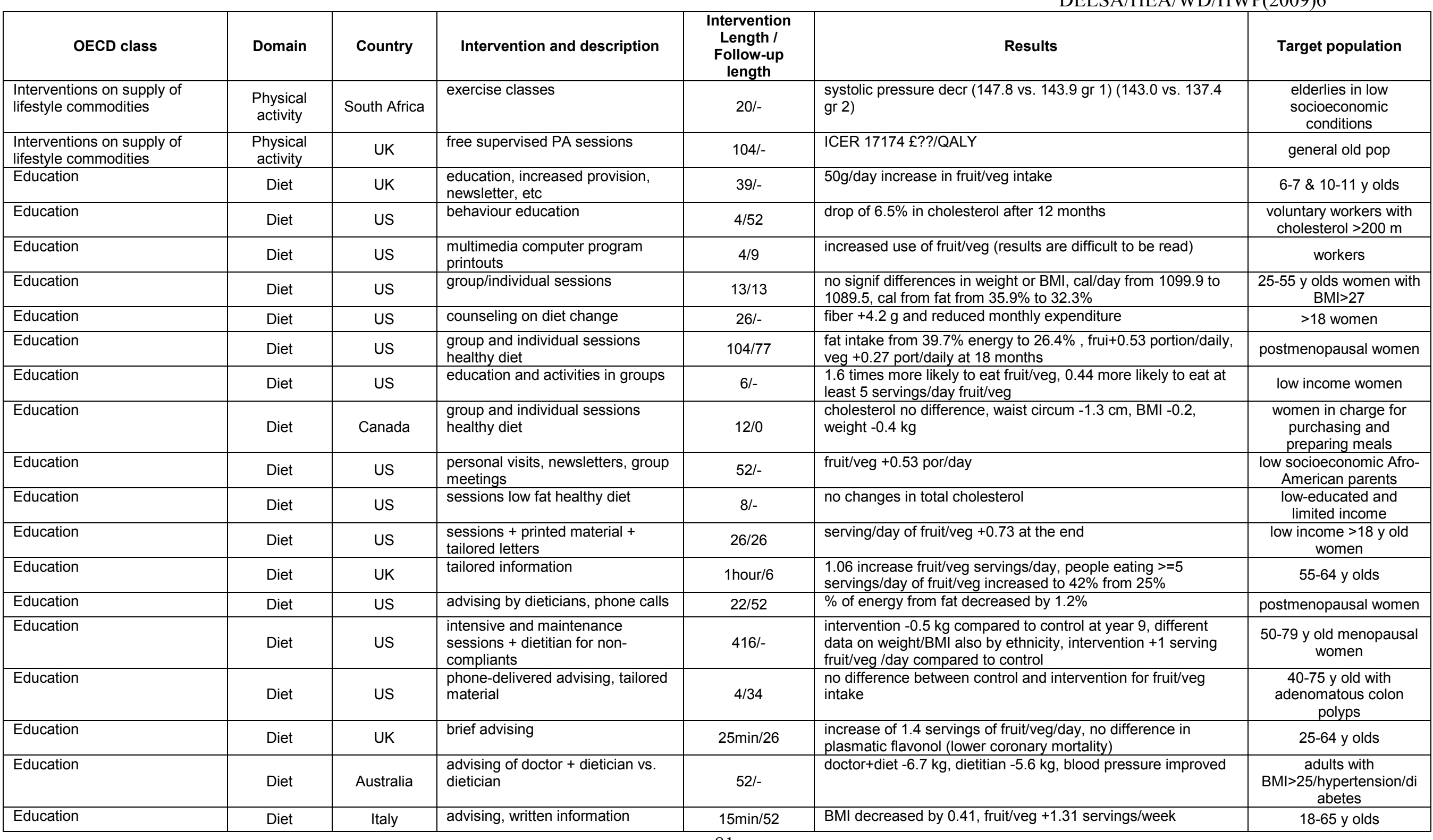


DELSA/HEA/WD/HWP(2009)6

\begin{tabular}{|c|c|c|c|c|c|c|}
\hline OECD class & Domain & Country & Intervention and description & $\begin{array}{l}\text { Intervention } \\
\text { Length / } \\
\text { Follow-up } \\
\text { length }\end{array}$ & Results & Target population \\
\hline Education & Diet & US & $\begin{array}{l}\text { counseling end of a service on } \\
\text { cancer+ mails }\end{array}$ & $2 / 52$ & 0.43 servings/day at 12 months & $\begin{array}{l}>18 \text { y olds calling the } \\
\text { cancer information } \\
\text { service }\end{array}$ \\
\hline Education & Diet & US & $\begin{array}{l}\text { partially computer-assisted } \\
\text { sessions +telephone contacts }\end{array}$ & $6-9 / 52$ & $\begin{array}{l}\text { non-signif change in cholesterol, self-reported fruit/veg }+0.93 \\
\text { por/day compared to control, fat intake }-16 \mathrm{~g} / \text { day }\end{array}$ & 40-70 y old women \\
\hline Education & Diet & US & $\begin{array}{l}\text { intensive and maintenance } \\
\text { sessions + dietician for non- } \\
\text { compliants }\end{array}$ & $416 /-$ & $\begin{array}{l}\text { intervention reduced fat by } 24.3 \mathrm{~g} / \mathrm{day} \text { compared to control: } 9.1 \\
\mathrm{~g} \text { from added fat, } 4.6 \mathrm{~g} \text { from meat and } 3.9 \text { from dessert; } \\
\text { patterns for different ethnicities }\end{array}$ & $\begin{array}{l}50-79 \text { y old menopausal } \\
\text { women }\end{array}$ \\
\hline Education & Diet & US & $\begin{array}{l}\text { personalised mails, phone } \\
\text { advising }\end{array}$ & $4 / 52$ & improvement in fat and fiber intake & $\begin{array}{l}\text { low socioeconomic low } \\
\text { education adults }\end{array}$ \\
\hline Education & Diet & UK & $\begin{array}{l}\text { individual nurse advising, phone } \\
\text { follow-up, mail material }\end{array}$ & $26 /-$ & $\begin{array}{l}\text { fruit/veg }+1.4 \mathrm{por} / \text { day, total cholesterol }-0.018 \mathrm{mmol} / \mathrm{l} \text {,blood } \\
\text { pressure }-2 \mathrm{mmHg}\end{array}$ & $25-64$ y olds \\
\hline Education & Diet & UK & nurse advising & $2 / 52$ & $\begin{array}{l}\text { no differences in BMI, cholesterol, blood pressure, }+1.5 \\
\text { fruit/veg portions/day, }+42 \% \text { people eating } 5 \text { portions } / \text { day }\end{array}$ & low income adults \\
\hline Education & Diet & US & written personalized counseling & $13 / 9$ & interv gr increased fruit/veg intake of 0.6 compared to control & $>18$ y olds \\
\hline Education & $\begin{array}{l}\text { Physical } \\
\text { activity }\end{array}$ & Brazil & multimedia campaign & 208/- & people knowing the healthy message are more active & $\begin{array}{l}\text { gen pop with focus on } \\
\text { students, collars and } \\
\text { elderly }\end{array}$ \\
\hline Education & $\begin{array}{l}\text { Physical } \\
\text { activity }\end{array}$ & Brazil & multimedia campaign walk & $416 /-$ & cost saving (but do not state the comparison) & student and gen pop \\
\hline Education & $\begin{array}{l}\text { Physical } \\
\text { activity }\end{array}$ & $\begin{array}{c}\text { New } \\
\text { Zealand }\end{array}$ & multimedia campaign PA & $260 /-$ & $\begin{array}{l}\text { no changes in PA level, 1999:38.6\% active, 2000:44.5\%, } \\
2002: 38.0 \%\end{array}$ & gen pop \\
\hline Education & $\begin{array}{l}\text { Physical } \\
\text { activity }\end{array}$ & Australia & $\begin{array}{l}\text { TV/magazine campaign regular } \\
\text { exercise }\end{array}$ & $17 / 0$ & $\begin{array}{l}\text { target group recalling the media campaign was } 2.08 \text { times } \\
\text { more likely to increase its PA }\end{array}$ & $\begin{array}{c}25-60 \text { year olds } \\
\text { motivated but } \\
\text { insufficiently active }\end{array}$ \\
\hline Education & $\begin{array}{l}\text { Physical } \\
\text { activity }\end{array}$ & Canada & $\begin{array}{l}\text { campaign: walk and use of } \\
\text { pedometer }\end{array}$ & $52 /-$ & $\begin{array}{l}\text { awareness of the campaign was associated with a } 13 \% \text { higher } \\
\text { odds of sufficient level of weekly walking }\end{array}$ & $>18$ y olds \\
\hline Education & $\begin{array}{l}\text { Physical } \\
\text { activity }\end{array}$ & US & $\begin{array}{l}\text { multimedia campaign to be more } \\
\text { PA }\end{array}$ & $52 /-$ & $\begin{array}{l}\text { significant relationship between awareness of the message } \\
\text { and PA }+34 \% \text {, high effect in at-risk group (low baseline) }\end{array}$ & $9-13$ y olds \\
\hline Education & $\begin{array}{l}\text { Physical } \\
\text { activity }\end{array}$ & US & $\begin{array}{l}\text { campaign to promote } 30 \text { min daily } \\
\text { walking }\end{array}$ & $8 / 0$ & $\begin{array}{l}23 \% \text { increase in walkers, } 32 \% \text { increase of the baseline } \\
\text { sedentary pop meeting the recommendation }\end{array}$ & sedentary $50-65$ y olds \\
\hline Education & $\begin{array}{l}\text { Physical } \\
\text { activity }\end{array}$ & US & $\begin{array}{l}\text { campaign to promote } 30 \text { min daily } \\
\text { walking }\end{array}$ & $8 / 4$ & $\begin{array}{l}16 \% \text { from non-active to active (non-signif compared to control), } \\
47 \% \text { increased total walking time (significant compared) }\end{array}$ & sedentary $40-65$ y olds \\
\hline Education & $\begin{array}{l}\text { Physical } \\
\text { activity }\end{array}$ & US & advising before a routine visit & $5 \mathrm{~min} / 5$ & $52 \%$ adopted regular activity, $37 \mathrm{~min} /$ week increase in walking & $\begin{array}{l}>18 \text { y old sedentary } \\
\text { patients }\end{array}$ \\
\hline Education & $\begin{array}{l}\text { Physical } \\
\text { activity }\end{array}$ & US & $\begin{array}{l}\text { counseling educational material }+ \\
\text { phone calls }\end{array}$ & $13 / 26$ & increased amount of PA measured as a score & $\begin{array}{l}20-64 \text { y olds exercising } \\
<15 \mathrm{~min} / \text { day }\end{array}$ \\
\hline Education & $\begin{array}{l}\text { Physical } \\
\text { activity }\end{array}$ & US & $\begin{array}{l}\text { personalised counseling, fitness } \\
\text { program }\end{array}$ & $52 /-$ & $\%$ of inactive decreased (38 vs. 56 ) & older people \\
\hline
\end{tabular}


DELSA/HEA/WD/HWP(2009)6

\begin{tabular}{|c|c|c|c|c|c|c|}
\hline OECD class & Domain & Country & Intervention and description & $\begin{array}{l}\text { Intervention } \\
\text { Length } / \\
\text { Follow-up } \\
\text { length } \\
\end{array}$ & Results & Target population \\
\hline & activity & & newsletter, phone calls & & & people \\
\hline Education & Combined & US & counseling nurse behaviour & $26 / 26$ & $\begin{array}{l}\text { cholesterol decreased by } 11.5 \mathrm{mg} / \mathrm{dl} \text {, systolic blood pressure } \\
\text { by } 3.6 \mathrm{mmHg} \text {, BMl by } 0.5 \text {, weight by } 2.8 \mathrm{lb} \text { at } 12 \text { month, \% } \\
\text { active increased by } 5.9 \% \text { at } 7 \text { months. Values no significative } \\
\text { compared to control }\end{array}$ & $\begin{array}{l}>50 \text { y old low income } \\
\text { women with at least } 1 \\
\text { CVD risk factor }\end{array}$ \\
\hline Education & Combined & UK & TV campaign with booklet & $7 / 13$ & $\begin{array}{l}\text { awareness of the campaign was high in all socio-econ groups, } \\
\text { memory for the message was poorer in those with lower level } \\
\text { of edu and ethnic minority }\end{array}$ & $\begin{array}{l}\text { gen pop with focus on } \\
\text { overw/obese }\end{array}$ \\
\hline Education & Combined & UK & lessons & $20 /-$ & $\begin{array}{l}\text { no changes in overweight/obesity, increase in consumption of } \\
\text { fruit/veg }\end{array}$ & $5-7$ y olds \\
\hline Education & Combined & US & $\begin{array}{l}\text { multimedia, information } \\
\text { distribution, group sessions \& } \\
\text { interactive activity }\end{array}$ & $130 /-$ & increase in fruit/veg intake no in fat\%; increase in exercising & workers \\
\hline Education & Combined & US & $\begin{array}{l}\text { encouragements to change } \\
\text { behaviours, activity }\end{array}$ & $12 /-$ & $\begin{array}{l}62 \% \text { reported weight loss, } 50 \% \text { increased fruit/veg cons, } 40 \% \\
\text { decreased TV view }\end{array}$ & volunteer workers \\
\hline Education & Combined & US & counseling, interactive sessions & $12 /-$ & $\begin{array}{l}\text { increase in fast walking ( } 108.9 \mathrm{~min} / \text { week vs. } 77.5) \text {, mod walk } \\
\text { (138.1 min vs. } 73.7) \text {. Decr soda servings/week (2.6 vs. } 1.4)\end{array}$ & $\begin{array}{c}\text { gen pop (high \% } \\
\text { Spanish) }\end{array}$ \\
\hline Education & Combined & US & $\begin{array}{l}\text { workbook vs. workbook+comp vs. } \\
\text { work+comp+staff }\end{array}$ & $52 /-$ & $\begin{array}{l}\text { weight }-2.2,-4.7,-7.4 \mathrm{lb} \text { at } 1 \text { year, BMl }-0.4-0.9-1.2 \text {, self-rep } \\
\text { calories }-398-283-324, \% \text { kcal from fat }-4.3-2.9-4.4 \text {, blocks } \\
\text { walked/day }+5.9+5.1+3.9\end{array}$ & adults with $\mathrm{BMI}>25$ \\
\hline Education & Combined & US & education course & $4 / 0$ & $\begin{array}{l}\text { weight }-7.9 \mathrm{lb} \text {, women }-6.4 \mathrm{lb}, \mathrm{LDL}-19.1 \text { men, women }-10 \text {, also } \\
\text { others parameters decreased }\end{array}$ & $\begin{array}{l}\text { upper-middle class }>40 \\
\text { y olds with risk of CAD }\end{array}$ \\
\hline Education & Combined & Australia & $\begin{array}{l}\text { mail information vs. } 1 / 2 \text { mail+1/2 } \\
\text { group vs. nothing }\end{array}$ & $17 / 52$ & no sign differ in BMI, LDL fell signif, HDL did not change & $\begin{array}{l}\text { couples living together } \\
\text { for less than } 2 \text { ys }\end{array}$ \\
\hline Education & Combined & US & $\begin{array}{l}\text { sessions on healthy behavior, diet } \\
\text { plan }\end{array}$ & 260/- & $\begin{array}{l}\text { at } 54 \text { months: weight decreased by } 0.2 \mathrm{lb} \text { vs. increase by } 5.2 \mathrm{lb} \\
\text { in control, LDL increased by } 3.5 \mathrm{mg} / \mathrm{dl} \text { vs. } 8.9 \text { in control, } \\
\text { triglycerides and glucose increased more in the control }\end{array}$ & $\begin{array}{l}44-50 \text { y old } \\
\text { premenopausal women }\end{array}$ \\
\hline Education & Combined & $\begin{array}{l}\text { New } \\
\text { Zealand }\end{array}$ & $\begin{array}{l}\text { oral advising+phone } \\
\text { calls+newsletter on PA }\end{array}$ & $52 /-$ & $\begin{array}{l}\text { mean tot energy expenditure increased by } 9.4 \mathrm{Kcal} / \mathrm{kg} / \text { week } \\
\text { and leisure exercise by } 34 \mathrm{~min} / \text { week more in intervention than } \\
\text { control, no difference in blood pressure }\end{array}$ & $40-79$ y olds \\
\hline $\begin{array}{l}\text { Education }+ \text { Interventions on } \\
\text { the work, or school, } \\
\text { environment }\end{array}$ & Diet & Sweden & $\begin{array}{l}\text { environment modification (fish in } \\
\text { schools) }\end{array}$ & $52 /-$ & increased consumption of fish & $14 \mathrm{y}$ olds \\
\hline $\begin{array}{l}\text { Education + Interventions on } \\
\text { the work, or school, }\end{array}$ & Diet & US & $\begin{array}{l}\text { environment, newsletters, } \\
\text { education }\end{array}$ & $104 /-$ & no stat difference & students \\
\hline
\end{tabular}


DELSA/HEA/WD/HWP(2009)6

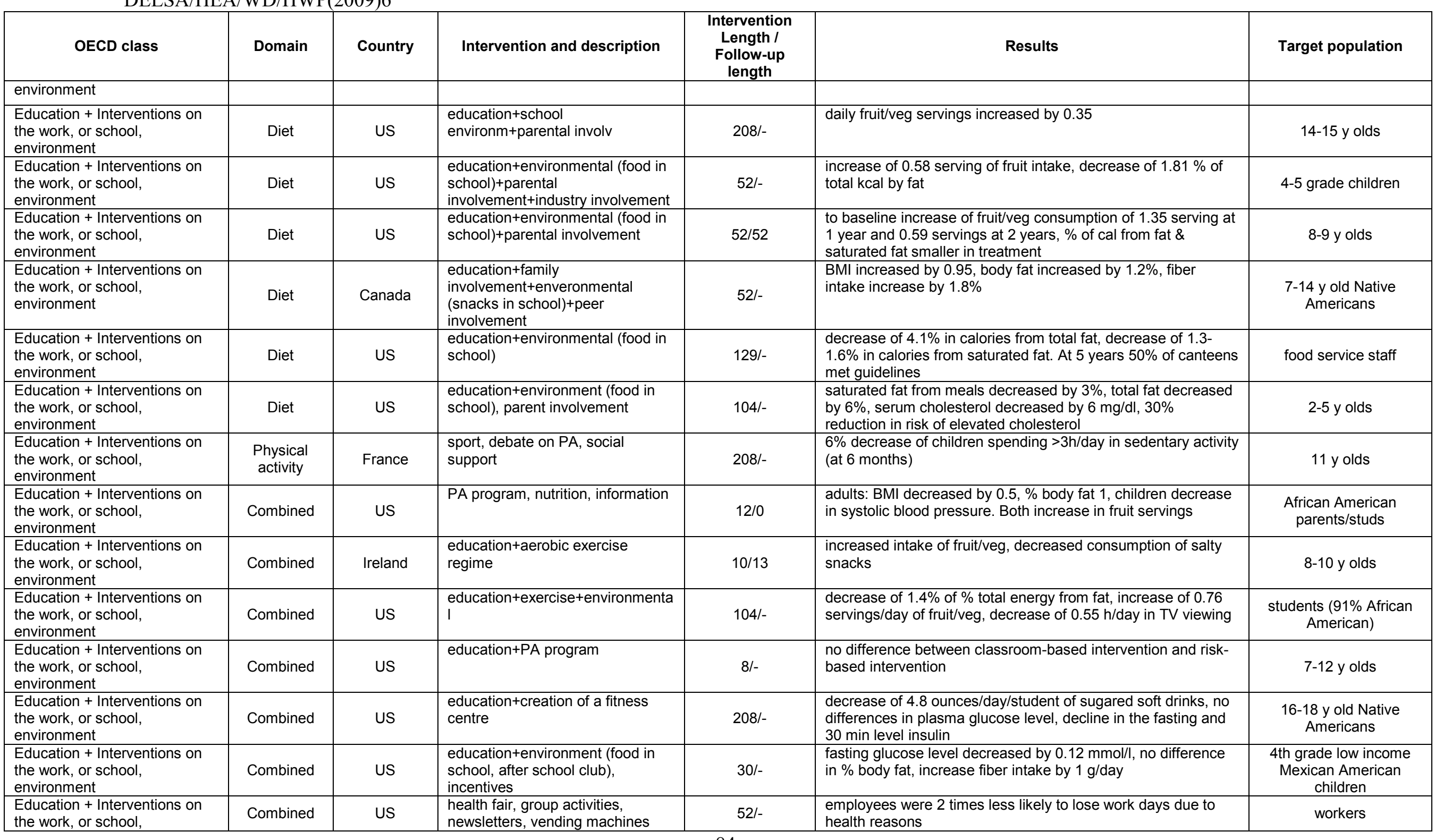


DELSA/HEA/WD/HWP(2009)6

\begin{tabular}{|c|c|c|c|c|c|c|}
\hline OECD class & Domain & Country & Intervention and description & $\begin{array}{l}\text { Intervention } \\
\text { Length } / \\
\text { Follow-up } \\
\text { length } \\
\end{array}$ & Results & Target population \\
\hline \multicolumn{7}{|l|}{ environment } \\
\hline $\begin{array}{l}\text { Education + Interventions on } \\
\text { the work, or school, } \\
\text { environment }\end{array}$ & Combined & US & education and activity & $11 /-$ & $\begin{array}{l}\text { cholesterol decreases of } 16 \mathrm{mg} / \mathrm{dl} \text { and } 5 \text { point increase in } \\
\text { fitness (VO2 max) in females, no stat sign in males }\end{array}$ & students \\
\hline $\begin{array}{l}\text { Education + Interventions on } \\
\text { the work, or school, } \\
\text { environment }\end{array}$ & Combined & Canada & $\begin{array}{l}\text { education+community } \\
\text { activities+mass } \\
\text { media+environmental (food in } \\
\text { school) }\end{array}$ & $416 /-$ & $\begin{array}{l}\text { no substantial differences in BMI and TV watching. Decrease } \\
\text { in fruit/veg intake }\end{array}$ & $6-11$ y old aboriginals \\
\hline $\begin{array}{l}\text { Education + Interventions on } \\
\text { the work, or school, } \\
\text { environment }\end{array}$ & Combined & UK & $\begin{array}{l}\text { education+PA } \\
\text { program+environment (food in } \\
\text { school) }\end{array}$ & $52 /-$ & no signif results & $7-11$ y olds \\
\hline $\begin{array}{l}\text { Education + Interventions on } \\
\text { the work, or school, } \\
\text { environment }\end{array}$ & Combined & US & $\begin{array}{l}\text { education+PA } \\
\text { program+environmental (food in } \\
\text { school)+parental involvement }\end{array}$ & $156 /-$ & $\begin{array}{l}\text { decrease in dietary energy }-265 \mathrm{kcal} \text { and } \% \text { of energy from fat - } \\
2.5 \text {, no change in BMl and body fat }\end{array}$ & $\begin{array}{l}\text { 8-11 y old Native } \\
\text { Americans }\end{array}$ \\
\hline $\begin{array}{l}\text { Education + Interventions on } \\
\text { the work, or school, } \\
\text { environment }\end{array}$ & Combined & US & $\begin{array}{l}\text { education+PA } \\
\text { program+environmental (food in } \\
\text { school) }\end{array}$ & $129 /-$ & $\begin{array}{l}\text { total cholesterol fell by } 1.3 \mathrm{mg} / \mathrm{dl} \text { (no signif compared to non- } \\
\text { interv), energy from tot fat decreased by } 2.4 \% \text { and from } \\
\text { saturated fat by } 1.4 \% \text {, no changes in fruit/veg intake, no } \\
\text { changes in obesity }\end{array}$ & 3 th grade student \\
\hline $\begin{array}{l}\text { Education }+ \text { Interventions on } \\
\text { the work, or school, } \\
\text { environment }\end{array}$ & Combined & US & $\begin{array}{l}\text { CVD program: contests, groups, } \\
\text { media, schools }\end{array}$ & $312 /-$ & $\begin{array}{l}\text { significant adverse trends for } \mathrm{HDL} \text { and triglycerides, non- } \\
\text { significant reduction in sedentary lifestyle, BMI increased }\end{array}$ & gen pop \\
\hline $\begin{array}{l}\text { Education + Intervention aimed } \\
\text { at directly influencing lifestyle } \\
\text { choices }\end{array}$ & Combined & Australia & $\begin{array}{l}\text { store management policy } \\
\text { changes, health promotion } \\
\text { activities, and nutrition education }\end{array}$ & 208/- & $\begin{array}{l}\text { reduction in the prev of hypercholesterolemia from } 31 \% \\
\text { baseline to } 15 \% \text { at } 4 \text { years. Increase in alpha-tocapherol, } \\
\text { lutein, zeaxanthin, beta-carotene, homocysteine decreased by } \\
3 \text { umol// }\end{array}$ & $\begin{array}{l}\text { aboriginals with high } \\
\text { CVD/diabetes risk }\end{array}$ \\
\hline $\begin{array}{l}\text { Education + Intervention on } \\
\text { the broader economic and } \\
\text { social environment }\end{array}$ & Diet & US & $\begin{array}{l}\text { information campaign vs. coupons } \\
\text { for vegetables }\end{array}$ & $-/ 9$ & $\begin{array}{l}\text { coupon has direct effect increasing the purchase of veg, info } \\
\text { had indirect effect through attitude. Best results when } \\
\text { combined }\end{array}$ & low income women \\
\hline Health care interventions & Diet & Australia & $\begin{array}{l}\text { cholesterol check, advising, } \\
\text { written information }\end{array}$ & $5 \mathrm{~min} / 17$ & $13.5 \%$ cholesterol decrease $(0.84 \mathrm{mmol} / \mathrm{l})$, no BMI changes & $\begin{array}{c}18-60 \text { y old with } \\
\text { cholesterol between } 5.5- \\
7.9 \mathrm{mmol} / \mathrm{l}\end{array}$ \\
\hline Health care interventions & Diet & UK & $\begin{array}{l}\text { initial health check, follow-up } \\
\text { checks and advising }\end{array}$ & $156 /-$ & $\begin{array}{l}\text { compared to control cholesterol }-0.19 \mathrm{mmol} / \mathrm{l}, \mathrm{BMI}-1.4 \% \text {, blood } \\
\text { pressure }-1.9 \%\end{array}$ & $35-64$ y olds \\
\hline Health care interventions & Diet & US & $\begin{array}{l}\text { clinician visit, advising, phone } \\
\text { counseling, information material }\end{array}$ & $22 / 34$ & $\begin{array}{l}0.29 \text { servings fruit/veg/day increase, } 3.3 \% \text { of part increased } \\
\text { fruit/veg servings to at least } 5 / \text { day }\end{array}$ & $\begin{array}{c}18-75 \text { y old low income } \\
\text { adults }\end{array}$ \\
\hline Health care interventions & $\begin{array}{l}\text { Physical } \\
\text { activity }\end{array}$ & Finland & prescription of PA & $30 / 26$ & increase of 0.9 session of $\mathrm{PA} /$ week at 6 months & $20-65$ y olds \\
\hline
\end{tabular}


DELSA/HEA/WD/HWP(2009)6

\begin{tabular}{|c|c|c|c|c|c|c|}
\hline OECD class & Domain & Country & Intervention and description & $\begin{array}{l}\text { Intervention } \\
\text { Length } / \\
\text { Follow-up } \\
\text { length } \\
\end{array}$ & Results & Target population \\
\hline Health care interventions & $\begin{array}{l}\text { Physical } \\
\text { activity }\end{array}$ & US & education+visits+PA program & $52 / 52$ & $\begin{array}{l}\text { LDL decreased by } 0.53 \mathrm{mmol} / / \text {, systolic blood pressure by } 9 \\
\mathrm{mmHG} \text {, no difference in BMI }\end{array}$ & $\begin{array}{l}<60 \text { y old siblings of } \\
\text { black patients } \\
\text { hospitalized for } \mathrm{CHD}\end{array}$ \\
\hline $\begin{array}{l}\text { Interventions on social and } \\
\text { community networks }\end{array}$ & Combined & Iran & $\begin{array}{l}\text { media, community, health system } \\
\text { involvement, policy, improve } \\
\text { health behaviors }\end{array}$ & $312 /-$ & no results & $\begin{array}{l}>19 \text { y olds with focus on } \\
\text { groups }\end{array}$ \\
\hline $\begin{array}{l}\text { Intervention aimed at directly } \\
\text { influencing lifestyle choices }\end{array}$ & Diet & US & $\begin{array}{l}\text { environment modification } \\
\text { reduction high fat choices }\end{array}$ & $52 /-$ & $\begin{array}{l}\text { to increase the rate of selection of low/moderate fat entrees } \\
\text { one have to both increase their availability and decrease the } \\
\text { availability of high-fat entrees; the first alone is not sufficient }\end{array}$ & $\begin{array}{l}\text { elementary school } \\
\text { students }\end{array}$ \\
\hline $\begin{array}{l}\text { Intervention aimed at directly } \\
\text { influencing lifestyle choices }\end{array}$ & Diet & US & $\begin{array}{l}\text { environment modification low fat } \\
\text { food+peer promotion }\end{array}$ & $104 /-$ & $\begin{array}{l}10 \% \text { increase in selling of low-fat food in year } 1, \text { year } 2: 33.6 \% \\
\text { of sale of low-fat food in intervention compared to } 22.1 \% \text { in } \\
\text { control }\end{array}$ & $\begin{array}{l}\text { secondary school } \\
\text { students }\end{array}$ \\
\hline $\begin{array}{l}\text { Intervention aimed at directly } \\
\text { influencing lifestyle choices }\end{array}$ & $\begin{array}{l}\text { Physical } \\
\text { activity }\end{array}$ & US & $\begin{array}{l}\text { environment modification stairs in } \\
\text { a bank, airport, office, university }\end{array}$ & $26 /-$ & star use increased & Hispanic gene pop \\
\hline $\begin{array}{l}\text { Intervention aimed at directly } \\
\text { influencing lifestyle choices }\end{array}$ & $\begin{array}{l}\text { Physical } \\
\text { activity }\end{array}$ & US & $\begin{array}{l}\text { environment modification stairs in } \\
\text { a mall }\end{array}$ & $13 / 0$ & $\begin{array}{l}\text { star use increased overall, white more than black and older } \\
\text { more than younger }\end{array}$ & $>18$ y olds \\
\hline $\begin{array}{l}\text { Intervention aimed at directly } \\
\text { influencing lifestyle choices }\end{array}$ & $\begin{array}{l}\text { Physical } \\
\text { activity }\end{array}$ & Australia & $\begin{array}{l}\text { environment modification stairs in } \\
\text { a hospital }\end{array}$ & $4 / 3$ & $\begin{array}{l}\text { stair used increased with the first interv then decreased during } \\
\text { the f-up then did not significantly changed during the second } \\
\text { interv and decreased below the baseline in the second f-up }\end{array}$ & hosp workers \\
\hline $\begin{array}{l}\text { Intervention aimed at directly } \\
\text { influencing lifestyle choices }\end{array}$ & Combined & Canada & $\begin{array}{l}\text { environment modification increase } \\
\text { health choices at school and } \\
\text { outside }\end{array}$ & $47 /-$ & $\begin{array}{l}9 \% \text { decrease of low active children, } 7-25 \% \text { increase in } \\
\text { steps/day }\end{array}$ & $\begin{array}{l}\text { elementary school } \\
\text { students }\end{array}$ \\
\hline
\end{tabular}




\section{ANNEX 6. LIST OF ARTICLES AND PUBLICATIONS ON THE EFFECTIVENESS OF INTERVENTIONS TO TACKLE OVERWEIGHT AND OBESITY THROUGH DIET AND PHYSICAL ACTIVITY}

(1) WHO. Intervention on diet and physical activity: what works. 2009. WHO, Geneva.

(2) Johnson DB, Beaudoin S, Smith LT, Beresford SA, LoGerfo JP. Increasing fruit and vegetable intake in homebound elders: The Seattle Seniors Farmers' Market Nutrition Pilot Program. Preventing Chronic Disease Public Health Research, Practice, and Policy 2004; 1(1):1-9. 369

(3) Smith LT, Johnson DB, Beaudoin S, Monsen ER, LoGerfo JP. Qualitative assessment of participant utilization and satisfaction with the Seattle Senior Farmers' Market Nutrition Pilot Program. Prev Chronic Dis 2004; 1(1):A06. 370 Intervention on the physical environment and transport system

(4) Brownson RC, Housemann RA, Brown DR et al. Promoting physical activity in rural communities: walking trail access, use, and effects. Am J Prev Med. 2000;18(3):235-241. 17

(5) Gomez LF, Mateus JC, Cabrera G. Leisure-time physical activity among women in a neighbourhood in Bogota, Colombia: prevalence and socio-demographic correlates. Cad Saude Publica. 2004;20(4):1103-1109.(http://www.scielo.br/pdf/csp/v20n4/26.pdf) . 10

(6) Oja P, Vuori I, Paronen O. Daily walking and cycling to work: their utility as health-enhancing physical activity. Patient Educ Couns. 1998;33(1 Suppl):S87-S94. 18

(7) Staunton CE, Hubsmith D, Kallins W. Promoting safe walking and biking to school: the Marin County success story. Am J Public Health. 2003;93(9):1431-1434. 19

(8) Wen LM, Thomas M, Jones H, Orr N, Mreton R, King L, Hawe P, Bindon J, Humphries J, Schnicht K, Corne S, Bauman A. Promoting physical activity in women: evaluation of a 2-year communitybased intervention in Sydney, Australia. Health Promotion International 2002; 17(2): 127-137. 54

(9) Twiss J, Dickinson J, Duma S et al. Community gardens: lessons learned from California Healthy Cities and Communities. Am J Public Health. 2003;93(9):1435-1438. 16

(10) Beresford SA, Thompson B, Feng Z, Christianson A, McLerran D, Patrick DL. Seattle 5-a-Day Worksite Program to increase fruit and vegetable consumption. Prev Med 2001; 32(3):230-238. 262

(11) Braeckman L, De Bacquer D, Maes L, De Backer G. Effects of a low-intensity worksite-based nutrition intervention. Occup Med (Lond) 1999; 49(8):549-555. 259

(12) Lassen A, Thorsen AV, Trolle E, Elsig M, Ovesen L. Successful strategies to increase the consumption of fruits and vegetables: results from the Danish '6 a day' Work-site Canteen Model Study. Public Health Nutr 2004; 7(2):263-270. 270 
(13) Sorensen G, Stoddard A, Peterson K, Cohen N, Hunt MK, Stein E, Palombo R, Lederman R. Increasing fruit and vegetable consumption through worksites and families in the Treatwell 5-a-day study. Am J Public Health 1999; 89(1):54-60.239

(14) Sorensen G, Stoddard A, Hunt MK, Hebert JR, Ockene JK, Avrunin JS, et al. The effects of a health promotion-health protection intervention on behavior change: the WellWorks Study. Am J Public Health 1998; 88(11):1685-1690. 249

(15) Buller DB, Morrill C, Taren D, Aickin M, Sennott-Miller L, Buller MK, et al. Randomized trial testing the effect of peer education at increasing fruit and vegetable intake. J Natl Cancer Inst 1999; 91(17):1491-1500. 251

(16) Buller D, Buller MK, Larkey L, Sennott-Miller L, Taren D, Aickin M, et al. Implementing a 5-a-day peer health educator program for public sector labor and trades employees. Health Educ Behav 2000; 27(2):232-240. 252

(17) Sorensen G, Thompson B, Glanz K, Feng Z, et al. Work site-based cancer prevention: primary results from Working Well Trial. Am J Public Health 1996; 86(7):939-947. 244

(18) Biener L, Glanz K, McLerran D, Sorensen G, Thompson B, Basen-Engquist K et al. Impact of the Working Well Trial on the worksite smoking and nutrition environment. Health Educ Behav 1999; 26(4):478-494. 245

(19) Patterson RE, Kristak AR, Glanz K, McLerran DF, Herbert JR, Heimendinger J, et al. Components of the Working Well Trial intervention associated with adoption of healthful diets. Am J Prev Med 1997; 13(4):271-276. 246

(20) Chan CB, Ryan DA and Tudor-Locke C. Health benefits of a pedometer-based physical activity intervention in sedentary workers. Prev Med 39: 1215-1222, 2004277

(21) Uusitalo U, Feskens EJM, Tuomilehto J, Dowse G, Haw U, Fareed D, Hemraj F, Gareeboo H, Alberti MM, Zimmet P. Fall in total cholesterol concentration over five years in association with changes in fatty acid composition of cooking oil in Mauritius: Cross sectional survey. Br Med J 1996; 313(7064):1044-1046.

(22) Kolbe-Alexander TL, Lambert EV and Charlton KE. Effectiveness of a community based low intensity exercise program for older adults. J Nutr Health Aging 10: 21-29, 2006. 352

(23) Munro JF, Nicholl JP, Brazier JE, Davey R and Cochrane T. Cost-effectiveness of a community based exercise programme in over 65 year olds: cluster randomised trial. J Epidemiol Community Health 58: $1004-1010,2004.356$

(24) Anderson AS, Porteous LE, Foster E, Higgins C, Stead M, Hetherington M et al. The impact of a school-based nutrition education intervention on dietary intake and cognitive and attitudinal variables relating to fruits and vegetables. Public Health Nutr 2005; 8(6):650-656. 148

(25) Byers T, Mullis R, Anderson J, Dusenbury L, Gorsky R, Kimber C et al. The costs and effects of a nutritional education program following work-site cholesterol screening. Am J Public Health 1995; 85(5):650-655.240

(26) Irvine AB, Ary DV, Grove DA, Gilfillan-Morton L. The effectiveness of an interactive multimedia program to influence eating habits. Health Educ Res 2004; 19(3): 290-305. 272 
(27) Auslander W, Haire-Joshu D, Houston C, Rhee CW, Williams JH. A controlled evaluation of staging dietary patterns to reduce the risk of diabetes in African-American Women. Diabetes Care 2002; 25(5):809-814.320

(28) Burney J, Haughton B. EFNEP: A nutrition education program that demonstrates cost-benefit. J Am Diet Assoc 2002; 102(1):39-45. 9

(29) Coates RJ, Bowen DJ, Kristal AR, Feng Z, Oberman A, Hall WD et al. The Women's Health Trial Feasibility Study in Minority Populations: Changes in dietary intakes. Am J Epidemiol 1999; 149(12):1104-1112. 312

(30) Devine CM, Farrell TJ, Hartman R. Sisters in health: experiential program emphasizing social interaction increases fruit and vegetable intake among low-income adults. J Nutr Educ Behav 2005; 37(5):265-270. 334

(31) Goulet J, Lamarche B, Nadeau G, Lemieux S. Effect of a nutritional intervention promoting the Mediterranean food pattern on plasma lipids, lipoproteins and body weight in healthy FrenchCanadian women. Atherosclerosis 2003; 170(1):115-124. 323

(32) Haire-Joshu D, Brownson RC, Nanney MS, Houston C, Steger-May K, Schechtman K, Auslander W. Improving dietary behavior in African Americans: the Parents As Teachers High 5, Low Fat Program. Prev Med 2003; 36(6):684-691. 325

(33) Hartman TJ, McCarthy PR, Park RJ, Schuster E, Kushi LH. Results of a community-based lowliteracy nutrition education program. J Community Health 1997; 22(5):325-341. 7

(34) Havas S, Treiman K, Langenberg P, Ballesteros M, Anliker J, Damron D, Feldman R. Factors associated with fruit and vegetable consumption among women participating in WIC. J Am Diet Assoc 1998; 98(10):1141-1148.4

(35) Baker AH, Wardle J. Increasing fruit and vegetable intake among adults attending colorectal cancer screening: the efficacy of a brief tailored intervention. Cancer Epidemiol Biomarkers Prev 2002; 11(2):203-206. 191

(36) Bowen DB, Ehret C, Pedersen M, Snetselaar L, Johnson M, Tinker L et al. Results of an adjunct dietary intervention program in the Women's Health Initiative. J Am Diet Assoc 2002; 102(11):1631-1637. 192

(37) Howard BV, Manson JE, Stefanick ML, Beresford SA, Frank G, Jones B et al. Low fat dietary pattern and risk of colorectal cancer: the Women's Health Initiative Randomised Controlled Dietary Modification Trial. JAMA 2006: 295 (6):639-49. 204

(38) Emmons KM, McBride CM, Puleo E, Pollak KI, Clipp E, Kuntz K et al. Project PREVENT: a randomized trial to reduce multiple behavioral risk factors for colon cancer. Cancer epidemiology, biomarkers \& prevention: a publication of the American Association for Cancer Research, cosponsored by the American Society of Preventive Oncology 2005; 14(6):1453-1459. 209

(39) Huxley RR, Lean M, Crozier A, John JH, Neil HA. Effect of dietary advice to increase fruit and vegetable consumption on plasma flavonol concentrations: results from a randomised controlled intervention trial. J Epidemiol Community Health 2004; 58(4):288-289. 206 
(40) Pritchard DA, Hyndman J, Taba F. Nutritional counselling in general practice: a cost-effective analysis. J Epidemiol. Community Health 1999;53:311-316. 180

(41) Sacerdote C, Fiorini L, Rosato R, Audenino M, Valpreda M, Vineis P. Randomized controlled trial: Effect of nutritional counselling in general practice. International Journal of Epidemiology 2006; 35(2):409-415. 215

(42) Marcus AC, Heimendinger J, Wolfe P, Rimer BK, Morra M, Cox D et al. Increasing fruit and vegetable consumption among callers to the CIS: results from a randomized trial. Prev Med 1998; 27(5 Pt 2):S16-S28. 309

(43) Marcus AC, Heimendinger J, Wolfe P, Fairclough D, Rimer BK, Morra M et al. A randomized trial of a brief intervention to increase fruit and vegetable intake: a replication study among callers to the CIS. Prev Med 2001; 33(3):204-216.310

(44) Stevens VJ, Glasgow RE, Toobert DJ, Karanja N, Smith KS. Randomized trial of a brief dietary intervention to decrease consumption of fat and increase consumption of fruits and vegetables. Am J Health Promot 2002; 16(3):129-134. 321

(45) Stevens VJ, Glasgow RE, Toobert DJ, Karanja N, Smith KS. One-year results from a brief, computerassisted intervention to decrease consumption of fat and increase consumption of fruits and vegetables. Prev Med 2003; 36(5):594-600. 322

(46) Patterson RE, Kristal A, Rodabough R, Caan B, Lillington L, Mossavar-Rahmani Y et al. Changes in food sources of dietary fat in response to an intensive low fat dietary intervention: early results from the Women's Health Initiative. J Am Diet Assoc 2003; 103(4):454-460. 193

(47) Kearney MH, Rosal MC, Ockene JK, Churchill LC. Influences on older women's adherence to a low fat diet in the Women's Health Initiative. Psychosomatic Medicine 2002; 64(3):450-457. 194

(48) Hopkins S, Burrows E, Bowen DJ, Tinker LF. Differences in eating pattern labels between maintainers and nonmaintainers in the women's health initiative. J Nutr Educ Behav 2001; 33(5):278-283. 195

(49) Langer RD, White E, Lewis CE, Kotchen JM, Hendrix SL, Trevisan M. The women's health initiative observational study: Baseline characteristics of participants and reliability of baseline measures. Annals of Epidemiology 2003; 13(9SUPPL.):S107-S121. 196

(50) Ritenbaugh C, Patterson RE, Chlebowski RT, Caan B, Fels-Tinker L, Howard B et al. The Women's Health Initiative dietary modification trial: Overview and baseline characteristics of participants. Annals of Epidemiology 2003; 13(9SUPPL.):S87-S97. 197

(51) Anderson GL, Manson J, Wallace R, Lund B, Hall D, Davis S et al. Implementation of the Women's Health Initiative study design. Annals of Epidemiology 2003; 13(9 SUPPL.):S5-S17. 198

(52) Fries E, Edinboro P, McClish D, Manion L, Bowen D, Beresford SAA et al. Randomized trial of a low-intensity dietary intervention in rural residents: The rural physician cancer prevention project. American Journal of Preventive Medicine 2005;28(2):162-168. 210

(53) Fries E, Edinboro P, McClish D, Murff HJ. A self-help intervention to change patient dietary behavior in rural communities. Journal of Clinical Outcomes Management 2005; 12(4):180-183. 211 
(54) John JH, Ziebland S, Yudkin PL, Roe L, Neil HA. Effects of fruit and vegetable consumption on plasma antioxidant concentrations and blood pressure: a randomised controlled trial. The Lancet 2002; 359:1969-1974. 168

(55) John JH, Yudkin PL, Neil HAW, Ziebland S. Does stage of change predict outcome in a primary-care intervention to encourage an increase in fruit and vegetable consumption? Health Education Research 2003; 18(4):429-438. 189

(56) John JH, Ziebland S. Reported barriers to eating more fruit and vegetables before and after participation in a randomised controlled trial: a qualitative study. Health Education Research 2004; 19(2):165-174. 190

(57) Steptoe A, Doherty S, Rink E, Kerry S, Kendrick T, Hilton S. Behavioural counselling in general practice for the promotion of healthy behaviour among adults at increased risk of coronary heart disease: randomised trial. BMJ 1999;319(7215):943-947. 181

(58) Steptoe A, Perkins-Porras L, McKay C, Rink E, Hilton S, Cappuccio FP. Behavioural counselling to increase consumption of fruit and vegetables in low income adults: randomized trial. British Medical Journal 2003; 326(7394):855. 182

(59) Steptoe A, Kerry S, Rink E, Hilton S. The impact of behavioral counseling on stage of change in fat intake, physical activity, and cigarette smoking in adults at increased risk of coronary heart disease. Am J Public Health 2001; 91(2):265-269. 183

(60) Delichatsios H, Hunt M, Lobb R, Emmons K, Gillman MW. EatSmart: Efficacy of a multifaceted preventive nutrition intervention in clinical practice. Preventive Medicine 2001; 33(2):91-98. 185

(61) Hunt MK, Lobb R, Delichatsios HK, Stone C, et al. Process evaluation of a clinical preventative nutrition intervention. Prev Med. 2001; 33(2 Pt 1):82-90. 186

(62) Matsudo V, Matsudo S, Andrade D, Araujo T, Andrade E, de Oliveira C, Braggion G. Promotion of physical activity in a developing country: the Agita Sao Paulo experience. Publ Health Nutr 2001; 5(1A): $1-10.38$

(63) Matsudo S, Matsudo V, Andrade D, Araujo T, Andrade E, de Oliveira C, Braggion G. Physical activity promotion: Experiences and evaluation of the Agita Sao Paulo Program using the ecological mobile model. Journal of Physical Activity and Health 2004; 1: 81-97. 39

(64) Bauman A, McLean G, Hurdle D, Walker S, Boyd J, van Aalst I, Carr H. Evaluation of the national 'Push Play' campaign in New Zealand-creating population awareness of physical activity. N Z Med J. 2003 Aug 8;116(1179):U534. 52

(65) Bauman AE, Bellew B, Owen N, Vita P. Impact of an Australian Mass Media Campaign Targeting Physical Activity in 1998. Am J Prev Med 2001;21(1):41-47. 37

(66) Craig CL, Tudor-Locke C, Bauman A. Twelve-month effects of Canada on the Move: a populationwide campaign to promote pedometer use and walking. Health Education Research. 2006; Epub, October 10, 2006. 45

(67) Huhman M, Potter LD, Wong FL, Banspach SW, Duke JC, Heitzler CD. Effects of a mass media campaign to increase physical activity among children: Year-1 results of the VERB campaign. Pediatrics 2005; 116(2): 277-284. 41 
(68) Reger B, Cooper L, Booth-Butterfield S, Smith H, Bauman A, Wootan M, Middlestadt S, Marcus B, Greer F. Wheeling Walks: A community campaign using paid media to encourage walking among sedentary older adults. Prev Med 2002; 35:285-292. 50"

(69) Reger-Nash, B, Fell P, Spicer D, Fisher BD, Cooper L, Chey T, Bauman A. BC Walks: Replication of a Communitywide Physical Activity Campaign. Prev Chronic Disease 2006; 3: [serial online] 2006 Jul [date cited]. Available from: URL:http://www.cdc.gov/pcd/ issues/2006/jul/05_0138.htm. 51

(70) Calfas KJ, Long BJ, Sallis JF et al. A controlled trial of physician counseling to promote the adoption of physical activity. SO: Preventive medicine. 1996;25(3):225-233. 223

(71) Green BB, McAfee T, Hindmarsh M et al. Effectiveness of telephone support in increasing physical activity levels in primary care patients. Am J Prev Med. 2002;22(3):177-183.220

(72) Phelan EA, Williams B, Leveille S, Snyder S, Wagner EH and LoGerfo JP. Outcomes of a community-based dissemination of the health enhancement program. J Am Geriatr Soc 50: 1519$1524,2002.355$

(73) Stewart AL, Verboncoeur CJ, McLellan BY, Gillis DE, Rush S, Mills KM, King AC, Ritter P, Brown BW, Jr. and Bortz WM. Physical activity outcomes of CHAMPS II: a physical activity promotion program for older adults. J Gerontol A Biol Sci Med Sci 56: M465-M470, 2001. 351

(74) Wilcox S, Griffin SF, Rheaume C, et al., Results of the first year of active for life: translation of 2 evidence-based physical activity programs for older adults into community settings 2006; Am J Public Health 96(7): 354

(75) Rosamond WD, Ammerman A, Holliday JL, Tawney KW, Hunt KJ, Keyserling T et al. Cardiovascular disease risk factor intervention in low-income women: The North Carolina WISEWOMAN Project. Preventive Medicine 2000; 31: 370-379. 184

(76) Miles A, Rapoport L, Wardle J, Afuape T, Duman M. Using the mass-media to target obesity: an analysis of the characteristics and reported behaviour change of participants in the BBC's 'Fighting Fat, Fighting Fit' campaign. Health

(77) Wardle J, Rapoport L, Miles A, Afuape T and Duman M. Mass education for obesity prevention: the penetration of the BBC's 'Fighting Fat, Fighting Fit' campaign. Health Education Research 2001; 16(3): 343-355. 46

(78) Warren JM, Henry CJ, Lightowler HJ, Bradshaw SM, Perwaiz S. Evaluation of a pilot school programme aimed at the prevention of obesity in children. Health Promot Int 2003; 18(4):287-296. 134

(79) Emmons KM, Linnan LA, Shadel WG, Marcus B, Abrams DB. The Working Healthy Project: a worksite health-promotion trial targeting physical activity, diet and smoking. J Occup Environ Med 1999; 41(7):545-555. 258

(80) Polacsek M, O’Brien L, Lagasse W, Hammar N. Move \& Improve: A Worksite Wellness Program in Maine. Prev Chronic Dis 2006; www.cdc.gov/pcd/issues/2006/jul/05_0123.htm 278

(81) Aldana SG, Greenlaw RL, Diehl HA, Salberg A, Merrill RM, Ohmine S, Thomas C. Effects of an intensive diet and physical activity modification program on the health risks of adults. J Am Diet Assoc 2005; 105(3):371-381. 335 
(82) Staten LK, Scheu LL, Bronson D, Pena V, Elenes J Pasos Adelante: the effectiveness of a communitybased chronic disease prevention program Prev Chronic Dis. 2005 Jan;2(1):A18. Epub 2004 Dec 15 341

(83) Wylie-Rosett J, Swencionis C, Ginsberg M, Cimino C, Wassertheil-Smoller S, Caban A, SegalIsaacson CJ, Martin T, Lewis J. Computerized weight loss intervention optimizes staff time: the clinical and cost results of a controlled clinical trial conducted in a managed care setting. J Am Diet Assoc 2001; 101:1155-62. 316

(84) Englert et al., Prev Med. 2004 Apr;38(4):432-41.Rationale and design of the Rockford CHIP, a community-based coronary risk reduction program: results of a pilot phase.

(85) Burke V, Giangiulio N, Gillam HF, Beilin LJ, Houghton S. Physical activity and nutrition programs for couples: a randomized controlled trial. J Clin Epidemiol 2003; 56(5):421-432. 326

(86) Burke V, Giangiulio N, Gillam HF, Beilin LJ, Houghton S. Changes in cognitive measures in a randomized controlled trial of a health promotion program for couples targeting diet and physical activity. Am J Health Promot 2004; 18(4):300-311. 327

(87) Simkin-Silverman LR, Wing RR, Boraz MA, Kuller LH. Lifestyle intervention can prevent weight gain during menopause: results from a 5-year randomized clinical trial. Ann Behav Med 2003; 26(3):212-220; 305

(88) Kuller LH, Simkin-Silverman LR, Wing RR, Meilahn EN, Ives DG. Women's Healthy Lifestyle Project: A randomised clinical Trial. Circulation. 2001; 103:32-44. 307

(89) Elley CR, Kerse N, Arroll B, Robinson E. Effectiveness of counselling patients on physical activity in general practice: cluster randomised controlled trial. BMJ. 2003;326(7393):793. 216

(90) Green Prescription online - http://www.sparc.org.nz/getting-active/green-prescription/overview 236

(91) Prell HC, Berg MC, Jonsson LM, Lissner L. A school-based intervention to promote dietary change. J Adolesc Health 2005; 36(6):515-529. 137

(92) Lytle LA, Kubik MY, Perry C, Story M, Birnbaum AS, Murray DM. Influencing healthful food choices in school and home environments: Results from the TEENS study. Prev Med 2006; 43: 813. 97

(93) Nicklas TA, Johnson CC, Farris R, Rice R, Lyon L, Shi R. Development of a school-based nutrition intervention for high school students: Gimme 5. Am J Health Promot 1997; 11(5):315-322. 86

(94) Perry CL, Bishop DB, Taylor G, Murray DM, Mays RW, Dudovitz BS et al. Changing fruit and vegetable consumption among children: the 5-a-Day Power Plus program in St. Paul, Minnesota. Am J Public Health 1998; 88(4):603-609 93

(95) Reynolds KD, Franklin FA, Binkley D, Raczynski JM, Harrington KF, Kirk KA, Person S. Increasing the fruit and vegetable consumption of fourth-graders: results from the high 5 project. Prev Med 2000; 30(4):309-319. 90

(96) Saksvig BI, Gittelsohn J, Harris SB, Hanley AJ, Valente TW, Zinman B. A pilot school-based healthy eating and physical activity intervention improves diet, food knowledge, and self-efficacy for native Canadian children. J Nutr 2005;135(10):2392-2398. 126 
(97) Osganian SK, Ebzery MK, Montgomery DH, Nicklas TA, Evans MA, Mitchell PD et al. Changes in the nutrient content of school lunches: results from the CATCH Eat Smart Food service Intervention. Prev Med 1996; 25(4):400-412. 78

(98) Dwyer JT, Hewes LV, Mitchell PD, Nicklas TA, Montgomery DH, Lytle LA et al. Improving school breakfasts: effects of the CATCH Eat Smart program on the nutrient content of school breakfasts. Prev Med 1996; 25(4):413-422. 79

(99) Williams CL, Bollella MC, Strobino BA, Spark A, Nicklas TA, Tolosi LB, Pittman BP. "Healthystart": outcome of an intervention to promote a heart healthy diet in preschool children. J Am Coll Nutr 2002; 21(1):62-71. 101

(100) Williams CL, Strobino BA, Bollella C, Brotanek J. Cardiovascular risk reduction in preschool children: The "Healthy Start" project. J Am Coll Nutr 2004; 23(2): 117-123. 102

(101) Simon C, Wagner A, Platat C, Arveiler D, Schweitzer B, Schlienger JL, Triby E. ICAPS: a multilevel program to improve physical activity in adolescents. Diabetes Metab. 2006 Feb;32(1):419

(102) Simon C, Wagner A, DiVita C, Rauscher E, Klein-Platat C, Arveiler D, Schweitzer B, Triby E. Intervention centred on adolescents' physical activity and sedentary behaviour (ICAPS): concept and 6-month results. Int J Obes Relat Metab Disord. 2004 Nov;28 Suppl 3:S96-S103. X.

(103) Engels HJ, Gretebeck RJ, Gretebeck KA, Jimenez L. Promoting healthful diets and exercise: efficacy of a 12-week after-school program in urban African Americans. J Am Diet Assoc 2005; 105(3):455459. 114

(104) Friel S, Kelleher C, Campbell P, Nolan G. Evaluation of the Nutrition Education at Primary School (NEAPS) programme. Public Health Nutr 1999; 2(4):549-555. 125

(105) Gortmaker SL, Cheung LW, Peterson KE, Chomitz G, Cradle JH, Dart H et al. Impact of a schoolbased interdisciplinary intervention on diet and physical activity among urban primary school children: eat well and keep moving. Arch Pediatr Adolesc Med 1999; 153(9):975-983. 100

(106) Harrell JS, McMurray RG, Gansky SA, Bangdiwala SI, Bradley CB. A public health vs. a risk-based intervention to improve cardiovascular health in elementary school children: The cardiovascular health in children study. Am J Public Health 1999; 89:1529-1535. 113

(107) Trevino RP, Yin Z, Hernandez A, Hale DE, Garcia OA, Mobley C. Impact of the Bienestar schoolbased diabetes mellitus prevention program on fasting capillary glucose levels: a randomized controlled trial. Arch Pediatr Adolesc Med 2004; 158(9):911-917. 124

(108) Pegus C, Bazzarre TL, Brown JS, Menzin J. Effect of the Heart At Work program on awareness of risk factors, self-efficacy, and health behaviours. J Occup Environ Med 2002; 44(3):228-236. 268

(109) Manios Y, Kafatos A, Mamalakis G. The effects of a health education intervention initiated at first grade over a 3 year period: physical activity and fitness indices. Health Ed Res 1998; 13: 593-606.

(110) Fardy PS, White RE, Haltiwanger-Schmitz K, Magel JR, McDermott KJ, Clark LT, Hurster MM. Coronary disease risk factor reduction and behavior modification in minority adolescents: the PATH program. J Adolesc Health 1996; 18(4):247-253. 109 
(111) Bayne-Smith M, Fardy PS, Azzollini A, Magel J, Schmitz KH, Agin D. Improvements in heart health behaviors and reduction in coronary artery disease risk factors in urban teenaged girls through a school-based intervention: the PATH program. Am J Public Health 2004; 94(9):1538-1543. 110

(112) Manios Y, Kafatos A. Health and nutrition education in elementary schools: changes in health knowledge, nutrient intakes and physical activity over a six year period. Public Health Nutr 1999; $2(3 \mathrm{~A}): 445-448 ; 62$

(113) Manios Y, Moschandreas J, Hatzis C, Kafatos A. Evaluation of a health and nutrition education program in primary school children of Crete over a three-year period. Prev Med 1999; 28(2):149159.98

(114) Manios Y, Moschandreas J, Hatzis C, Kafatos A. Health and nutrition education in primary schools of Crete: changes in chronic disease risk factors following a 6-year intervention programme. Br J Nutr 2002; 88(3):315-324. 99

(115) Paradis G, Levesque L, Macaulay AC, Cargo M, McComber A, Kirby R et al. Impact of a diabetes prevention program in body size, physical activity, and diet among Kanien'keha:ka (Mohawk) children 6 to 11 years old: 8 year results from the Kahnawake Schools Diabetes Prevention Project. Pediatrics 2005; 115(2):333-339. 130

(116) Jimenez MM, Receveur O, Trifonopoulos M, Kuhnlein H, Paradis G, Macaulay AC. Comparison of the dietary intakes of two different groups of children (grades 4 to 6 ) before and after the Kahnawake Schools Diabetes Prevention Project. J Am Diet Assoc 2003; 103(9):1191-1194. 131

(117) Macaulay AC, Paradis G, Potvin L, Cross EJ, Saad-Haddad C, McComber A et al. The Kahnawake Schools Diabetes Prevention Project: intervention, evaluation, and baseline results of a diabetes primary prevention program with a native community in Canada. Prev Med 1997; 26(6):779-790. 132

(118) Sahota P, Rudolf MC, Dixey R, Hill AJ, Barth JH, Cade J. Randomised controlled trial of primary school based intervention to reduce risk factors for obesity. Br Med J 2001; 323(7320):1029-1032. 68

(119) Sahota P, Rudolf MC, Dixey R, Hill AJ, Barth JH, Cade J. Evaluation of implementation and effect of primary school based intervention to reduce risk factors for obesity. Br Med J 2001; 323(7320):1027-1029. 69

(120) Caballero B, Clay T, Davis SM, Ethelbah B, Rock BH, Lohman T et al. Pathways: a school-based, randomized controlled trial for the prevention of obesity in American Indian schoolchildren. Am J Clin Nutr 2003; 78(5):1030-1038. 64

(121) Davis SM, Clay T, Smyth M, Gittelsohn J, Arviso V, Flint-Wagner H et al. Pathways curriculum and family interventions to promote healthful eating and physical activity in American Indian schoolchildren. Prev Med 2003; 37: S24-S34. 65

(122) Stevens J, Story M, Ring K, Murray DM, Cornell CE, Juhaeri, Gittelsohn J. The impact of the Pathways intervention on psychosocial variables related to diet and physical activity in American Indian schoolchildren. Prev Med 2003; 37(6):S70-S79. 66 
(123) Steckler A, Ethelbah B, Martin CJ, Stewart D, Pardilla M, Gittelsohn J et al. Pathways process evaluation results: a school-based prevention trial to promote healthful diet and physical activity in American Indian third, fourth and fifth grade students. Prev Med 2003; 37(6):S80-S90. 67

(124) Aldana SG, Greenlaw RL, Diehl HA, Salberg A, Merrill RM, Ohmine S. The effects of a worksite chronic disease prevention program. J Occup Environ Med 2005; 47(6):558-564. 275

(125) Armitage CJ, Conner M. Efficacy of a minimal intervention to reduce fat intake. Soc Sci Med 2001; 52(10):1517-1524. 263

(126) Webber LS, Osganian SK, Feldman HA, Wu M, McKenzie TL, Nichaman M et al. Cardiovascular risk factors among children after a 2 1/2- -year intervention - The CATCH study. Prev Med 1996; $25: 432-441.70$

(127) Edmundson E, Parcel GS, Feldman HA, Elder J, Perry CL, Johnson CC et al. The effects of the child and adolescent trial for cardiovascular health upon psychosocial determinants of diet and physical activity behavior. Prev Med 1996; 25(4):442-454. 71

(128) Lytle LA, Stone EJ, Nichaman MZ, Perry CL, Montgomery DH, Nicklas TA et al. Changes in nutrient intakes of elementary school children following a school-based intervention: results from the CATCH Study. Prev Med 1996; 25(4):465-477. 72

(129) Nader PR, Sellers DE, Johnson CC, Perry CL, Stone EJ, Cook KC et al. The effect of adult participation in a school-based family intervention to improve children's diet and physical activity: the child and adolescent trial for cardiovascular health. Prev Med 1996; 25(4):455-464. 73

(130) Nader PR, Stone EJ, Lytle LA, Perry CL, Osganian SK, Kelder S et al. Three-year maintenance of improved diet and physical activity: The CATCH cohort. Arch Pediatr Adolesc Med 1999; 153(7):695-704. 74

(131) Hoelscher DM, Feldman HA, Johnson CC, Lytle LA, Osganian SK, Parcel GS et al. School-based health education programs can be maintained over time: results from CATCH Institutionalization study. Prev Med 2004; 38(5):594-606. 75

(132) Luepker RV, Perry CL, Osganian V, Nader PR, Parcel GS, Stone EJ, Webber LS. The child and adolescent trial for cardiovascular health (CATCH). J Nutr Biochem 1998; 9: 525-534. 76

(133) Perry CL, Lytle L, Feldman H, Nicklas T, Stone E, Zive M. Effects of the Child and Adolescent Trial for Cardiovascular Health (CATCH) on fruit and vegetable intake. J Nutr 1998; 30(6):354-360. 77

(134) Nafziger AN, Erb TA, Jenkins PL, Lewis C, Pearson TA. The Otsego-Schoharie healthy heart program: prevention of cardiovascular disease in the rural US. Scand J Public Health Suppl. 2001;56:21-32. 56

(135) Rowley KG, Su Q, Cincotta M, Skinner M, Skinner K, Pindan B, White GA, O’Dea K. Improvements in circulating cholesterol, antioxidants, and homocysteine after dietary intervention in an Australian Aboriginal community. Am J Clin Nutr 2001; 74(4):442-448. 319

(136) Anderson JV, Bybee DI, Brown RM, McLean DF, Garcia EM, Breer ML, Schillo A. 5-a-Day fruit and vegetable intervention improves consumption in a low income population. J Am Diet Assoc 2001; 101(2):195-202. 6 
(137) Redman S, Sanson FR, Kreft S, Fleming J, Dickinson J. Is the Australian National Heart Foundation programme effective in reducing cholesterol levels among general practice patients? Health Promotion International 1995; 10(4):293-303.174

(138) Anon. Effectiveness of health checks conducted by nurses in primary care: final results of the OXCHECK study. Imperial Cancer Research Fund OXCHECK Study Group. BMJ 1995; 310(6987):1099-1104. 169

(139) Field K, Thorogood M, Silagy C, Normand C. O’Neill, Muir J. Strategies for reducing coronary risk factors in Primary care: which is most cost-effective? BMJ 1995; 310:1109-1112. 170

(140) Langham S, Thorgood M, Normand C, Muir J, Jones L, Fowler G. Costs and cost effectiveness of health checks conducted by nurses in primary care: the Oxcheck study. BMJ 1996; 312: 1265-68. 171

(141) Emmons KM, Stoddard AM, Fletcher R, Gutheil C, Suarez EG, Lobb R et al. Cancer prevention among working class, multiethnic adults: results of the healthy directions-health centers study. Am J Public Health 2005; 95(7):1200-1205. 207

(142) Lobb R, Gonzalez SE, Fay ME, Gutheil CM, Hunt MK, Fletcher RH et al. Implementation of a cancer prevention program for working class, multiethnic populations. Prev Med 2004; 38(6):766776208

(143) Aittasalo M, Miilunpalo S, Kukkonen-Harjula K, Pasanen M. A randomized intervention of physical activity promotion and patient self-monitoring in primary health care. Preventive Medicine. 2006;42(1):40-46. 226

(144) Becker DM, Yanek LR, Johnson WR, Jr., Garrett D, Moy TF, Reynolds SS et al. Impact of a community-based multiple risk factor intervention on cardiovascular risk in black families with a history of premature coronary disease. Circulation 2005;111(10):1298-1304. 214

(145) Sarraf-Zadgan N, Sadri G, Afzali HM, et al., Isfahan Healthy Heart Program: A comprehensive integrated community-based program for cardiovascular disease prevention and control. Acta Cardiol 2003; 58(4): 309-20. 61

(146) Bartholomew JB, Jowers EM. Increasing frequency of lower-fat entrees offered at school lunch: an environmental change strategy to increase healthful selections. J Am Diet Assoc 2006;106(2): 248252. 144

(147) French SA, Story M, Fulkerson JA, Hannan P. An environmental intervention to promote lower-fat food choices in secondary schools: outcomes of the TACOS Study. American journal of public health 2004; 94(9):1507-1512. 128375

(148) Coleman, KJ \& Gonzalez EC. Promoting Stair Use in a US-Mexico Border Community Am J Public Health, 2001;91(12):2007-2009. 21

(149) Andersen RE, Franckowiak SC, Snyder J et al. Can inexpensive signs encourage the use of stairs? Results from a community intervention. Ann Intern Med.1998;129(5):363-369. 12

(150) Marshall AL., Bauman AE., Patch C., Wilson J., Chen J. Can motivational signs prompt increases in accidental physical activity in an Australian health-care facility? Health Education Research (17), 6: 743-749, 2002280 
(151) Russell WD, Hutchinson J. Comparison of health promotion and deterrent prompts in increasing use of stairs over escalators. Percept Mot Skills. 2000;91(1):55-61. 22

(152) Naylor PJ, Macdonald HM, Reed KE, McKay HA. Action Schools! BC: A socio-ecological approach to modifying chronic disease risk factors in elementary school children. Preventing Chronic Disease: Public Health Research, Practice and Policy 2006; 3(2) 156

(153) Naylor PJ, MacDonald HM, Zebedee JA, McKay HA. Lessons learned from Action Schools! BC- an 'active school' model to promote physical activity in elementary schools. J Sci Med Sport 2006; 9(5): 413-23. 


\section{REFERENCES}

Adam, T., D.B. Evans and C.J.L. Murray (2003), "Econometric Estimation of Country-Specific Hospital Costs", Cost Effectiveness and Resource Allocation, 1, 3.

Adam, T. and D.B. Evans (2006), "Determinants of Variation in the Cost of Inpatient Stays Versus Outpatient Visits in Hospitals: a Multi-Country Analysis", Social Science and Medicine, 63, pp. 1700-10.

Allais, O. et al. (2008), "The Effects of a "Fat Tax"on the Nutrient Intake of French Households", paper presented at the 2008 International Congress of the European Association of Agricultural Economists, Ghent, 26-29 August, http://ageconsearch.umn.edu/bitstream/43967/2/299.pdf, accessed 21 October 2009.

Barendregt, J.J. (2003), "A Generic Model for the Assessment of Disease Epidemiology: the Computational Basis of DisMod II", Population Health Metrics, 14;1(1), p.4.

Bolton, R.N. (1983). "Modeling the Impact of Television Food Advertising on Children's Diets", in J.H. Leigh, C.R. Martin Jr (eds.), Current Issues and Research in Advertising. MI: Division of research, Graduate School of Business Administration, University of Michigan, Ann Arbor.

Buller, D.B. et al. (1999), "Randomized Trial Testing the Effect of Peer Education at Increasing Fruit and Vegetable Intake", Journal of the National Cancer Institute 91(17), pp. 1491-1500.

Butland, B. et al. (2007), Foresight - Tackling obesities: future choices - project report http://www.foresight.gov.uk/OurWork/ActiveProjects/Obesity/Obesity.asp

Chisholm, D. et al. (2004), "Reducing the Global Burden of Depression: Population-Level Analysis of Intervention Cost-Effectiveness in 14 World Regions", British Journal of Psychiatry, 184, pp. 393403.

Chisholm, D. et al. (2004), "Reducing the Global Burden of Hazardous Alcohol Use: a Comparative CostEffectiveness Analysis", Journal of Studies on Alcohol, 65, pp. 782-793.

Chou, S., I. Rasha and M. Grossman (2008), "Fast-Food Restaurant Advertising on Television and its Influence on Childhood Obesity",Journal of Law and Economics, 51, pp. 599-618.

Craig, C.L., C. Tudor-Locke and A. Bauman (2007), "Twelve-Month Effects of Canada on the Move: a Population-Wide Campaign to Promote Pedometer Use and Walking", Health Education Research, 22(3), pp. 406-13.

Dixon, H. et al. (1998), "Public Reaction to Victoria's '2 Fruit 'n' 5 Veg Every Day' Campaign and Reported Consumption of Fruit and Vegetables", Preventive Medicine, 27(4), pp. 572-582. 
Emmons, K.M. et al. (1999), "The Working Healthy Project: a Worksite Health Promotion Trial Targeting Physical Activity, Diet and Smoking", Journal of Occupational \& Environmental Medicine, 41(7), pp. 545-555.

Evans, C. (2003), "Studying the studies: an overview of recent research into taxation operating costs", eJournal of Tax Research, 1(1),pp. 64-92.

Evans, D.B. et al. (2005), "Methods to Assess the Costs and Health Effects of Interventions for Improving Health in Developing Countries", BMJ, 331, pp. 1137-40.

Foerster SB, California's "5-a-Day - for better health" campaign: an innovative population-based effort to effect large scale dietary change. American Journal of Preventive Medicine 1995; 11:124-131.

Gortmaker, S.L. et al. (1999), "Impact of a School-Based Interdisciplinary Intervention on Diet and Physical Activity among Urban Primary School Children: Eat Well and Keep Moving", Archives of Pediatrics \& Adolescent Medicine, 153(9), pp. 975-983.

Groot, M.T. et al. (2006), "Costs and Health Effects of Breast Cancer Interventions in Epidemiologically Different Regions of Africa, North America, and Asia", Breast Journal, 12, Supplement 1 S81-90.

Heijink, R. et al. (2008), "Cost of Illness: an International Comparison. Australia, Canada, France, Germany and the Netherlands", Health Policy, 88(1), pp. 49-61.

Herbert, J.R. et al. (1999), "A Dietician-Delivered Group Nutrition Program Leads to Reductions in Dietary Fat, Serum Cholesterol and Body Weight: the Worcester-Area Trial for Counselling in Hyperlipidaemia (WATCH)", Journal of the American Dietetic Association, 99(5), pp. 544-52.

Hespel, V. and M. Berthod-Wurmser (2008), "La pertinence et la faisabilité d'une taxation nutritionnelle", République Française, Inspection Générale de Finances et Inspection Générale des Affaires Sociales.

Hutubessy, R., D. Chisholm and T. Tan Torres (2003), "Generalized Cost-Effectiveness Analysis for National-Level Priority-Setting in the Health Sector", Cost Effectiveness and Resource Allocation, $1,8, \underline{\text { http://www.resource-allocation.com/content/1/1/8. }}$.

Johns, B., T, Adam and D.B. Evans (2006), "Enhancing the Comparability of Costing Methods: CrossCountry Variability in the Prices of Non-Traded Inputs to Health Programmes", Cost Effectiveness and Resource Allocation, 4, 8.

Johns, B. et al. (2003), "Programme Costs in the Economic Evaluation of Health Interventions", Cost Effectiveness and Resource Allocation, 1, 1.

Johns, B. et al. (2006), "Enhancing the Comparability of Costing Methods: Cross-Country Variability in the Prices of Non-Traded Inputs to Health Programmes", Cost Effectiveness and Resource Allocation, 4, 8 .

Luepker, R.V. et al. (1998), "The child and adolescent trial for cardiovascular health (CATCH)", Journal of Nutritional Biochemistry, 9, pp. 525-534.

Millstone, E. and T. Lobstein (2007), "The PorGrow Project: Overall Cross-National Results, Comparisons and Implications", Obesity Review, vol. 8 suppl. 2, pp. 29-36. 
Mytton, O. et al. (2007), “Could Targeted Food Taxes Improve Health?”, Journal of Epidemiology Community Health, 61(8), pp. 689-694.

Murray, C. J. L. et al. (2000), "Development of WHO Guidelines on Generalized Cost-Effectiveness Analysis", Health Economics, 9, pp. 235-251.

Murray, C. J. L. et al (2003), "Effectiveness and Costs of Interventions to Lower Systolic Blood Pressure and Cholesterol: a Global and Regional Analysis on Reduction of Cardiovascular Disease", The Lancet, 361, pp. 717-725.

Murray, C. J. L. and D. B. Evans (2003), "Health Systems Performance Assessment: Goals, Framework and Overview", in C. J. L. Murray and D. B. Evans (eds), Health System Performance Assessment: Debates, Methods and Empiricism, Geneva, World Health Organization, pp. 3-18.

OFCOM (2008), "Changes in the Nature and Balance of Television Food Advertising to Children: A Review of HFSS Advertising Restrictions", http://www.ofcom.org.uk/research/tv/reports/hfssdec08

Ockene, I.S., et al. (1996), "Effect of Training and a Structured Office Practice on Physician-Delivered Nutrition Counseling: the Worcester-Area Trial for Counseling in Hyperlipidemia (WATCH)", American Journal of Preventive Medicine, vol. 12(4), pp. 252-258.

Perry, C.L. et al. (1998), "Changing Fruit and Vegetable Consumption Among children: the 5-a-Day Power Plus Program in St. Paul, Minnesota", American Journal of Public Health, vol. 88(4), pp. 603-609.

Pritchard, D.A., J. Hyndman and F. Taba (1999), "Nutritional Counselling in General Practice: a CostEffective Analysis", Journal of Epidemiology and Community Health, vol. 53, pp. 311-316.

Powell, L.M. and F.J. Chaloupka (2009), "Food Prices and Obesity: Evidence and Policy Implications for Taxes and Subsudues", the Milbank Quarterly, vol 87, no 1, pp. 229-257.

Reynolds, K.D. et al. (2000), "Increasing the Fruit and Vegetable Consumption of Fourth-Graders: Results from the High 5 Project", Preventive Medicine, vol. 30(4), pp. 309-319.

Sassi, F. and J. Hurst (2008), "The Prevention of Lifestyle-Related Chronic Diseases: an Economic Framework", OECD Health Working Papers, No. 32, OECD Publishing, OECD.

Sassi, F. et al. (2009), "The Obesity Epidemic: Analysis of Past and Projected Future Trends in Selected OECD Countries", OECD Health Working Papers, No. 45, OECD Publishing, OECD.

Sassi, F. et al. (2009), "Education and Obesity in Four OECD Countries", OECD Health Working Papers, No. 46, OECD publishing, OECDShibuya, K. et al. (2003), "WHO Framework Convention on Tobacco Control: Development of an Evidence-Based Global Public Health Treaty", British Medical Journal, vol. 327, pp. 154-157.

Sorensen, G. et al. (1998), "The Effects of a Health Promotion-Health Protection Intervention on Behavior Change: the WellWorks Study", American Journal of Public Health, vol. 88(11), pp. 1685-1690.

Sorensen, G. et al. (1999), "Increasing Fruit and Vegetable Consumption through Worksites and Families in the Treatwell 5-a-day Study", American Journal of Public Health, vol. 89(1), pp. 54-60. 
Sorensen, G. et al. (1996), "Worksite-Based Cancer Prevention: Primary Results from Working Well Trial", American Journal of Public Health, vol. 86(7), pp. 939-947.

Tan Torres, T. et al. (2003), "Making Choices in Health: WHO Guide to Cost-Effectiveness Analysis", Geneva, World Health Organization.

Tengs, T. O. et al (1995), "Five Hundred Life-Saving Interventions and their Cost-Effectiveness" [see comments], Risk Analysis, vol. 15, pp. 369-390.

Variyam, J.N. (2006), "Nutrition labels and obesity”, NBER Working Paper 11956.

Variyam, J.N. (2008), “Do Nutrition Labels Improve Dietary Outcomes?”, Health Economics, 17, pp. 695708.

World Health Organization (2002), "Some Strategies to Reduce Risk", World Health Report 2002:

Reducing Risks, Promoting Health Life, Chapter 5, pp. 101-144. Geneva, WHO. 


\section{OECD HEALTH WORKING PAPERS}

A full list of the papers in this series can be found on the OECD website: www.oecd.org/els/health/workingpapers

No. 47 HEALTH CARE QUALITY INDICATORS PROJECT: PATIENT SAFETY INDICATORS REPORT 2009 (2009) Saskia Drösler, Patrick Romano, Lihan Wei

No. 46 EDUCATION AND OBESITY IN FOUR OECD COUNTRIES (2009) Franco Sassi, Marion Devaux, Jody Church, Michele Cecchini and Francesca Borgonovi

No. 45 THE OBESITY EPIDEMIC: ANALYSIS OF PAST AND PROJECTED FUTURE TRENDS IN SELECTED OECD COUNTRIES (2009) Franco Sassi, Marion Devaux, Michele Cecchini and Elena Rusticelli

No. 44 THE LONG-TERM CARE WORKFORCE: OVERVIEW AND STRATEGIES TO ADAPT SUPPLY TO A GROWING DEMAND (2009) Rie Fujisawa and Francesca Colombo

No. 43 MEASURING DISPARITIES IN HEALTH STATUS AND IN ACCESS AND USE OF HEALTH CARE IN OECD COUNTRIES (2009) Michael de Looper and Gaetan Lafortune

No. 42 POLICIES FOR HEALTHY AGEING: AN OVERVIEW (2009) Howard Oxley

No. 41 THE REMUNERATION OF GENERAL PRACTITIONERS AND SPECIALISTS IN 14 OECD COUNTRIES: WHAT ARE THE FACTORS EXPLAINING VARIATIONS ACROSS COUNTRIES? (2008) Rie Fujisawa and Gaetan Lafortune

No. 40 INTERNATIONAL MOBILITY OF HEALTH PROFESSIONALS AND HEALTH WORKFORCE MANAGEMENT IN CANADA: MYTHS AND REALITIES (2008) Jean-Christophe Dumont, Pascal Zurn, Jody Church and Christine Le Thi

No. 39 PHARMACEUTICAL PRICING \& REIMBURSEMENT POLICIES IN GERMANY (2008) Valérie Paris and Elizabeth Docteur

No. 38 MIGRATION OF HEALTH WORKERS: THE UK PERSPECTIVE TO 2006 (2008) James Buchan, Susanna Baldwin and Miranda Munro

No. 37 THE US PHYSICIAN WORKFORCE: WHERE DO WE STAND? (2008) Richard A. Cooper

No. 36 MIGRATION POLICIES OF HEALTH PROFESSIONALS IN FRANCE (2008) Roland Cash and Philippe Ulmann

No. 35 NURSE WORKFORCE CHALLENGES IN THE UNITED STATES: IMPLICATIONS FOR POLICY (2008) Linda H. Aiken and Robyn Cheung

No. 34 MISMATCHES IN THE FORMAL SECTOR, EXPANSION OF THE INFORMAL SECTOR: IMMIGRATION OF HEALTH PROFESSIONALS TO ITALY (2008) Jonathan Chaloff

No. 33 HEALTH WORKFORCE AND INTERNATIONAL MIGRATION: CAN NEW ZEALAND COMPETE? (2008) Pascal Zurn and Jean-Christophe Dumont

No. 32 THE PREVENTION OF LIFESTYLE-RELATED CHRONIC DISEASES: AN ECONOMIC FRAMEWORK (2008) Franco Sassi and Jeremy Hurst 
No. 31 PHARMACEUTICAL PRICING AND REIMBURSEMENT POLICIES IN SLOVAKIA (2008) Zoltán Kaló, Elizabeth Docteur and Pierre Moïse

No. 30 IMPROVED HEALTH SYSTEM PERFORMANCE THROUGH BETTER CARE COORDINATION (2007) Maria M. Hofmarcher, Howard Oxley, and Elena Rusticelli

No. 29 HEALTH CARE QUALITY INDICATORS PROJECT 2006 DATA COLLECTION UPDATE REPORT (2007) Sandra Garcia-Armesto, Maria Luisa Gil Lapetra, Lihan Wei, Edward Kelley and the Members of the HCQI Expert Group

No. 28 PHARMACEUTICAL PRICING AND REIMBURSEMENT POLICIES IN SWEDEN (2007) Pierre Moïse and Elizabeth Docteur

No. 27 PHARMACEUTICAL PRICING AND REIMBURSEMENT POLICIES IN SWITZERLAND (2007) Valérie Paris and Elizabeth Docteur

No. 26 TRENDS IN SEVERE DISABILITY AMONG ELDERLY PEOPLE: ASSESSING THE EVIDENCE IN 12 OECD COUNTRIES AND THE FUTURE IMPLICATIONS (2007) Gaétan Lafortune, Gaëlle Balestat, and the Disability Study Expert Group Members

No. 25 PHARMACEUTICAL PRICING AND REIMBURSEMENT POLICIES IN MEXICO (2007) Pierre Moïse and Elizabeth Docteur

No. 24 PHARMACEUTICAL PRICING AND REIMBURSEMENT POLICIES IN CANADA (2006) Valérie Paris and Elizabeth Docteur

No. 23 HEALTH CARE QUALITY INDICATORS PROJECT, CONCEPTUAL FRAMEWORK PAPER (2006) Edward Kelley and Jeremy Hurst

No. 22 HEALTH CARE QUALITY INDICATORS PROJECT, INITIAL INDICATORS REPORT (2006) Soeren Mattke, Edward Kelley, Peter Scherer, Jeremy Hurst, Maria Luisa Gil Lapetra and the HCQI Expert Group Members

No. 21 THE SUPPLY OF PHYSICIAN SERVICES IN OECD COUNTRIES (2006) Steven Simeons and Jeremy Hurst

No. 20 CONSUMER DIRECTION AND CHOICE IN LONG-TERM CARE FOR OLDER PERSONS, INCLUDING PAYMENTS FOR INFORMAL CARE: HOW CAN IT HELP IMPROVE CARE OUTCOMES, EMPLOYMENT AND FISCAL SUSTAINABILITY? (2005) Jens Lundsgaard

No. 19 TACKLING NURSE SHORTAGES IN OECD COUNTRIES (2004) Steven Simoens, Mike Villeneuve and Jeremy Hurst

No. 18 PRIVATE HEALTH INSURANCE IN THE NETHERLANDS. A CASE STUDY (2004) Nicole Tapay and Francesca Colombo

No. 17 SKILL-MIX AND POLICY CHANGE IN THE HEALTH WORKFORCE: NURSES IN ADVANCED ROLES (2004) James Buchan and Lynn Calman

No. 16 SHA-BASED NATIONAL HEALTH ACCOUNTS IN THIRTEEN OECD COUNTRIES: A COMPARATIVE ANALYSIS (2004) Eva Orosz and David Morgan 
No. 15 PRIVATE HEALTH INSURANCE IN OECD COUNTRIES: THE BENEFITS AND COSTS FOR INDIVIDUALS AND HEALTH SYSTEMS (2004) Francesca Colombo and Nicole Tapay

No. 14 INCOME-RELATED INEQUALITY IN THE USE OF MEDICAL CARE IN 21 OECD COUNTRIES (2004) Eddy van Doorslaer, Cristina Masseria and the OECD Health Equity Research Group

No. 13 DEMENTIA CARE IN 9 OECD COUNTRIES: A COMPARATIVE ANALYSIS (2004) Pierre Moise, Michael Schwarzinger, Myung-Yong Um and the Dementia Experts' Group

No. 12 PRIVATE HEALTH INSURANCE IN FRANCE (2004) Thomas C. Buchmueller and Agnes Couffinhal

No. 11 THE SLOVAK HEALTH INSURANCE SYSTEM AND THE POTENTIAL ROLE FOR PRIVATE HEALTH INSURANCE: POLICY CHALLENGES (2004) Francesca Colombo and Nicole Tapay

No. 10 PRIVATE HEALTH INSURANCE IN IRELAND. A CASE STUDY (2004) Francesca Colombo and Nicole Tapay

No. 9 HEALTH CARE SYSTEMS: LESSONS FROM THE REFORM EXPERIENCE (2003) Elizabeth Docteur and Howard Oxley

No. 8 PRIVATE HEALTH INSURANCE IN AUSTRALIA. A CASE STUDY (2003) Francesca Colombo and Nicole Tapay

No. 7 EXPLAINING WAITING-TIMES VARIATIONS FOR ELECTIVE SURGERY ACROSS OECD COUNTRIES (2003) Luigi Siciliani and Jeremy Hurst

No. 6 TACKLING EXCESSIVE WAITING TIMES FOR ELECTIVE SURGERY: A COMPARISON OF POLICIES IN 12 OECD COUNTRIES (2003) Jeremy Hurst and Luigi Siciliani

No. 5 STROKE CARE IN OECD COUNTRIES: A COMPARISON OF TREATMENT, COSTS AND OUTCOMES IN 17 COUNTRIES (2003) Lynelle Moon, Pierre Moïse, Stéphane Jacobzone and the ARD-Stroke Experts Group 
DELSA/HEA/WD/HWP(2009)6

\section{RECENT RELATED OECD PUBLICATIONS}

HEALTH AT A GLANCE 2009: OECD INDICATORS (2009).

See http://www.oecd.org/health/healthataglance for more information

ACHIEVING BETTER VALUE FOR MONEY IN HEALTH CARE (2009), OECD HEALTH POLICY STUDIES

OECD HEALTH DATA 2009 (2009), available on CD-ROM (in single-user or network installations). The database can be queried in English, French, German, Spanish and Italian. Japanese and Russian are also available but exclusively in the online version. www.oecd.org/health/healthdata

OECD REVIEWS OF HEALTH SYSTEMS - TURKEY (2009)

THE LOOMING CRISIS IN THE HEALTH WORKFORCE: CAN OECD COUNTRIES RESPOND? (2008)

PHARMACEUTICAL PRICING POLICIES IN A GLOBAL MARKET (2008)

OECD REVIEWS OF HEALTH SYSTEMS - SWITZERLAND (2006)

LONG-TERM CARE FOR OLDER PEOPLE (2005), OECD HEALTH PROJECT SERIES

HEALTH TECHNOLOGIES AND DECISION MAKING (2005), OECD HEALTH PROJECT SERIES

OECD REVIEWS OF HEALTH CARE SYSTEMS - FINLAND (2005)

OECD REVIEWS OF HEALTH CARE SYSTEMS - MEXICO (2005)

PRIVATE HEALTH INSURANCE IN OECD COUNTRIES (2004), OECD HEALTH PROJECT SERIES

TOWARDS HIGH-PERFORMING HEALTH SYSTEMS - POLICY STUDIES (2004), OECD HEALTH PROJECT SERIES

TOWARDS HIGH-PERFORMING HEALTH SYSTEMS (2004), OECD HEALTH PROJECT SERIES

OECD REVIEWS OF HEALTH CARE SYSTEMS - KOREA (2003)

A DISEASE-BASED COMPARISON OF HEALTH SYSTEMS: WHAT IS BEST AND AT WHAT COST? (2003)

MEASURING UP: IMPROVING HEALTH SYSTEMS PERFORMANCE IN OECD COUNTRIES (2002)

A SYSTEM OF HEALTH ACCOUNTS (2000)

SHA Revision information and proposals at http://www.oecd.org/health/sha/revision

For a full list, consult the OECD On-Line Bookstore at www.oecd.org, or write for a free written catalogue to the following address:

OECD Publications Service

2, rue André-Pascal, 75775 PARIS CEDEX 16

or to the OECD Distributor in your country 
DELSA/HEA/WD/HWP(2009)6 